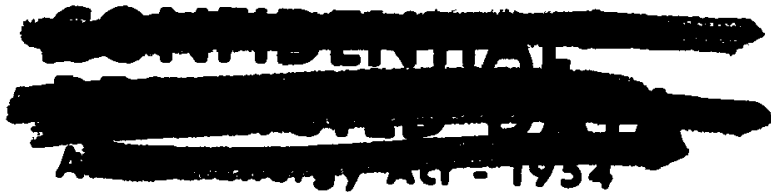

RECORD COPY

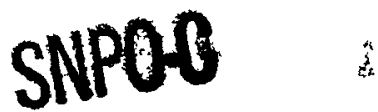

NOTICE

This report was prepared as an account of work sponsored by the United States Government. Neither the United States nor the United States Energy Research and Development Adminustration, nor any of their employees, nor any of therr contractors, their employees, nor any of therr contractors, subcontractors, or their employees, makes any warranty, express or impled, or assumes any legal hability or responsibility for the accuracy, completeness or usefulness of any information, apparatus, product or process disclosed, or represents that its use would not infringe privately owned rights.

\section{Westinghouse Astronuclear Laboratory}

FEB 151966
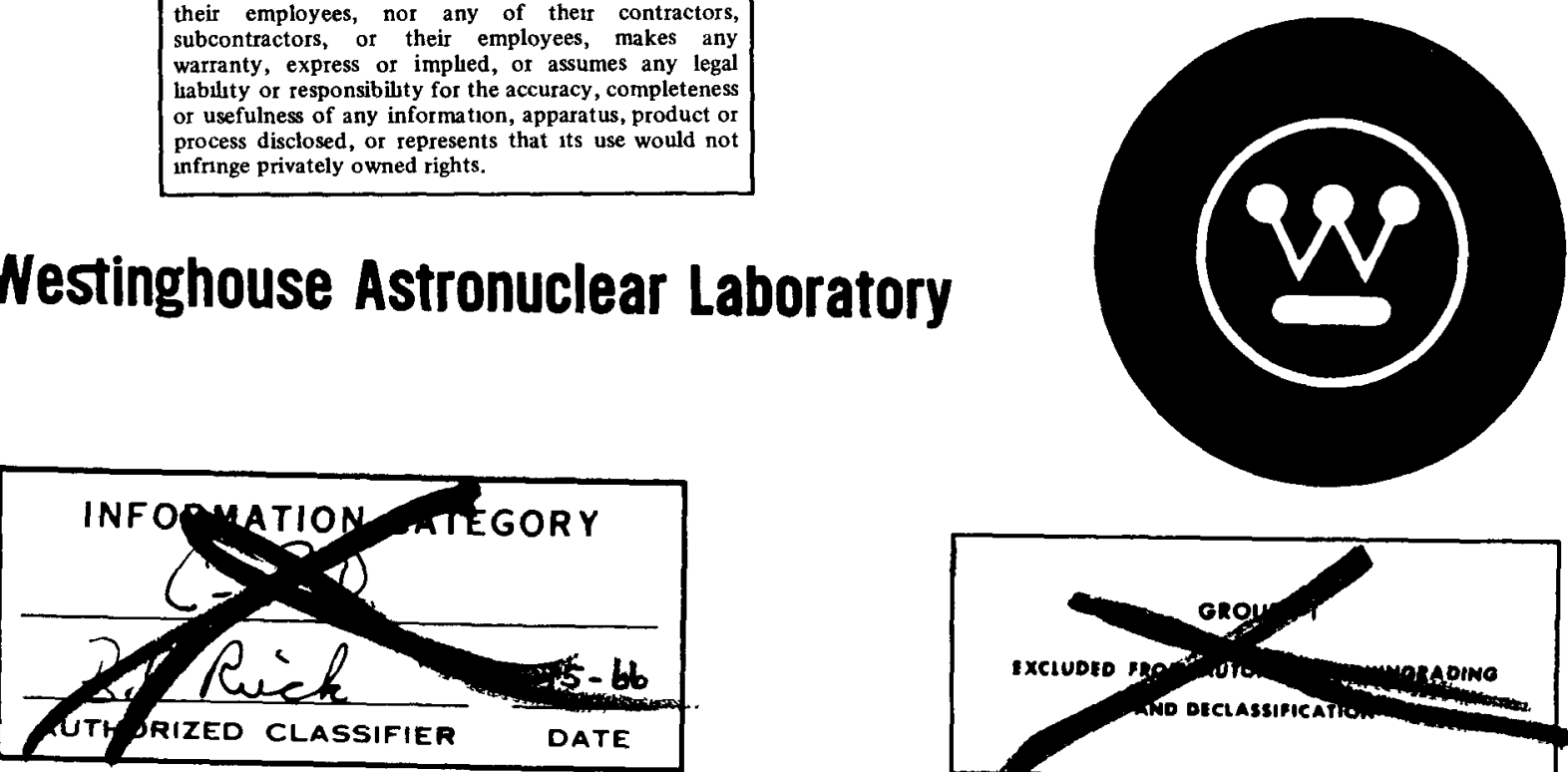

Prepared By:

Safeguard Engineering

Classification Easnedist

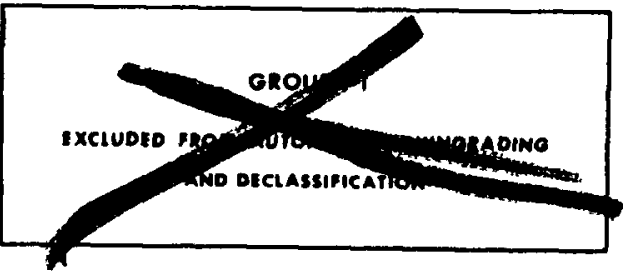

by autuerity st

by $H_{1}, C_{1}$, Is, SEP 121973

WANL-TNR-206

W. H. Arnold

\title{
PROGRAM REPORT ON THE ANTI-CRITICALITY POISON WIRE \\ SYSTEM
}

Reunio COPY

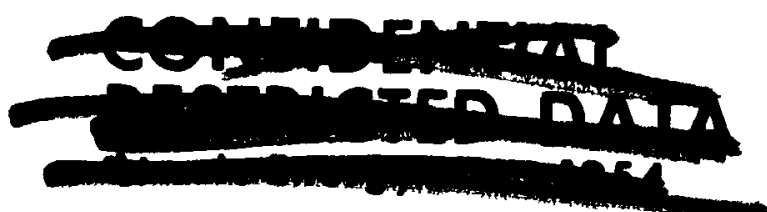

DISTRRUUTION OE IHIS DOCUMENT IS UNLIMITED

( Title Unclassified)

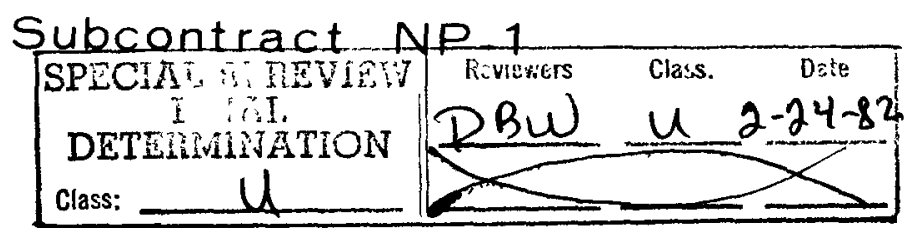




\section{DISCLAIMER}

This report was prepared as an account of work sponsored by an agency of the United States Government. Neither the United States Government nor any agency Thereof, nor any of their employees, makes any warranty, express or implied, or assumes any legal liability or responsibility for the accuracy, completeness, or usefulness of any information, apparatus, product, or process disclosed, or represents that its use would not infringe privately owned rights. Reference herein to any specific commercial product, process, or service by trade name, trademark, manufacturer, or otherwise does not necessarily constitute or imply its endorsement, recommendation, or favoring by the United States Government or any agency thereof. The views and opinions of authors expressed herein do not necessarily state or reflect those of the United States Government or any agency thereof. 


\section{DISCLAIMER}

Portions of this document may be illegible in electronic image products. Images are produced from the best available original document. 
PAGE BLANK 


\section{ABSTRACT}

This report documents the status of the development program for the Anti-Criticality Poison Wire System (ACPS). The need for an in-flight poison wire system for maintaining the NERVA reactor sub-critical from assembly to operation in space was realized early in the NERVA program.

At the present time, a shipping type of poison wire is in use. However, its use for space operation is limited due to material rigidity, excessive weight and neutronic values. It was therefore necessary to develop a flexible poison wire capable of being extracted from the reactor core and through the nozzle throat for system storage or ejection.

The system design is based on criteria derived from normal and accidental environmental conditions which might conceivably be encountered during assembly and space flight. In addition to listing the criteria upon which the ACPS system is based, a description of the entire system, operational sequences, and control features is provided. Reliability has been stressed and is reflected in the conceptual design of each component.

Problems of hardware availability, manufacturing technique, and material selection have been substantially resolved. Fabrication and successful testing of key sections of the ACPS have been accomplished. 
PAGE BLANK 


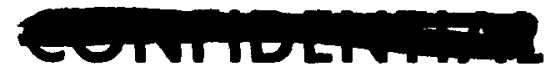

(2v) Astronuclear

WANL-TNR-206

\section{FOREWORD}

This report was prepared by the Safeguards Engineering Department of the Westinghouse Astronuclear Laboratory. The contributors to the report are as follows:
O. J. Elgert
Chapter IV, Neutronics
D. Y. Lee
Chapter III, Design Criteria Chapter V, System Description Chapter VI, Operational Sequence Chapter VII, Reliability of the Anti-Criticality Poison Wire System
E. W. Lohr
Chapter II, Poison Wire Design and Construction
G. E. Parker
Report supervision and assistance
Chapter I, Introduction
D. W. Call
Assistance in neutronic calculations
W. E. Friedhof
Appendix B, Reactivity Measurements in PAX-C 
PAGE BLANK 


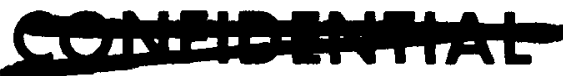

TABLE OF CONTENTS
(W) Astronuclear

Laboratory

WANL-TNR-206

Chapter

$\underline{\text { Page }}$

SUMMARY

Xv

CONCLUSIONS

xix

INTRODUCTION

$1-1$

2-1

A. Functional Criteria

B. Poison Wire Configuration

$2-4$

C. Poison Wire Manufacturing

2-18

D. Poison Wire Qualification

$2-22$

E. Demonstration Wire Withdrawal Tests

$2-32$

F. Poison Wire Retention

2-35

III

DESIGN CRITERIA FOR THE ACPS

A. General Information

B. Exposure to Fire and High Temperatures

3-2

C. Impact of Reactor and Nozzle with Ground

3-2

Due to Explosion

D. Additional Design Considerations

IV

NEUTRONICS

A. Poison Wire Reactivity Requirements

4-1

B. Poison Wire Reactivity Calculations

4-2

C. Reactivity Effects

4-12

SYSTEM DESCRIPTION

A. ACPS Component Sections

B. Redundant Systems

A. Wire Extraction and System Ejection 6-1

VII

RELIABILITY OF THE ANTI-CRITICALITY POISON WIRE SYSTEM

A. Reliability

7-1

Appendix

A

B

C
ACPS COMPONENT AND SYSTEMS TESTING

$A-1$

PAX-C REACTOR CORE, ACPS FLEXIBLE POISON WIRE MEASUREMENTS

REFERENCES
B-1

$\mathrm{C}-1$ 
PAGE BLANK 


\section{LIST OF ILLUSTRATIONS}

Figure

Anti-Criticality Poison Wire System

Page

$1-6$

2-1 Characteristics of Prototype Poison Wire

2-2 Typical Longitudinal Dimensions of the Poison Wire

2-3 Comparison Between Strengths of E and S Types of Fiberglass

2-4 Demonstration Wire Bundle

2-5 Shrinkable Tubing Conveying Apparatus

2-6 Poison Material Fracturing Mill

2-7 Fuel Element Coolant Channels Prior to Wire Pull Test

Fuel Element Coolant Channels after 35 Wire Pulls

Fuel Element Coolant Channels after 50 Wire Pulls

2-11 Flexible Poison Wire Tip after 50 Pulls

2-12 Demonstration Wires Inserted in Dummy Fuel Cluster

2-13 Demonstration Wire Withdrawal Assembly 2-34

2-14 Wire Distribution in Available Core Sector Coolant Channels 2-36

2-15 Typical Bundle of Poison Wires 2-38

3-1 ACPS Pre-Launch Condition 3-4

4-1 Radial Worth of Poison Wires - Flooded Reactor 4-11

4-2 Reactivity Variation Effects of Poison Wire Diameter and Density 4-14

4-3 Poison Wires Required for $0.95 K_{\text {eff }}$ Versus Diameter and Density 4-15

4-4 Reactivity Versus Poison Wire Height 4-16

4-5 Reactivity Versus Poison Wire Height and Diameter 4-17

4-6 Wires Required Versus Diameter and Height 4-18

5-1 Plan View of Retaining Plate and Retaining Fingers 5-3

5-2 Detail Cross Section A-A of Piston 5-4 
PAGE BLANK 


\section{LIST OF ILLUSTRATIONS (CONT' D.)}

6-4 Release Initiated in ACPS Ejection Sequence 6-6

B-1 Effect on Core Reactivity as a Function of Density - PAX-C B-2

B-2 PAX Test Flexible Poison Wires - Case $1 \quad$ B-9

B-3 PAX Test Flexible Poison Wires - Case $2 \quad$ B-10

B-4 PAX Test Flexible Poison Wires - Case $3 \quad$ B-11

B-5 PAX Test Flexible Poison Wires - Case $6 \quad$ B-12

B-6 PAX Test Flexible Poison Wires - Case $7 \quad$ B-13

B-7 PAX Test Flexible Poison Wires - Case $8 \quad$ B-14

B-8 Poison Wire Effectiveness as a Function of the Degree of Flooding B-15

B-9 Core Reactivity Under Various Poisoning and Flooding Conditions B-16

B-10 Poison Wire Worth as a Function of Density - PAX-C Core B-17

B-11 PAX-C Drum Worths as a Function of the Degree of Flooding B-20 
PAGE BLANK 


\section{Conmelenmint}

LIST OF TABLES (w) Astronuclear

Laboratory

WANL-TNR-206

Table

Page

2-1 Capabilities Required in the Poison Wire and System Design

2-3

2-2 Poison Wire Design and Operating Criteria

2-5

2-3 Weight Distribution of Active Poison Length of Poison Wire

2-8

Proposed for Flight Application

2-4 Composition of Various Boron Compounds

2-10

2-5 Boron Carbide Sintering Development

Fiberglass Sleeving Tensile Breaking Strength

2-15

2-7 Variation of Poison Wire Breaking Strength With Temperature

Functional Data

3-6

4-1

Neutron Broad Group Energy Levels

4-4

4-2 Effect of Neutron Source On Poison Wire Disadvantage Factors

4-6

4-3 Effect of Neutron Energy Spectrum on Poison Wire Disadvantage Factors

4-4 Poison Wire Disadvantage Factors for Various Poison Diameters and Densities

4-5 Eigenvalue and Buckling Iterations for 2600 Wires of $0.147 \mathrm{~cm}$ Diameter and 90 Percent Density (Fully Flooded)

Flooded Core Reactivity Calculations

B-1 Description of Experimental Materials

B-2 $\quad B^{10} C$ Poison Wire Worth - Measurements on PAX-C (Changes to Core) 
PAGE BLANK 


\section{SUMMARY}

The Anti-Criticality Poison Wire System has been designed to meet the need for safeguarding the NERVA engine from the time of assembly to its eventual use in outer space. Poison wires are uniformly distributed throughout the core cross section in axially aligned coolant channels. Consequently, the wires must be bent during the withdrawal process in order to pull them through the nozzle throat which has a maximum diameter less than the diameter at which most of the wires are inserted. This feature has led to the development of a flexible wire which will not impose damaging forces upon the reactor and nozzle components during a withdrawal process.

Accident situations, orbital flight, and flight termination possibilities dictate the conditions that must be withstood by the materials and structure of the wires. These conditions include the resistance to high temperatures to inhibit poison removal during a plausible fire; pliability at ultra-low temperatures to facilitate wire removal under orbital flight conditions; and a high degree of insolubility to sea water to prevent poison removal over long periods of immersion following re-entry and ocean impact.

The element boron showed the greatest promise as a neutron absorbing ingredient of the poison wire. To provide adequate resistance to deterioration and dissipation under credible situations involving fire and water immersion, the boron is combined into a suitable chemical compound. The chemical compound chosen was boron carbide $\left(\mathrm{B}_{4} \mathrm{C}\right)$ since it is highly stable, the properties are well known, and it is readily available.

To reduce the weight of the poison wire system for space flight, $\mathrm{B}_{4} \mathrm{C}$ prepared from boron highly enriched with the isotope of atomic weight 10 should be used. If boron enriched 80 to 90 percent with boron 10 is employed, the number of wires required to obtain a given poisoning effectiveness is approximately one-third of the number as compared to the use of natural boron.

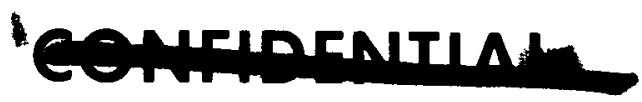




\section{W Astronuclear}

WANL-TNR-206

To provide flexibility in the poison wire, a technique was developed to break the hard ceramic boron carbide sticks comprising the core of the wire into short pieces, each nominally $1 / 8$ inch in length. Further assurance of wire flexibility was obtained by utilizing fiberglass braid in the poison stick encasement as a means of transmitting tensile forces through the length of the wire. Fiberglass braid is not only flexible and strong, but it is also resistant to high temperature.

The outer surface of the prototype poison wire is a Teflon sheath which is shrunk over the fiberglass braid. The low friction coefficient of Teflon minimizes resistance to forces applied during withdrawal of the poison wire from the reactor.

Approximately 400 wires were fabricated in accordance with the construction described above. These were bundled near one end to form groups of ten wires per bundle. The nuclear poison of these wires was simulated by the use of properly dimensioned pencil lead material. Various quantities of these wires were pulled from an arrangement of NERVA reactor dummy fuel clusters to determine withdrawal forces required for flexible wires.

The apparatus used to withdraw the wires from the dummy fuel clusters was designed and constructed to demonstrate principles and techniques that could be employed to withdraw the wires during flight of the NERVA engine. In essence, the wires were terminated at a retractor head positioned near a simulation of the throat of the engine nozzle. A stainless steel tape connected the retractor head unit to a spool on the shaft of a pneumatic motor. Upon admission of air to the motor, tape was wound on the spool, and the wires connected to the retractor head were withdrawn from the dummy fuel clusters.

A load cell in series with the tape and retractor head was used to measure the pull forces. Average force under sliding friction conditions (the measured force divided by the total number of wires pulled) was determined to be $0.122 \mathrm{~kg}$ per wire. Peak average force is estimated to be higher than this by a factor of 1.25. On this basis, a withdrawal system capable of exerting approximately $310 \mathrm{~kg}$ is required to remove 2000 wires, which are uniformly distributed throughout the core cross section, from the reactor.

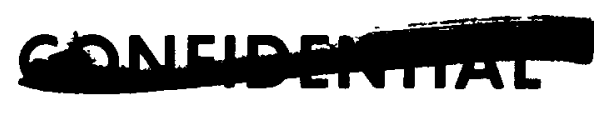




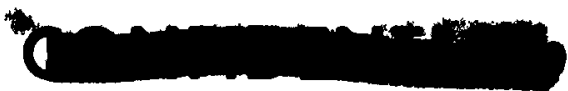

(2) Astronuclear Laboratory

WANL-TNR-206

The neutron absorbing poison requirements of the wires were dictated by the necessity of assuring subcriticality under the worst conditions that can be postulated (i.e., a complete immersion and water flooded reactor). An analys is was performed to determine the reactivity effects of changing $\mathrm{B}_{4}^{10} \mathrm{C}$ density, wire diameter, wire length, and the number of wires. The following information summarizes results that were obtained for a fully flooded reactor.

1) The reactivity of the fully flooded non-poisoned reactor is $1.59 \mathrm{~K}_{\text {eff }}$.

2) Reactivity variation is relatively insensitive to $\mathrm{B}_{4}^{10} \mathrm{C}$ density over the range 80 to 90 percent theoretical.

3) A 10 percent change in the number of wires in the range of 2000 to 2200 wires results in about a 0.04 reactivity change.

4) A change in wire diameter from $0.137 \mathrm{~cm}$ to $0.157 \mathrm{~cm}$ results in about 0.08 reactivity change.

5) Two thousand wires, containing 85 percent theoretical density $\mathrm{B}_{4}^{10} \mathrm{C}$ of $0.147 \mathrm{~cm}$ diameter, uniformly distributed throughout the core are adequate to maintain the fully flooded reactor at or below a reactivity of 0.95 .

$\mathrm{B}_{4}^{10} \mathrm{C}$ material containing boron of 70 to 80 percent isotope 10 enrichment was prepared in powder form, extruded, and sintered to obtain cylindrical sticks. Approximately 90 wires using these sticks were fabricated for the purpose of evaluation in the PAX critical assembly.

PAX reactor critical tests were conducted to determine the worth of the poison wires. The $B_{4}^{10} \mathrm{C}$ diameter averaged $0.1416 \mathrm{~cm}$ and its specific gravity averaged $1.87 \mathrm{gm} / \mathrm{cc}$. Experimentally determined wire worth at the center of the reactor was 1) 5.3 cents to 6.0 cents each with a dry reactor, and 2) 9.2 cents to 13.9 cents each for a water flooded reactor (water simulated with polyethylene rods). The calculated worth of the poison wires in the same location in the reactor core was 1) about 4.0 cents each in a dry reactor and 2) 6.9 to 9.3 cents in a flooded reactor. These test results indicate that 2000 wires are more than adequate to maintain a water flooded core subcritical. 
(2) Astronuclear

WANL-TNR-206

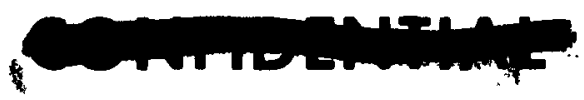

For purposes of perspective and future reference, a preliminary wire withdrawal actuator design was prepared. This concept provided the basis for analysis of the action involved in withdrawal of poison wires and in ejection of the ACPS from the nozzle. This analysis confirmed that an ACPS was feasible, and that its operation was compatible with flight vehicle staging and NERVA engine startup.

Since the poison wire is the essential component of the ACPS, criteria, fabrication, and qualification of the wire are discussed in the beginning of the report. The next section is devoted to criteria that the ACPS fulfills. This is followed by results on analytical and experimental investigations of the neutron absorbing worth of the prototype wire and the neutronic effectiveness of an installation of poison wires. The closing sections of the report provide a conceptual description, a review of plausible system operation, and a qualitative reliability evaluation. 


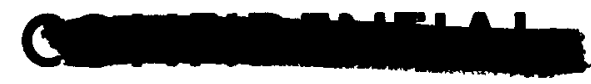
(2.) Astronuclear

WANL-TNR-206

\section{CONCLUSIONS}

An installation of poison wires is the only conceivable countermeasure for which the following benefits are concurrently obtained.

1) Poison wires are immediately in effect upon installation without further implementation of additional measures or procedure.

2) Since a potential hazard is completely eliminated, operations involving the NERVA engine and the vehicle on which it is installed may be conducted in a manner similar to those employed with chemically fueled engines and vehicles.

3) The nuclear reactor presents no additional hazard in any accident or situation associated with rocket vehicles and the ir launch facilities.

The neutron absorbing capability of a poison wire configuration has been proven by experiment. It has been established on the basis of these experimental results that the number of wires (2000) required for an ACPS system is reasonable and compatible with the means of removal and the nozzle dimensions. The neutron absorbing poison, boron-10, is available. Boron- 10 can be combined into a compound, $\mathrm{B}_{4}^{10} \mathrm{C}$, which is producible in a dimensionally suitable form with the desired density.

The wires can be fabricated with flexibility suitable for use with the reactor and nozzle components. The materials fabricated into the wires combine satisfactory tensile strength with adequate resistance to water immersion and high temperatures to which they might be exposed in accident or flight termination situations. The wire materials also reta in flexibility at low temperature, and therefore they are suitable for removal following an extended time in orbit. Since the wire construction contains no metal, the burden, with respect to weight, is minimized.

An ACPS can be designed which will withdraw the wires from the reactor and remove itself and the wires completely from the nozzle. Based on the analysis performed, these actions can be accomplished without damage to the nozzle or to the reactor. ACPS operation with respect to the time required to complete the sequence of action is compatible with programming of flight vehicle staging for either suborbital or orbital start.

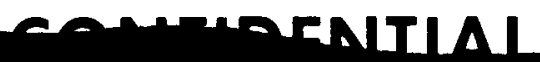


CHAPTER I

INTRODUCTION

A countermeasure device which eliminates the possibility of an accidental NERVA reactor criticality is presented and analyzed in this report. In various conceivable accident situations the NERVA reactor would not be maintained in a subcritical state by the control drum system which is utilized in normal operations.

The control drums do not contain enough neutron absorbing material to prevent a nuclear excursion if, for example, the reactor is submerged in water or if hydrogenous rocket propellant of high density enters the reactor core. Furthermore, during the period preceding launch and flight, it may not be desirable at all times to maintain the control drums in an inoperable condition by using positive mechanical lock techniques to prevent rotation of the control drums from the least nuclear reactive position (maximum neutron absorbency of the drums). For instance, it may be desirable for check-out and launch preparation purposes to exercise the drum rotation of a complete NERVA engine.

For these reasons, a method which supplements the control drums is required to guarantee subcriticality of the reactor. This guarantee should be maintained until capability of the reactor to operate is brought about by a deliberate sequence of actions following the launch of a flight vehicle carrying the NERVA engine.

The means proposed to guarantee subcriticality of the reactor is the Anti-criticality Poison Wire System (ACPS). Prominent features of the system are shown in figure 1-1. In essence, anti-criticality poisoning consists of special neutron absorbent wires manufactured for insertion into the coolant channels of the reactor core. A sufficient number of these wires prevent attainment of a self-sustaining nuclear fission reaction within the reactor fuel by 
absorbing neutrons required in the reaction. The neutron absorbent material of the wires is boron, the "poison".

To prepare the reactor for operation in flight the wires must be removed from the reactor core. Consequently, another essential feature of the ACPS is a wire withdrawal mechanism. The wire withdrawal mechanism may be installed in the throat and divergent portion of the NERVA engine nozzle. Following withdrawal of the poison wires from the reactor core during flight, the entire ACPS will be ejected from the nozzle prior to starting the NERVA engine.

With the ACPS installed, activities associated with the NERVA engine need not differ greatly from those associated with chemically fueled propulsion engines. Precautions during ground handling situations and during launch and orbital operations of the NERVA engine will be quite similar to those of chemical propellant engines.

The ACPS is conceived as a highly self-contained system. Therefore, withdrawal of the wires from the reactor core is dependent, to a minimum extent, upon actions and fulfillment of conditions external to the system. For this reason, the ACPS may be used on a flight in which either orbital startup or suborbital startup of the NERVA engine is programmed since withdrawal of the wires requires only an appropriate actuating signal.

According to the ACPS design, there is no difference between the NERVA I engine and the larger NERVA II engine, except in scale. As a result of the change in scale, a change in the dimensions of the wire and in the number of wires may be required. In this event the wire withdrawal mechanism of the system will be larger and somewhat heavier. Since the changes are of a dimensional nature, the ACPS design would be applicable to the NERVA I or the NERVA II engine.

The currently conceived ACPS, as illustrated in figure 1-1, consists of an arrangement of flexible poison wires inserted in the reactor coolant channels and connected to a mechanical withdrawal actuator contained in a pair of concentric cylinders approximately 7.0 feet in length. The system is seated in the throat region of the nozzle and is braced in the divergent section.

Installation or removal of apparatus can be conducted without jeopardizing the integrity of the nozzle. This conclusion is supported by the consideration that during preparations for 


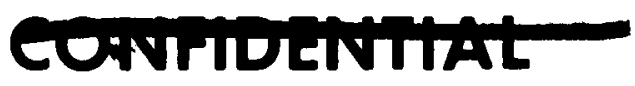

(W. Astronuclear

WANL-TNR-206

each of the current series of reactor ground tests, a plug is installed in the nozzle throat to permit reactor assembly pressurization. Use of this device has not caused damage to any of the nozzles.

With regard to operation of the system, the poison wires are withdrawn into the inner guide cylinder retainer upon transmission of the actuating signal. In order to assure that a premature ejection does not take place, another separate signal initiates the system ejection procedure following separation of the preceding stage of the flight vehicle from the nuclear stage. Ejection of the complete system, including the nozzle protective foam, is conducted in a manner independent of external means. The ACPS has the following distinct advantages:

1) It is self contained and independent.

2) The reactor is positively poisoned, and no portion of the core can be formed into a critical mass under accident conditions as long as the wires are in place.

3) The ACPS will not damage the reactor, the engine, or other components of the flight vehicle.

4) The ACPS will maintain reactor subcriticality from the time of reactor assembly to the time of wire withdrawal in flight.

It was recognized that a flexible poison wire must be developed in order to make the ACPS a reality. Concentrated studies of wire development problems, in addition to the revision of previously proposed withdrawal and ejection techniques, have resulted in an ACPS concept that is feasible. Many features of the poison wires and many system operating principles have been proven from the fabrication and trial of prototypes.

As currently fabricated, the prototype flexible poison wire consists of encased boron carbide $\left(B_{4} C\right)$ cylindrical granules. The $B_{4} C$ can be manufactured with boron enriched with the isotope of boron $10\left(B^{10}\right)$. The encasement is comprised of a plastic granule retaining tube enveloped by a flexible fiberglass braid and an outer sheath of Teflon. The pliability which results from this aonstruction of the flexible wire reduces the possibility of damage to reactor or nozzle parts.

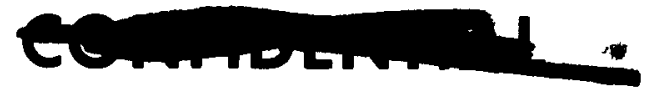




\section{-}

Upon review of various nuclear poisons reported in Reference 1, it was concluded that the element boron, especially the isotope $B^{10}$, showed the most promise as a neutron absorbing ingredient for the poison wire. Adequate resistance of the nuclear poison to deterioration and dissipation under credible accident situations involving fire and water immersion is required. For this reason the boron contained in the poison wire is combined into the chemical compound boron carbide which is highly stable. As a benefit, with respect to increasing flight payload, a system weight reduction results upon utilizing boron carbide prepared from boron enriched 80 to 90 percent with $B^{10}$. The number of wires required to obtain a given effectiveness is approximately one-third the number used when employing natural boron.

Previous investigations ${ }^{2}$ demonstrated that Teflon sheathed flexible wires could be withdrawn from the core coolant channels without damaging reactor core components. These investigations also showed that the use of Teflon as an outer sheath was beneficial in reducing withdrawal resistance.

Measurements of the neutron absorbing capability of the wires indicate that 2000 wires will be more than adequate to maintain the desired subcriticality. A review of geometrical arrangements indicated that 3000 wires could be withdrawn readily through the throat of the NERVA I nozzle.

The insertion of poison wires into the coolant channels of the reactor core is a practical and proven means for maintaining subcriticality. With respect to all NERVA reactors manufactured and under construction, this method of obtaining the desired degree of subcriticality has been incorporated and utilized in the reactor assembly procedure, the preparations for

IWANL-TME-603, Selection of Material, Number and Distribution of Poison Wires for the Anti-Criticality Poison Wire System, November 1963 (CRD)

2 WANL-TNR-155, Status Report on the Anti-Criticality Poison Wire System, March 1964 (CRD) 
reactor transportation, and the shipment of the NERVA reactor to testing installations. A complement of 6800 wires is installed in a reactor for the purpose of transportation or shipment. This large number of wires is required since the neutron absorbing chemical element of the wires is manufactured with a mixture of natural boron which is not as effective as the boron 10 isotope.

These wires used for shipment purposes are stainless steel tubes filled with $\mathrm{B}_{4} \mathrm{C}$ and encased in polyethylene. Wires of this type are inserted during reactor assembly and removed immediately prior to attachment of the nozzle to the reactor. This procedure is satisfactory for the reactors used in the NRX ground test series; however, the shipping wires are not flexible enough to permit the removal of most of them through the nozzle. Therefore, the shipping type wires cannot be employed during preparations for engine flight following attachment of the nozzle to the reactor. Nevertheless, the shipping type wire has provided a sound basis for development of the flexible wire since extensive experience was obtained on poison wire neutronic computational methods, 3 and insight was gained on wire fabrication techniques.

The need for maximum reliability in all ACPS components has influenced the direction of all investigations. It has been kept in mind that the ACPS is an absolute safeguard in principle since no circumvention can obtain reactor operation if the poison wires are in place. Consequently, a method of maximum dependability is required to withdraw the wires. Furthermore, it has been realized that the ACPS cannot jeopardize the integrity of the reactor and nozzle components.

\section{WANL-TME-1 172, Status Report on the Flexible Poison Wire Development, May 1965.}

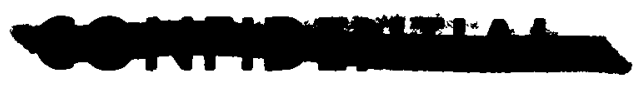




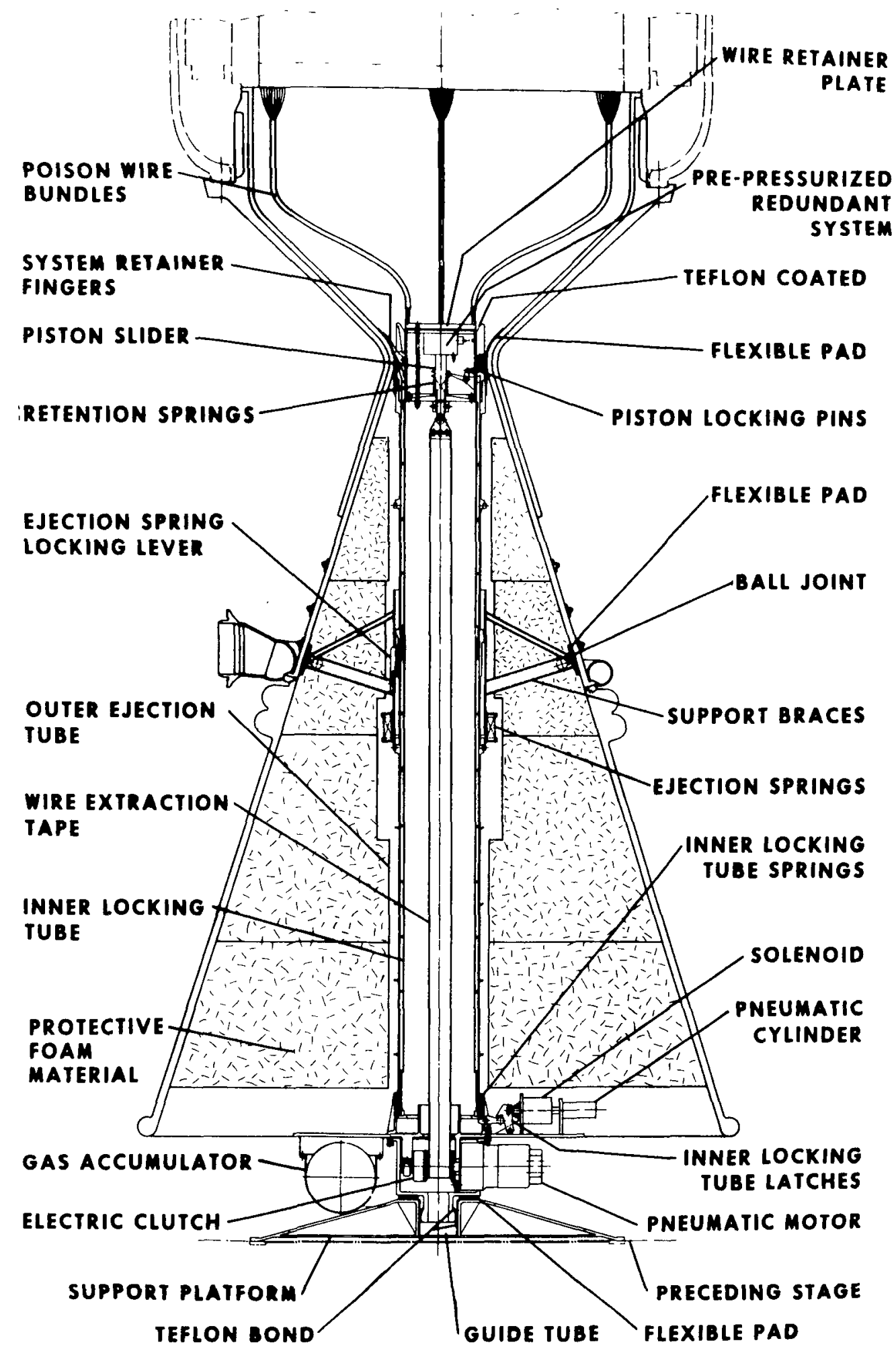

Figure 1-1. Anti-Criticality Poison Wire System

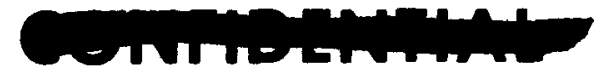




\section{CHAPTER II POISON WIRE DESIGN AND CONSTRUCTION}

\section{A. FUNCTIONAL CRITERIA}

An intrinsic advantage of the poison wire concept, in comparison to other safeguard concepts, is its passive character. Upon installation of the poison wires, the safeguarding capability is immediately in effect. Safeguard devices of an active nature that might be employed in place of poison wires require steps of activation, other than installation, in order to bring them into effect.

The decision to utilize the poison concept el iminates much of the exhaustive effort in hazards analys is which is required to determine, in minute detail, all possible situations in which criticality could accidentally occur. Furthermore, the utilization of poison wires makes it possible to conduct activities which would not be desirable, under other circumstances, or would require the establishment of prolonged safeguard procedures.

A nuclear incident is not possible during the engine assembly period if the wires are in place. Furthermore, the nuclear engine may be handled in the same manner as a chemical propellant engine at the vehicle assembly location. Transportation of the nuclear engine to the launch pad will involve only conventional methods. Even in the event of a flight cancellation, due to storm or hurricane, the complete vehicle may be readily returned to weather protective enclosures and facilities by means customarily available. Also, the need for a special or remotely isolated launch pad is no greater with a poison wire equipped nuclear engine vehicle than that involved with chemical propellant vehicles.

The poison wire system, as proposed, presumes removal of the poison wires following most or all staging of the nuclear engine vehicle during flight. Therefore poison wire equipped nuclear engine vehicles do not present greater hazards than chemical engine vehicles with respect to reaction time required to activate a destruct system at launch or as a result of deficiencies of tracking systems in detecting early flight path deviations.

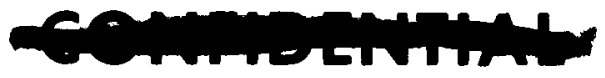


The launch pad hazard level is not raised as a result of nuclear moderating properties of liquid hydrogen and hydrogen containing petroleum based fuel since the possible presence of these materials has been considered in establishing the number of wires to be inserted into the nuclear reactor. For the same reason, no hazard exists for the possibility of complete water immersion. In the event of a drop from a considerable height or in the event of an explosion, it is not plausible that the wires would become separated from the nuclear fueled mass due to the impact or crushing action alone.

The development of the flexible poison wire is based, in part, on the poison wire used at the present time for reactor shipping purposes. Although the shipping type of poison wire is adequate for its purpose, the particular features and requirements for its manufacture prevent it from being a desirable component for reactor flight applications. The shipping type poison wire consists of $a^{B}{ }_{4} C$ powder compacted into a stainless steel tube. The final diameter is obtained by swaging the powder-filled tube to the appropriate size.

Bending is required in order to withdraw the wire from the reactor core via the nozzle throat. The metal tube encasing the poison wire is susceptible to buckling which produces sharp corners and edges. The swaging process inhibits the flexibility of the poison wire as a result of work hardening of the metal wall.

Consequently, features incorporated in the current wire design have been derived primarily from efforts to increase wire flexibility and to lower the risk of producing changes in the wire cross-sectional geometry as a result of crushing or buckling of the wire. Accordingly, the margin has been increased, with respect to maintaining the integrity of the reactor core components which contact with the wire.

The current conception of the poison wire has been established to fulfill the accident requirements listed in table $2-1$. The poison wires must provide a neutron absorption capability sufficient to prevent reactor criticality under credible situations of potential hazard with an adequate margine of safety. It has been judged that a maximum reactivity of 0.95 under the 


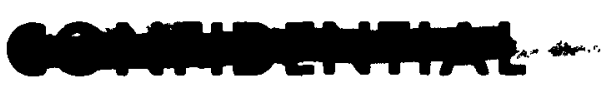

(w) Astronuclear

\section{TABLE 2-1}

\section{CAPABILITIES REQUIRED IN THE POISON WIRE AND SYSTEM DESIGN}

Water immersion and hydrogenous material accident requirements:

1) With the core completely immersed and flooded with water or hydrogenous propulsion engine propellant, the poison wire system must be capable of maintaining $0.95 \mathrm{~K}_{\text {eff }}$ with the control drums in the most reflective position.

2) Under conditions of accidental discharge of liquid hydrogen through the reactor, the system must prevent the ejection of the wires and retard hydrogen flow by throttling at the nozzle throat.

3) The wires must not be affected by water corrosion and erosion.

4) The wire poison and encasement materials must be non-soluble in water.

Fire and explosion hazards:

1) AEC regulations, with respect to reactor shipment containers, shall be fulfilled.

2) Reactor subcriticality shall be maintained in the event of vehicle and launch pad fire and explosion.

Impact and compaction hazards:

1) Wires to be designed to stay in the reactor as long as the pressure vessel and nozzle are basically intact.

2) Any attitude of the engine at the time of impact shall tend to produce embedment of the wires into the reactor core.

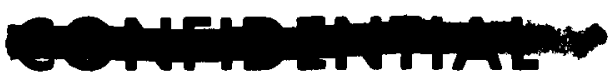




\section{(2) Astronuclear \\ - Laboratory}

WANL-TNR-206

most unfavorable combination of circumstances will provide a conservative margin of safety without incurring excessive secondary penal ties such as large poison system weight. A reactivity of 0.95 means that the neutrons produced from a given number of nuclear fissions (and therefore available for further reactions) is 95 percent of the neutrons which entered the reactions. It follows that a reactivity less than 100 percent results in a decay of the number of fissions per unit time.

Factors which influence and determine wire design specifications are listed in table 2-2. These conditions establish strength requirements as well as dimensional limitations. Wire life, durability, and flexibility requirements are also implied in this information.

\section{B. POISON WIRE CONFIGURATION}

\section{Dimensions and Weight Distribution}

Figure 2-1 represents a cross section of the neutron absorbing portion of the poison wire. Dimensions of this illustration are based on maximum values expected. Typical longitudinal dimensions are indicated in figure 2-2 which illustrates the prototype poison wire construction. The weight distribution of basic wire components is presented in table 2-3.

\section{Wire Components}

The major wire component groups are the:
a) Center poison granules
b) Encasement
c) Segregation and support elements
d) Termination

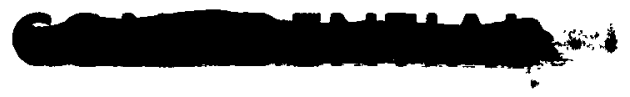




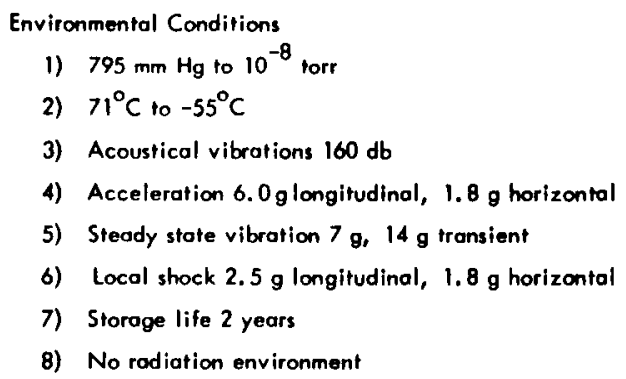

Materials Requirements

1) Minimum weight for function

2) Bend rodius of $2.54 \mathrm{~cm}$

3) Outside cover TFE or FEP Toflon

4) Neutron poison material $\mathrm{B}_{4}^{10} \mathrm{C}$

5) Elongation $0.5 \%$ between $21^{\circ}$ and $71^{\circ} \mathrm{C}$

6) Minimum tensile strangth of wire $0.9 \mathrm{~kg}$

7) Double encasement seal for $\mathrm{B}_{4}^{10} \mathrm{C}$

System Functional Requirements

1) Pull rate, 15 to $25 \mathrm{~cm} / \mathrm{sec}$

2) Maximum time for wire extraction, 10 seconds

3) Maximum peok pull force for any wire, $450 \mathrm{gm}$

4) Bundling rigidity sufficient to reloin wires

5) Functionally removable from reactor and nozzle

6) Flexible attactment to retaining device.

Mochanical Limirations

1) Diameter of wires, $0.219 \mathrm{~cm}$ at maximum operoting temperature and minimum pressure

2) Practical upper limit of wires, 3,000

3) Fin ished outer cooting must be smooth

4) Minimum active ${ }_{3}^{10} \mathrm{C}$ length in core, $131 \mathrm{~cm}$

5) Maximum permissible penetration in core, $137 \mathrm{~cm}$

6) Wire tips designed to minimize peok extroction lood

7) Wires copable of use at least five times

Neutronic Requirements

1) Wires must be copable of $0.95 \mathrm{k}$ eff shutdown with control drums at $180^{\circ}$ minimum neutron absorbency position and complete immersion in woter

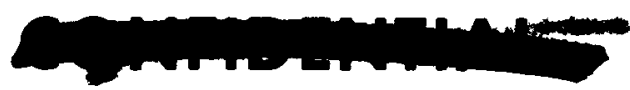


0.013 CM BRAIDED FIBERGLASS SLEEVING OF 0.189 CM. OD
0.147 CM BORON CARBIDE CENTER

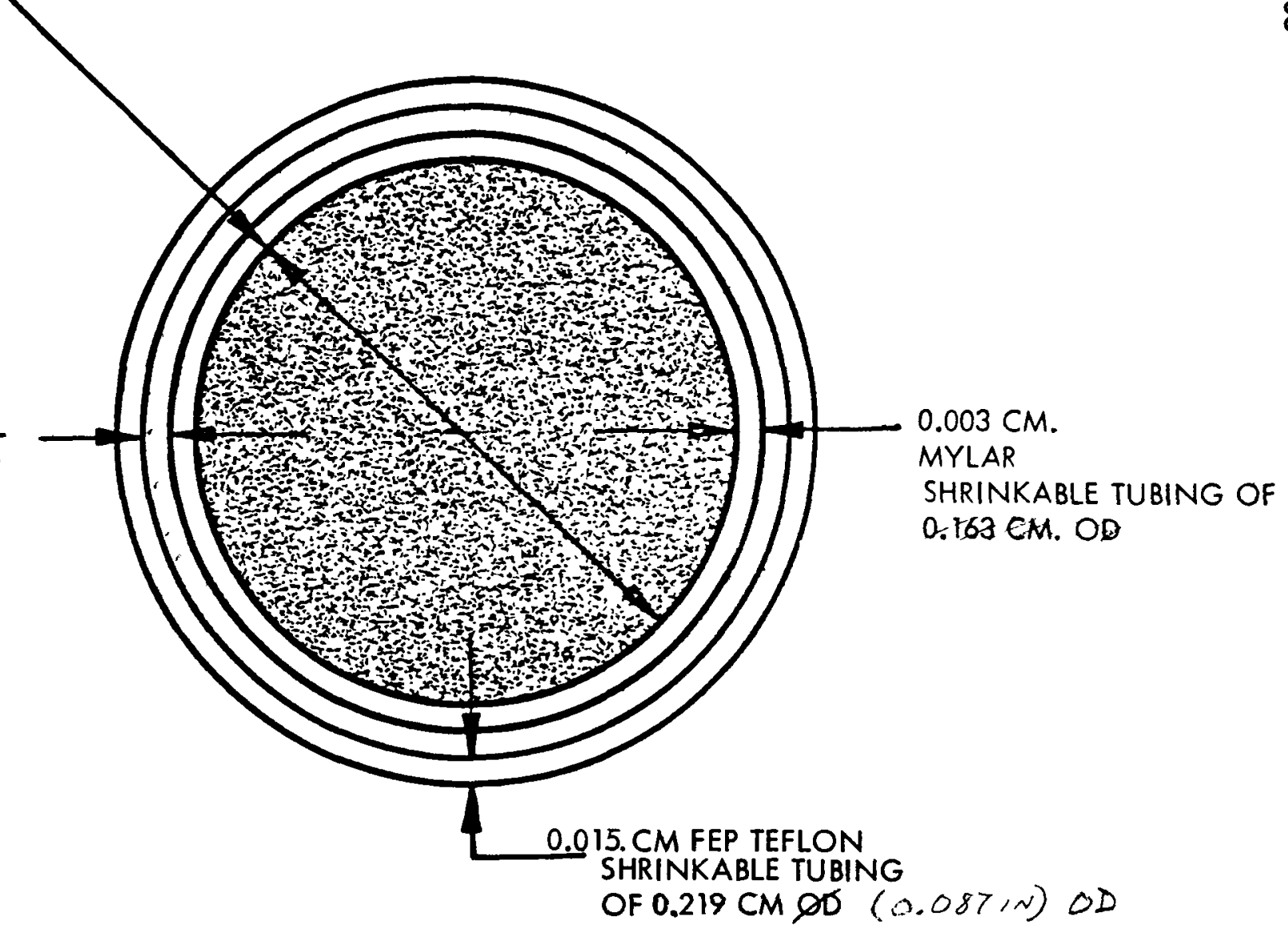

Figure 2-1. Characteristics of Prototype Poison Wire 


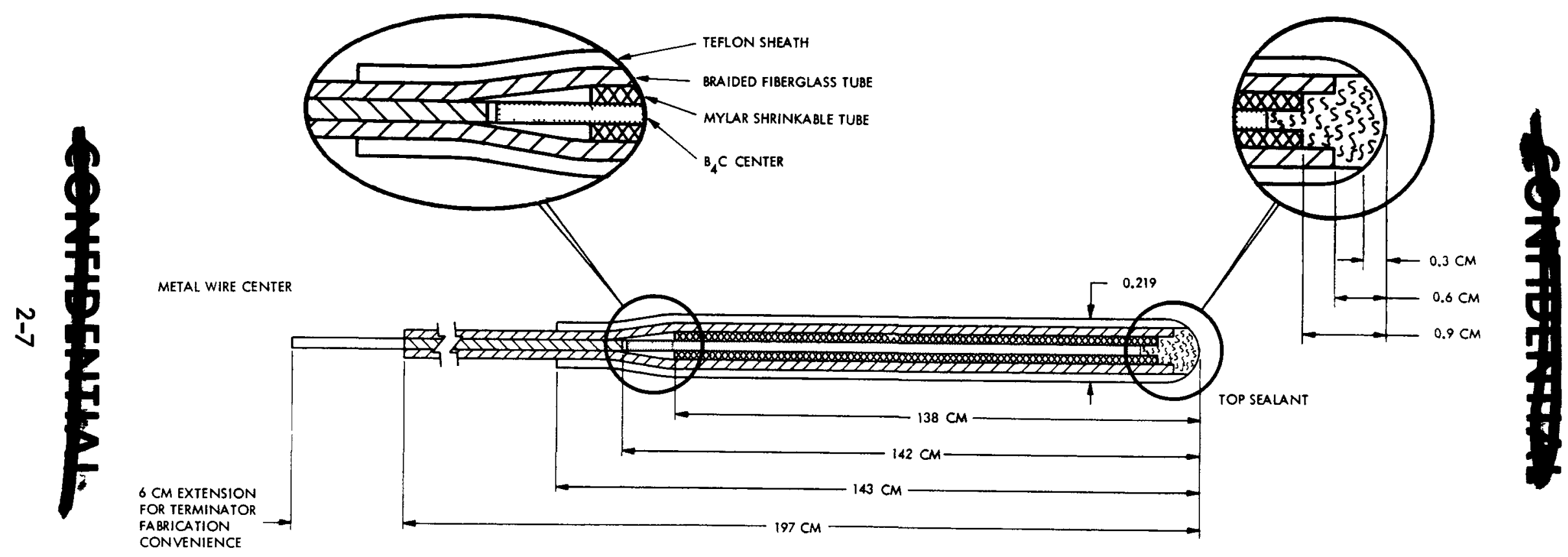

$610730-13 B$

Figure 2-2. Typical Langitudinat-Dimensions and Gomponents of the Paisan Wire
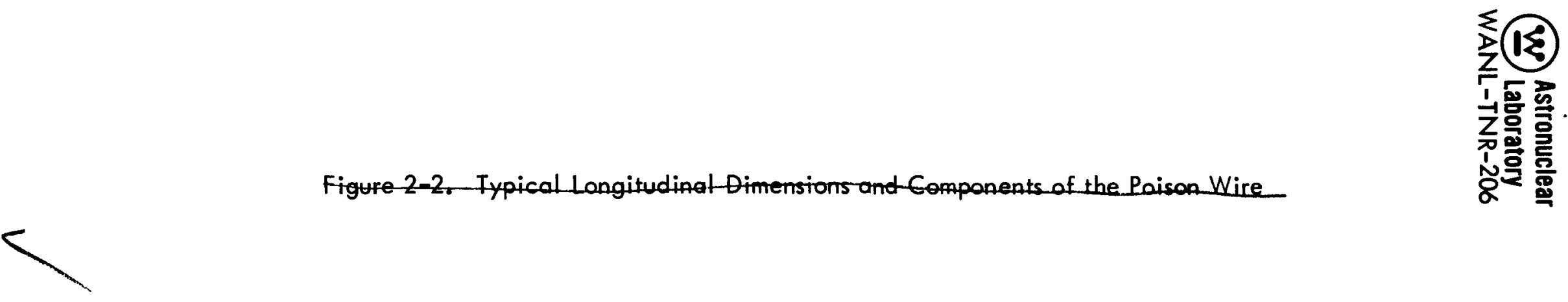
(w) Astronuclear

Laboratory

WANL-TNR-206

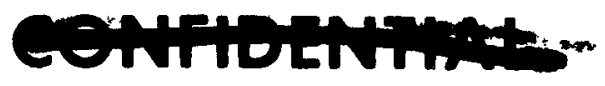

TABLE 2-3

WEIGHT DISTRIBUTION OF ACTIVE-POISON LENGTH OF

POISON WIRE PROPOSED FOR FLIGHT APPLICATION

\begin{tabular}{|c|c|c|}
\hline & $\begin{array}{l}\text { Weight per Unit } \\
\text { length, gm } / \mathrm{cm}\end{array}$ & $\begin{array}{l}\text { Proportion of } \\
\text { Total Weight, \% }\end{array}$ \\
\hline $\begin{array}{l}\text { Center Poison Material } \\
89.5 \mathrm{w} / \mathrm{O} \mathrm{B}{ }_{4}^{10} \mathrm{C}\end{array}$ & & \\
\hline $87.5 \%$ theoretical density & 0.0358 & 42.2 \\
\hline Mylar Plastic, poison sheath & 0.0039 & 4.6 \\
\hline Fiberglass sleeve & 0.0240 & 28.3 \\
\hline Teflon outer sheath & 0.0211 & 24.9 \\
\hline TOTAL & 0.0848 & 100.0 \\
\hline
\end{tabular}


The center portion contains the neutron absorbing ingredient, elemental boron, which is chemically combined in $B_{4} C$. The encasement prevents the loss of core material, but primarily it compensates for strength and property deficiencies of the core material.

The segregation elements determine the particular wires which are grouped together or fastened to a given connector. Since a member may combine the function of segregation with wire retention and support, these parts are treated under a single classification.

The termination of the wires, or a wire bundle, on the end attached to the pull actuator may take several different forms. The form of termination is not entirely dependent on the bundling or support members with which it is associated; however, it is dependent on the nature of the interface with the pull actuator. Consequently, the termination is a separate item in establishing the major wire components.

\section{Wire Center Composition}

The $B^{10}$ isotope contained in the central poison material is the active ingredient effective in absorbing neutrons. Since $B^{10}$ does not occur naturally separate from boron eleven $\left(B^{11}\right)$, some of the latter is always present despite processing undertaken to increase the proportion of $B^{10}$.

Pure boron, regardless of the isotopic proportions, is not acceptable as a poison material. Under conditions of high temperature, pure boron oxidizes to form water soluble compounds. In a situation involving a fire followed by water submergence, formation of boron oxide with subsequent dissolving and removal is a plausible result.

To enhance temperature resistance of the poison material and to reduce water solubility, the boron within a boron compound is utilized to obtain adequate neutron absorbing capability. Table 2-4 compares the various boron compounds considered. $\mathrm{B}_{4} \mathrm{C}$ was chosen since its effectiveness in neutron absorbing capability ranks high. More important, $B_{4} C$ is readily available, and processing techniques are well established compared to those required for the other boron compounds.

The most extensive compilation of information available reports the results of a study by

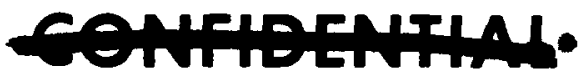


TABLE 2-4

COMPOSITION OF VARIOUS BORON COMPOUNDS

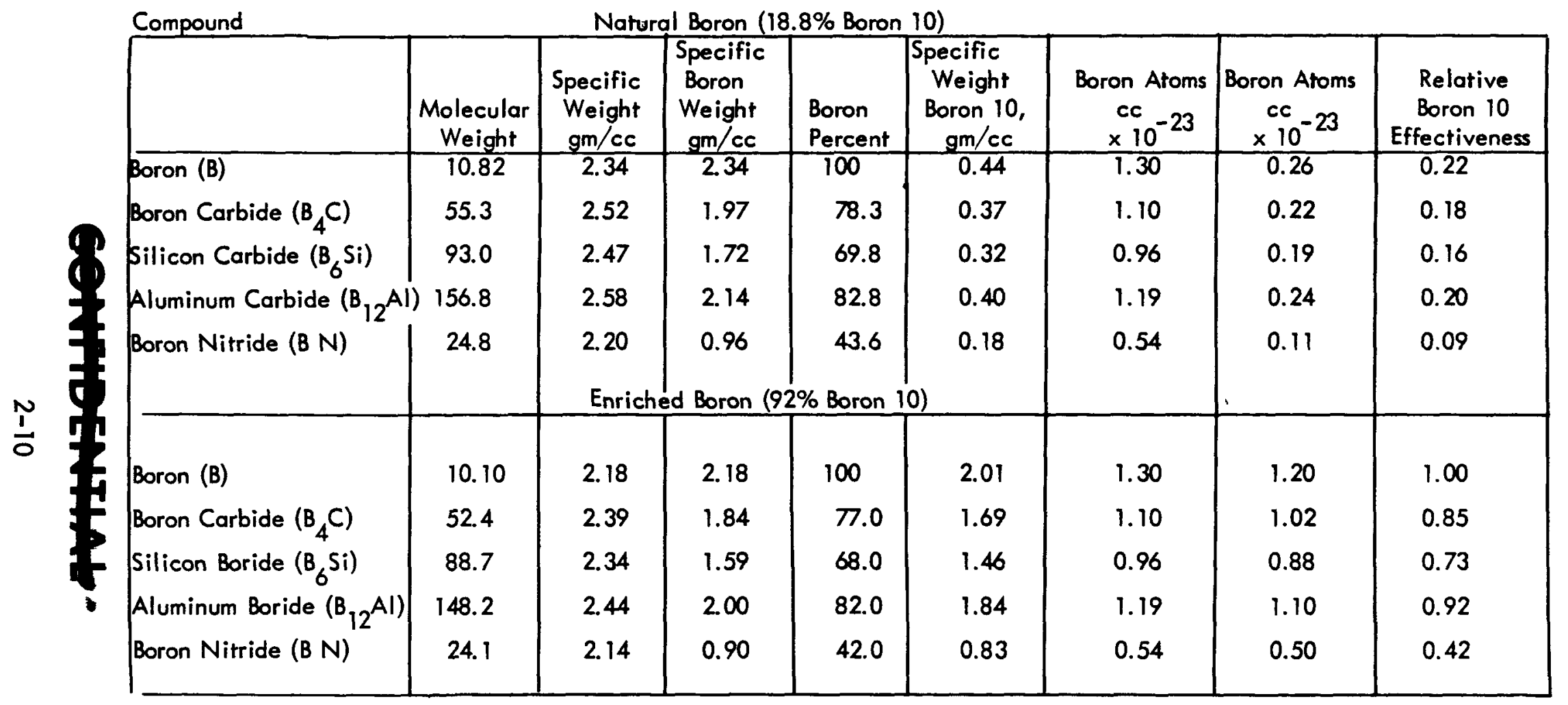


two Russian investigators. 4 on the resistance of refractory compounds toward chemical reagents. These results show that the dissolving of boron carbide cannot be detected with certainty following one and one-half weeks of immersion in concentrated hydrochloric, sulfuric, and nitric acid solutions. Since these experiments could not conclusively provide evidence of boron carbide solubility in high hydrogen ion concentrations, it is reasonable to presume that no solubility exists for sea water in which the hydrogen ion concentration is relatively low.

The $B_{4} C$ material has a number of characteristics which are incompatible with the removal action in which the poison wires are involved. The final form of the $\mathrm{B}_{4} \mathrm{C}$ for the application is a sintered stick which is manufactured from a finely divided powder. In the final form the $\mathrm{B}_{4} \mathrm{C}$ is hard and brittle and like most ceramics, fractures under low tensile stress.

Table 2-5 summarizes the results of $\mathrm{a}_{4} \mathrm{C}$ processing development which was conducted at WANL. The sintering temperature is extremely critical since proper sintering occurs in a range which is only one-half of 1.0 percent of the centigrade temperature level. Particle size of the $B_{4} C$ powder entering the process has a pronounced effect on sintering. Selected additives influence the sintering process in a desirable manner by lowering processing temperature and by inducing a higher density in the finished core sticks. Selection and processing of $\mathrm{B}_{4} \mathrm{C}$ is discussed in detail in Reference 3.

4. Poison Encasement

a Functional Basis

The encasement performs several functions:

1) Prevents the escape of poisoning material.

2) Maintains the circular configuration of the poison wire cross section.

3) Transmits and absorbs tensile forcesduring removal of the poison wires.

4) Minimizes frictional interaction between the wire and contacting

surfaces of reactor components.

4 G. V. Samsonov, Handbooks of High-Temperature Materials, Volume 2 -Properties Index, Plenum Press, New York, 1964

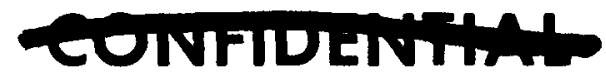


(2) Astronuclear

WANL-TNR-206

TABLE 2-5

\section{BORON CARBIDE SINTERING DEVELOPMENT}

1) Laboratory samples produced 80 to $90 \%$ density $B_{4} C$.

2) Organic binder affects :

$$
\begin{aligned}
& \text { extrusion capabilities } \\
& \text { green strength } \\
& \text { sintered density }
\end{aligned}
$$

3) Sintering temperature requirements for $\mathrm{B}_{4} \mathrm{C}$.

$$
\begin{aligned}
& 2250^{\circ} \mathrm{C} \quad \mathrm{B}_{4} \mathrm{C} \text { does not sinter } \\
& 2260^{\circ}-2270^{\circ} \mathrm{C} \quad \mathrm{B}_{4} \mathrm{C} \text { even sintering } \\
& 2280^{\circ} \mathrm{C} \quad \mathrm{B}_{4} \mathrm{C} \text { eutectic melting }
\end{aligned}
$$

4) Particle distribution for $\mathrm{B}_{4} \mathrm{C}$ sintering .

10 to 45 microns poor sintering

5 to 20 microns improved sintering

1 to 10 microns good sintering

5) Natural impurities, no significant effects.

6) Added Impurities:

Increase $\mathrm{B}_{4} \mathrm{C}$ sintered density

Lower sintering temperatures

7) Cover gases control:

oxidation

void formation

sintering process 
5) Permits translation of the wire through a curved path without damage to any part of the wire.

6) Maintains poison wire integrity and resists deterioration in the presence of extreme environmental and emergency conditions.

In order to maximize performance of these functions and to provide a reasonable bending durability for repeated use and handling, a flexible encasement construction is required. In numerous electrical applications the flexible construction is obtained by means of a woven braid surrounding the central conductor or tube. The material from which the braid is woven is varied to suit various environmental and strength requirements. Utilization of this principle for poison wire encasement was selected because of its applicability and because it is well proven in other applications.

\section{b. Material Selection for Braided Sleeve Encasement}

Both metallic and nonmetallic materials may be utilized to form braid. Small diameter wire of almost any material may be woven into a braid. The use of a metallic braid is one means of maximizing resistance to high temperatures. A disadvantage of the metallic braid is the greater weight penalty in comparison to the use of nonmetallic material of which fiberglass is typical. Compared to the value of $0.024 \mathrm{gm} / \mathrm{cm}$ with respect to fiberglass sleeving from table 2-3, type 304 stainless steel wire of $0.0101 \mathrm{~cm}$ diameter which is braided with maximum surface coverage directly onto poison material sticks, weighs $0.038 \mathrm{gm} / \mathrm{cm}$ which is 50 percent heavier. Consequently, in using this type 304 stainless steel, $0.0101 \mathrm{~cm}$ diameter wire braid in place of fiberglass braid in figure 2-1, the weight of the poison wire would increase from 0.085 to $0.099 \mathrm{gm} / \mathrm{cm}$ or 16.5 percent. A further weight penalty is associated with the metallic braid. Braid openings through which core material might migrate leave approximately 25 percent of the surface uncovered. The weight of the sealant required to fill these openings is not included in the above values.

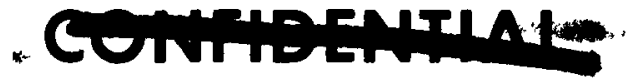


Fiberglass is a nonmetallic material which is in common use for electrical conductor braided sleeving. It has high strength coupled with high temperature capability. The common electrical or E-type fiberglass can sustain a weight load up to $650^{\circ} \mathrm{C}$. Special fiberglass S-type which has a weight load carrying ability up to $870^{\circ} \mathrm{C}$ is also available and is suitable for braiding. The use of the S-type glass in the poison wire braided sleeving enhances the temperature resistance of the poison wire. Figure 2-3 shows a strength comparison of the $E$ and $\mathrm{S}$ glass fibers. This figure is based on Owens-Corning Fiberglass Corporation Circular NY-AD-64-3A. Values are based on the strength of very small $0.0075 \mathrm{~cm}$ diameter filaments.

Table 2-6 provides a comparison of sleeving braided with each type of glass. Braids 1 through 4 have the same weave pattern. Although braids 1 through 5 are all suitable dimensionally, braid 5 will be employed since it provides a surface texture less rough than other braids which were evaluated.

It is apparent upon examination of table 2-6 that room temperature tensile strength of fiberglass braid decreases upon exposure of the braid to high temperatures. This reduction in strength probably results from the volatization of starches and other organic treating obtained without further conditioning, subsequent to braiding, is stronger than conditioned braiding.

Complete surface coverage is not a problem with fiberglass sleeving since this is the usual characteristic of stock fiberglass braiding. The numerous fine fiberglass filaments composing each strand of the sleeving permit the crossed strands to flatten, bend, and conform to each other. Upon pulling or drawing of the braid, apparent closure of all openings in the braid occurs as conforming actions of the strands produce contact between adjacent filaments. Fiberglass braided sleeving is available in an extremely wide variety of braid patterns, yarn sizes, and electric conductor sizes, and also, it appears to be adequate from the standpoint of tensile strength and temperature resistance; therefore, it will receive first consideration with respect to construction of a flexible poison wire.

\section{c Braid Coating and Outer Sheath}

Coating or sheathing of the braid is desirable from two standpoints:

1) It serves as a seal to prevent loss of the poisoning material through the openings in the braid wall.

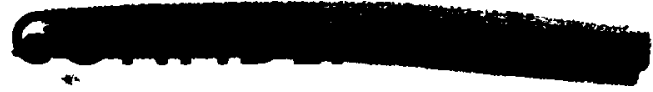



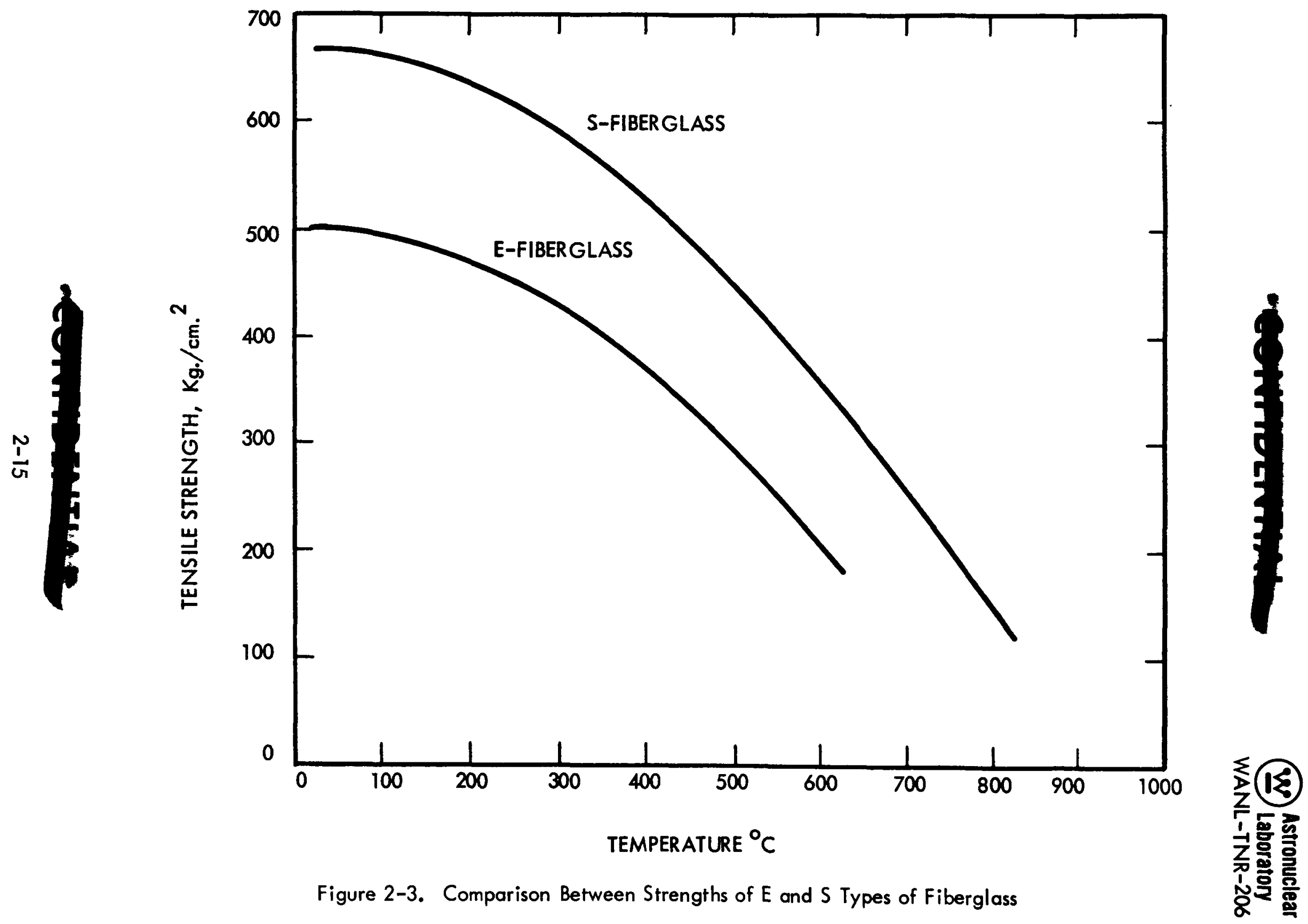

Figure 2-3. Comparison Between Strengths of E and S Types of Fiberglass 
TABLE 2-6

FIBERGLASS SLEEVING TENSILE BREAKING STRENGTH

\begin{tabular}{|c|c|c|c|c|c|}
\hline \multirow[b]{2}{*}{$\begin{array}{l}\text { Braided } \\
\text { Sleeving } \\
\text { Designation }\end{array}$} & \multirow{2}{*}{$\begin{array}{l}\text { Type } \\
\text { of } \\
\text { Glass } \\
\text { in Yarn }\end{array}$} & \multirow{2}{*}{$\begin{array}{c}\text { Treatment } \\
\text { Subsequent } \\
\text { to } \\
\text { Braiding }\end{array}$} & \multicolumn{3}{|c|}{$\begin{array}{l}\text { Average Breaking Strength } \\
\text { (Two Specimens), kg }\end{array}$} \\
\hline & & & Unheated & $\begin{array}{c}\text { Heated One } \\
\text { Hour at } 427^{\circ} \mathrm{C} \\
\end{array}$ & $\begin{array}{l}\text { Heated One } \\
\text { Hour at } 538^{\circ} \mathrm{C} \\
\end{array}$ \\
\hline 1 & $E$ & None & 26.6 & 14.1 & 6.6 \\
\hline Variation & & & $22.4-30.9$ & $12.9-15.4$ & $5.7-7.6$ \\
\hline 2 & $E$ & Normalized & 14.0 & 12.2 & 7.4 \\
\hline Variation & & & $11.8-16.3$ & $10.6-13.9$ & $3.9-10.9$ \\
\hline 3 & $S$ & None & 43.5 & 18.1 & 8.7 \\
\hline Variation & & & $41.6-45.4$ & $15.5-20.8$ & $8.2-9.2$ \\
\hline 4 & $S$ & $\begin{array}{l}\text { Normalized } \\
\text { and Treated }\end{array}$ & 15.3 & 13.3 & 7.2 \\
\hline Variation & & & $12.7-17.9$ & $13.0-13.7$ & $5.0-9.6$ \\
\hline 5 & $E$ & None & 31.4 & 12.4 & 8.8 \\
\hline Variation & & & & $10.4-14.4$ & $7.6-10.1$ \\
\hline
\end{tabular}




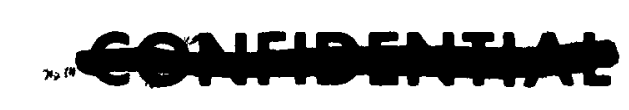

(W. Astronuclear

WANL-TNR-206

2) It serves as a means of reducing frictional resistance during poison wire removal from the reactor core.

Since a characteristic of fiberglass braid is 100 percent coverage, application of a special coating to seal braid openings is not mandatory. However it may be desirable to decrease the macroscopic roughness of the braid. This may be accomplished by employing a filler to reduce the depth of "valleys" between "peaks" which are produced by the lay of the wire or yarn. Based upon preliminary investigations, room temperature curing silicone rubber seems quite suitable for the purpose of filling the braid openings. This type of material is useful from $-55^{\circ}$ to more than $260^{\circ} \mathrm{C}$. Throughout this temperature range the silicone material remains flexible and would not be displaced from the braid openings by flexing of the poison wire.

In order to minimize frictional resistance and to minimize mechanical interaction of irregularities of the braid and the reactor core coolant channel surfaces, both fiberglassbraided and metal-braided poison wires may be inserted into a Teflon sheath. The Teflon sheath is tubing which is shrunk onto the exterior of the fiberglass sleeve for the purpose of obtaining a smooth outer surface on the poison wire. The sheath also serves to prevent passage of core material through the braid wall. Teflon sheath wall thicknesses of 0.010 to $0.015 \mathrm{~cm}$ may be attained.

\section{d Tip Requirements}

The tip of the wire attains the greatest insertion depth into the reactor and requires a special construction. The wire tip portion is approximately $1.2 \mathrm{~cm}$ in length and it:

1) Prevents the loss of core material through the end of the encasement.

2) "Smooths" and "rounds-off" the end of the encasement to eliminate contact of sharp edges with the coolant channel wall.

3) Provides a transition length to reduce gouging action and large localized forces on the coolant channel exit surfaces as the wire leaves the channel.

The objectives of 1) and 2) are obtained by molding into place the desired configuration from material with appropriate adhesive characteristics. Objective 3) is realized by selection and combination of materials to shape the resistance which the tip plug presents 


\section{(W) Astronuclear

to a specific type of poison wire bending couple. This type of couple appears if the tip plug made from material of selected elasticity and resilience deflects and deforms upon application of the bending couple. This deformation causes more of the tip cylindrical surface to contact the channel wall resulting in less force per unit area. Consequently, there is less likelihood of the tip penetrating and chipping the coating of the coolant channel wall.

\section{POISON WIRE MANUFACTURING}

\section{General Approach}

Approximately 400 simulated poison wires have been constructed to a demonstration design for utilization in the poison wire and withdrawal system evaluation tests. In many respects these demonstration wires are similar to the representative wire design of figure 2-2. The wire of figure 2-2 represents the results of an approach which satisfies poison wire criteria but permits manufacture by simple means. Flexibility is thereby intrinsic with respect to future modification of the design and manufacturing techniques.

A group or bundle of the demonstration wires is shown in figure 2-4. In these wires special lead material of the proper diameter was substituted for the $\mathrm{B}_{4} \mathrm{C}$ indicated in figure 2-2. Since the wires were utilized only for tests of a mechanical nature, the pencil lead substitution provided a means for economy of material. Furthermore, the metal wire extension of figure 2-2 was not included in the fabrication of the wires of figure 2-4. Since precise ACPS specifications have not been prepared, no sufficient basis exists for establishing the characteristics desired in the section of the wire extending from the reactor core. The manner in which the metal wire may be utilized is discussed later in this report.

\section{Fabrication}

The following information describes some of the methods used in making poison wires. The first step in manufacturing a poison wire consists of insertion of cylindrical poison pieces, 0.142 to $0.147 \mathrm{~cm}$ in diameter, into a thin walled plastic tube. Upon Insertion, the poison pieces are butted end-to-end in contact with each other. The thin walled plastic tube unites numerous poison pieces into a single element of the desired length. Construction of the poison

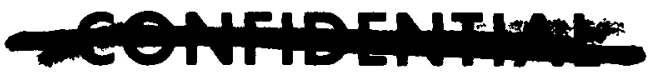




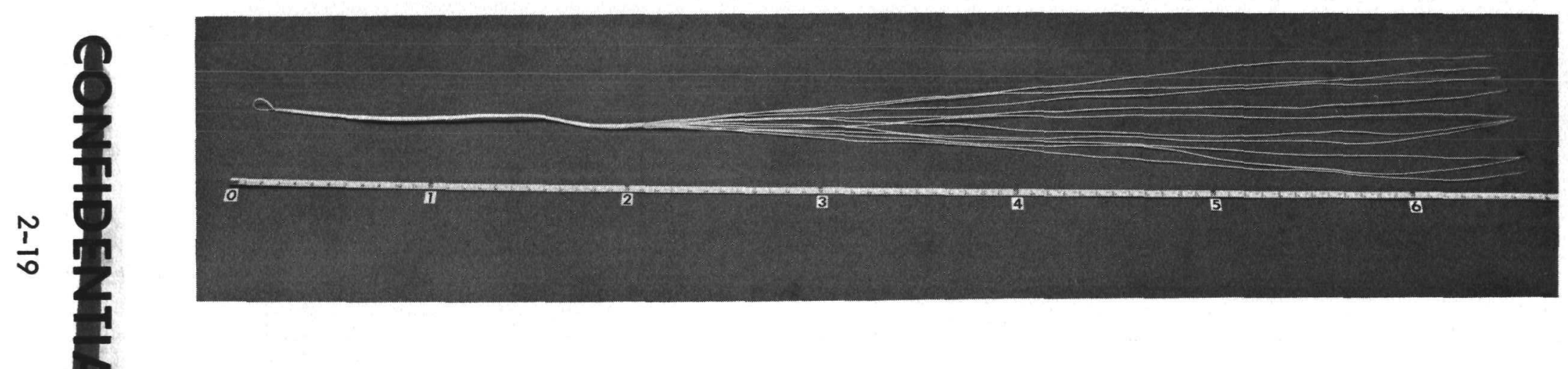

Figure 2-4. Demonstration Wire Bundle

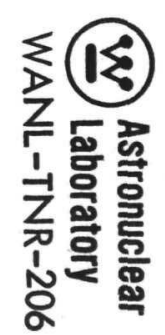




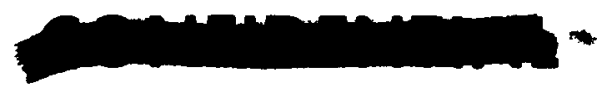

wire is therefore facilitated since only a single unit must be manipulated. To minimize encasement wall thickness the thin plastic tube has a maximum thickness of $0.0075 \mathrm{~cm}$ after shrinkage onto the poison pieces.

As an example of the design flexibility, metal wire has been incorporated into the illustration of figure 2-2. The metal wire is utilized in this application to prevent collapse of the encasement and to stiffen the wire throughout the length which cannot be inserted into the reactor core. Substituting material other than poison material into the wire center provides a means of changing wire characteristics without incurring an abrupt discontinuity in the encasement.

The central, sheathed poison unit is slipped into a braided fiberglass sleeve to complete the next step of the poison wire construction. It is expected that the encasement thickness contribution of the fiberglass sleeve will be no greater than $0.013 \mathrm{~cm}$.

Insertion of the fiberglass enclosed unit into a Teflon sheath is the next step of the process. The application of heat to shrink the Teflon tube tightly onto the fiberglass completes the encasement of the poison wire. The Teflon sheath, subsequent to shrinkage, will contribute approximately $0.015 \mathrm{~cm}$ to the encasement thickness.

For purposes of production of a large number of wires the operations identified above may be mechanized. For instance, insertion of the poison sticks into the sheathing could probably be accomplished by utilizing a vibratory feeder in conjunction with appropriate holding fixtures. The latter would compensate for spooling curl by aligning the tubing and funnel the sticks, fed one at a time, into the tubing entrance.

Wire units which are encased in unshrunken tubing can be conveyed past heating elements to obtain shrinkage of the tubing. Figure 2-5 is a photograph of the apparatus which has been successfully employed. In order to obtain shrunken tubing surfaces of uniform, satisfactory texture, the combination of velocity past the electric heating elements and the shrinking temperature must be closely controlled to predetermined levels. The necessary precision feedcontrol of the wire units to the heating elements has been accomplished by an electric motor driven apparatus. Desirable combinations of feed and temperature are established by varying the settings of an autotransformer which provides current to the heating elements and by varying the speed of the motor driving the conveyor. 

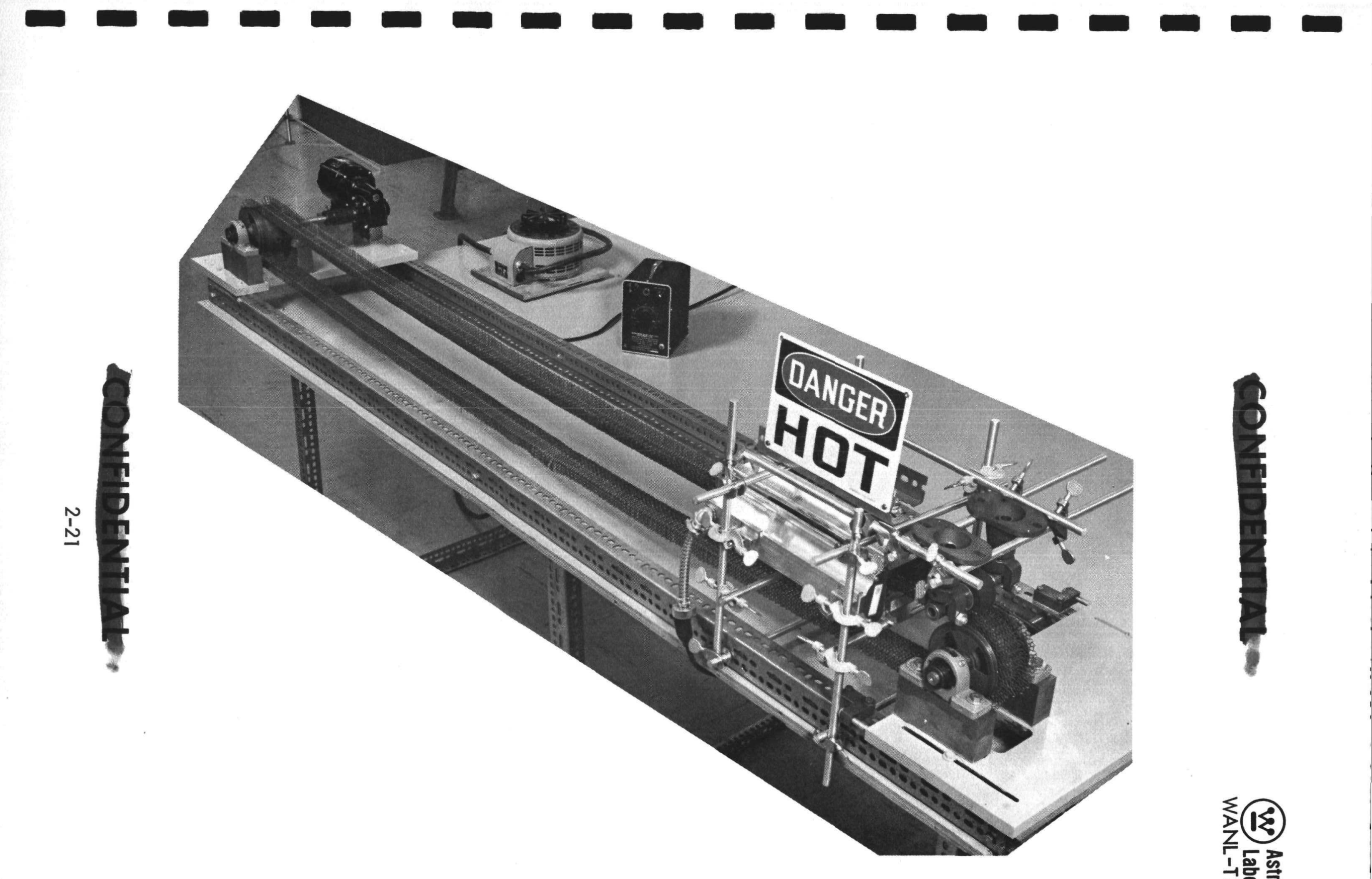

Figure 2-5. Shrinkable Tubing Conveying Apparatus

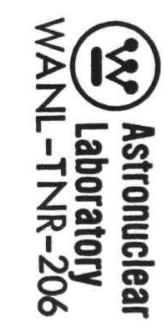


The $B_{4} C$ poison as produced consists of sticks 7.5 to $15 \mathrm{~cm}$ in length which are inserted into the sheath. To obtain the flexibility characteristics required of the wire, the sticks must be broken into short pieces, $0.3 \mathrm{~cm}$ or less in length after the sheath is shrunk into place. Severing of the sheath during fracturing of the poison sticks should be prevented since the purpose of the sheath is to reduce the number of pieces which must be manipulated during subsequent encapsulating operations.

A method which produces fracturing consists of passing the sheathed poison unit through a mill consisting of a rubber roll which compresses, during rotation, against a driven steel roll. The rubber deforms to accommodate the intrusion of the wire poison unit. During rotation, the compressed rubber springs back as contact with the steel roll diminishes. As the original shape is restored, the rubber applies a bending force to the portion of the poison unit which has passed the nominal line of maximum compression between the two rolls. This extension of the sheathed poison unit is bent in cantilever fashion against the curved surface of the steel roll until fracture occurs. Figure 2-6 shows the apparatus which was successfully employed following construction in accordance with the principle described.

Upon completion of individual wires, specific numbers of them are brought together to form bundles. Bundles will be formed to:

a) Facilitate the installation of wires

b) Aid in maintaining a specific position of the wire insertion

c) Provide a structurally self supporting configuration to permit elimination of support accessories.

d) Reduce the number of connections to be made at the interface with the pull actuator.

Figure 2-4 represents a typical bundle of wires to be utilized in wire and actuator feasibility trials.

\section{POISON WIRE QUALIFICATION}

1. Direction of Qualification Effort

All wire designs for the ACPS will be mechanically qualified to establish confidence that no credible loading will compromise wire functions and that durability margins are adequate.

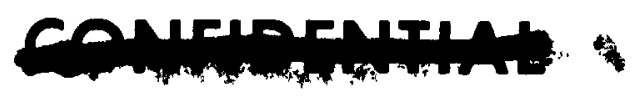



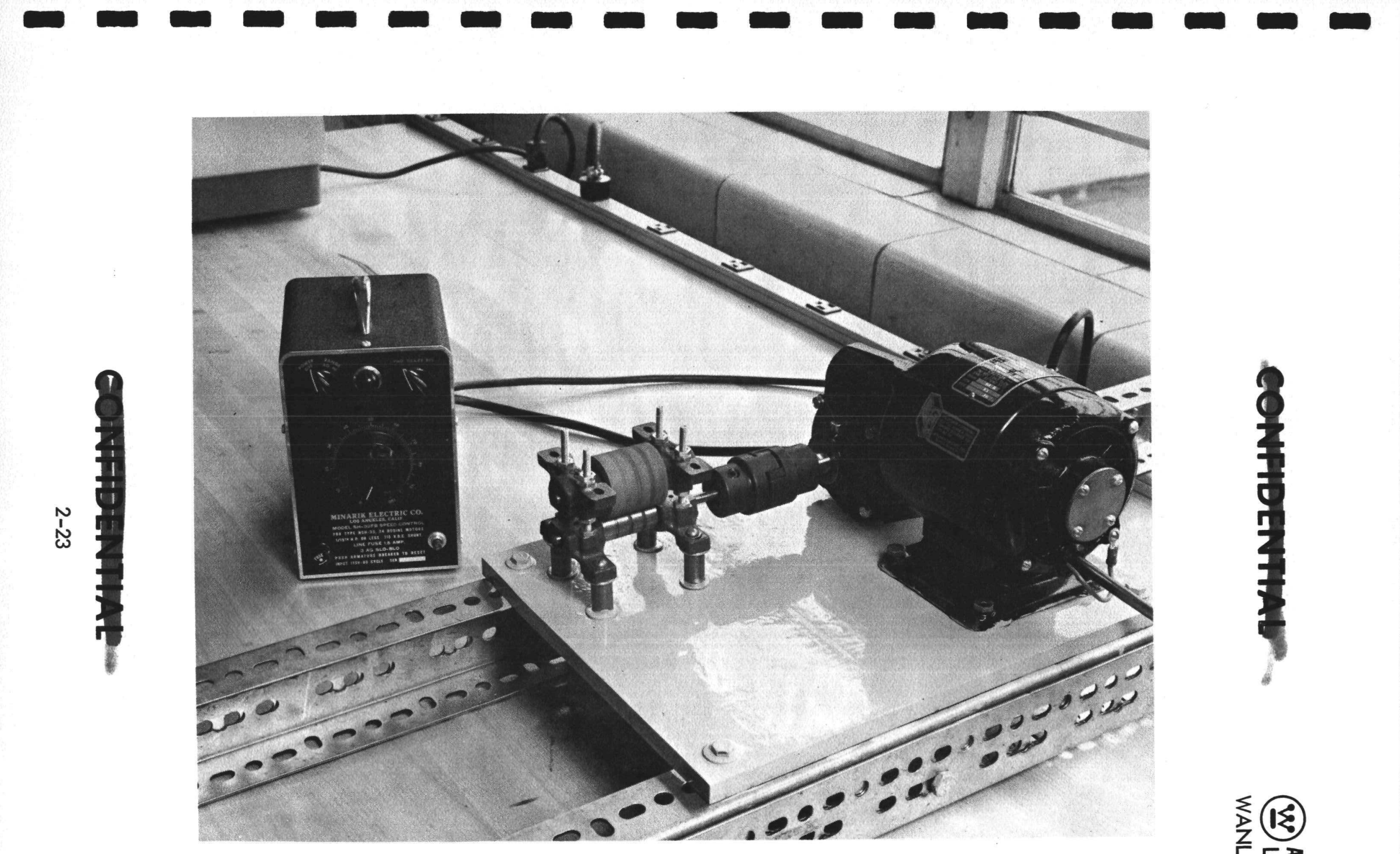

Figure 2-6. Poison Material Fracturing Mill

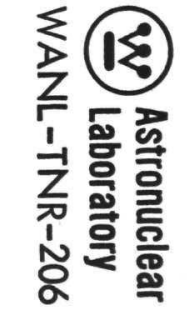


High margins of various types of capability assure satisfactory endurance of the poison wire to manipulation and handling stresses. In the event a reactor shipment wire is based on the ACPS design, high margins of capability will increase life expectancy. Exceedingly high strength, compared to the loads that will be applied, increases the number of times that the wires can be used. Therefore, the testing and qualification efforts of the ACPS wires should be expended in establishing the primary wire function listed as follows:

a) Insertion of the wires in the core is maintained until positive action is taken to remove the wires.

b) The wires withdraw unequivocally upon actuation of the wire withdrawal system.

c) The wires in no way jeopardize the integrity and operability of the reactor and nozzle as a result of either installation or withdrawal.

\section{Wire Qualification Criteria}

Tables 2-1 and 2-2 give the accident and operating conditions which the wires must be capable of withstanding. Table 2-2 provides tensile pull strength related to various temperatures which will be useful in evaluating the capability of the wires to withstand the conditions stated in tables 2-1 and 2-2. Table 2-7 shows that the wire pull strength is far greater than adequate from temperatures lower than $-167^{\circ} \mathrm{C}$ to those up to $204^{\circ} \mathrm{C}$. The wire is a composite of various materials; therefore, the results of a particular test cannot be attributed entirely to one element of the wire since the wire elements interact to influence one another. For this reason arbitrary and non-standard demonstrations must be conceived in order to prove that the wire properly qualifies.

A number of wires should be tested to prove that the arbitrary demonstrations are valid. A major criteria determining test validity is the completion of a test without any undesirable change in the characteristics of the wires. During these tests most of the effort should be directed to determining the following qualities and capabilities:

a) Roughness and texture

b) Flexibility

c) Tensile pull strength

d) Dimensional changes, breaks, or cracks in any of the wire elements 


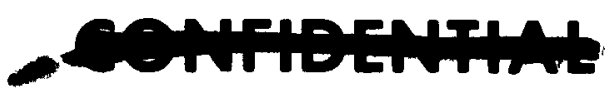

(w) Astronuclear
Laboratory

TABLE 2-7

VARIATION OF POISON WIRE BREAKING STRENGTH WITH TEMPERATURE

\begin{tabular}{|c|c|c|}
\hline Temperature & $\begin{array}{c}\text { Breaking Strength } \\
\text { of Individual } \\
\text { Test Specimen } \\
(\mathrm{kg})\end{array}$ & $\begin{array}{c}\text { Average } \\
\text { Breaking Strength } \\
(\mathrm{kg})\end{array}$ \\
\hline$-178^{\circ} \mathrm{C}$ & $\begin{array}{l}38.0 \\
47.6 \\
39.5\end{array}$ & 41.6 \\
\hline$-55^{\circ} \mathrm{C}$ & $\begin{array}{l}54.8 \\
39.9 \\
44.2\end{array}$ & 46.3 \\
\hline Room Temperature & $\begin{array}{l}33.1 \\
26.0 \\
32.3\end{array}$ & 30.6 \\
\hline $121^{\circ} \mathrm{C}$ & $\begin{array}{l}17.1 \\
19.0 \\
17.9\end{array}$ & 18.0 \\
\hline $204^{\circ} \mathrm{C}$ & $\begin{array}{l}15.4 \\
15.2 \\
11.1\end{array}$ & 13.8 \\
\hline
\end{tabular}


(w)

Astronuclear

Laboratory

WANL-TNR- 206

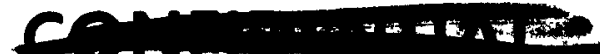

e) Use of the wire does not produce any damage to the reactor coolant channel

f) The poison of the wires will remain in the reactor core under conditions of high temperatures, explosion, and impact

3. Wire Qualification Tests

The qualification effort should consist of the following tests:

a) Tensile pull tests

b) Flexing and handling durability tests, such as repeatedly wrapping the wire around a cylindrical mandrel.

c) Removing a particular wire many times from the same reactor core coolant channel to ascertain the effects on both the wire and the channel surfaces.

d) Heating a wire to high temperatures while it is inserted in a simulated fuel channel to demonstrate that the poison remains in the channel.

e) Stress and bending endurance tests at low temperatures.

f) Vibration tests to determine tendencies to compaction and bunching of encased materials.

Figures 7, 8 and 9 are photographs of a reactor support block hole into which one of the demonstration wires was inserted and pulled out many times. The fixture to hold the block and to guide the direction of wire pull is shown in figure 2-10. A magnification of 12 was employed to photograph the hole.

The condition of the hole before the wire pull test is shown in figure 2-7. Hole outlet conditions after 35 pulls and after 50 pulls are shown in figures 8 and 9 respectively.

Following insertion, the wire was pulled through the tube which was mounted at an angle of 30 degrees from the plane of the outlet face of the block (60 degrees from the hole axis). The rate of wire pull was approximately $20 \mathrm{~cm}$ per second. As can be seen from the photographs, no support block damage is detectable in a comparison of pretest conditions and after 50 pulls. The tip of the demonstration wire used is shown in figure $2-11$ after 50 pulls from the hole. No change can be seen in the condition of the tip. No special modifications were made of the demonstration wire tips. The appearance of all tips was similar to that of figure 2-11. 


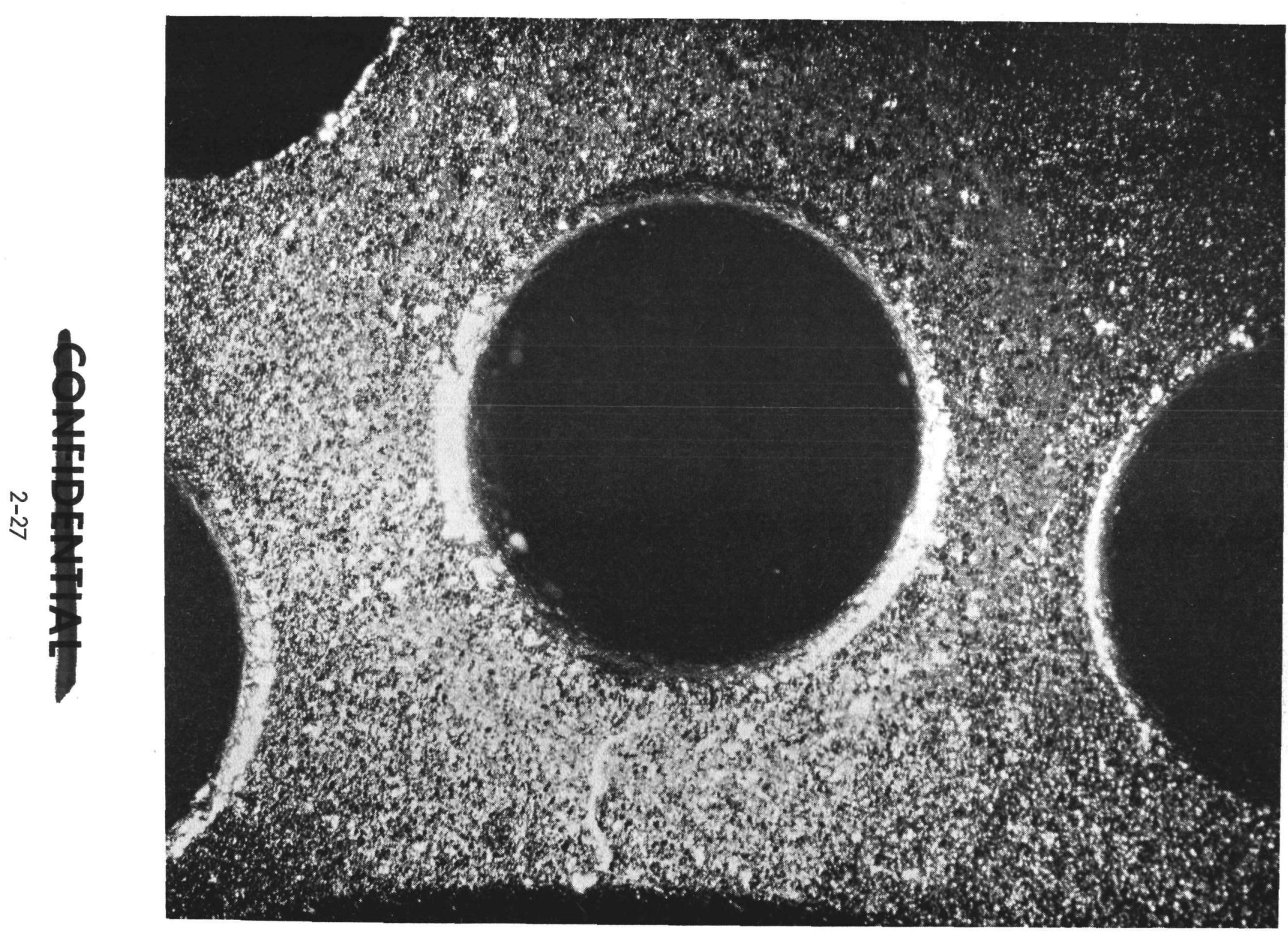

Figure 2-7. Fuel Element Coolant Channels Prior to Wire Pull Test 


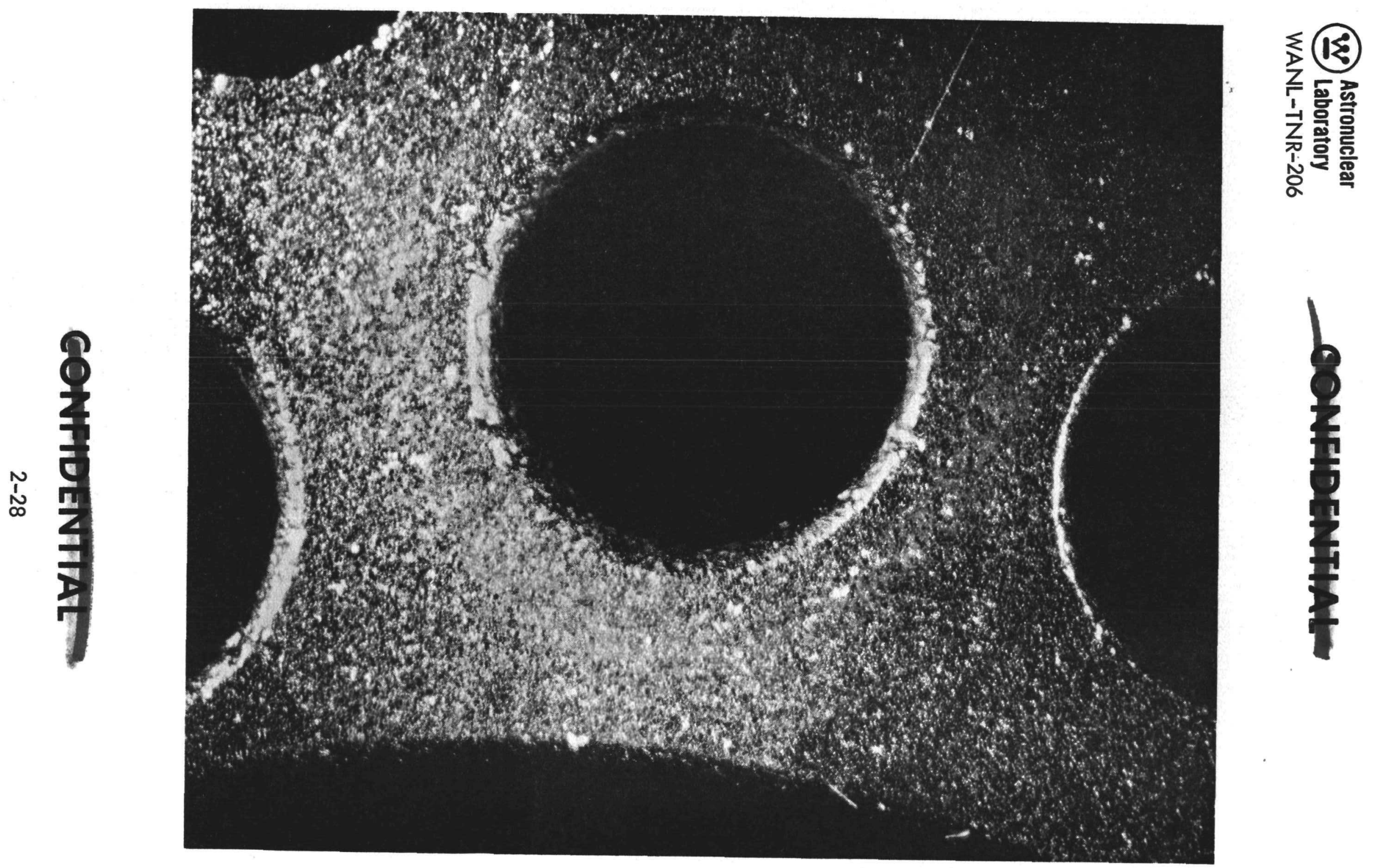

Figure 2-8. Fuel Element Coolant Channels After 35 Wire Pulls 


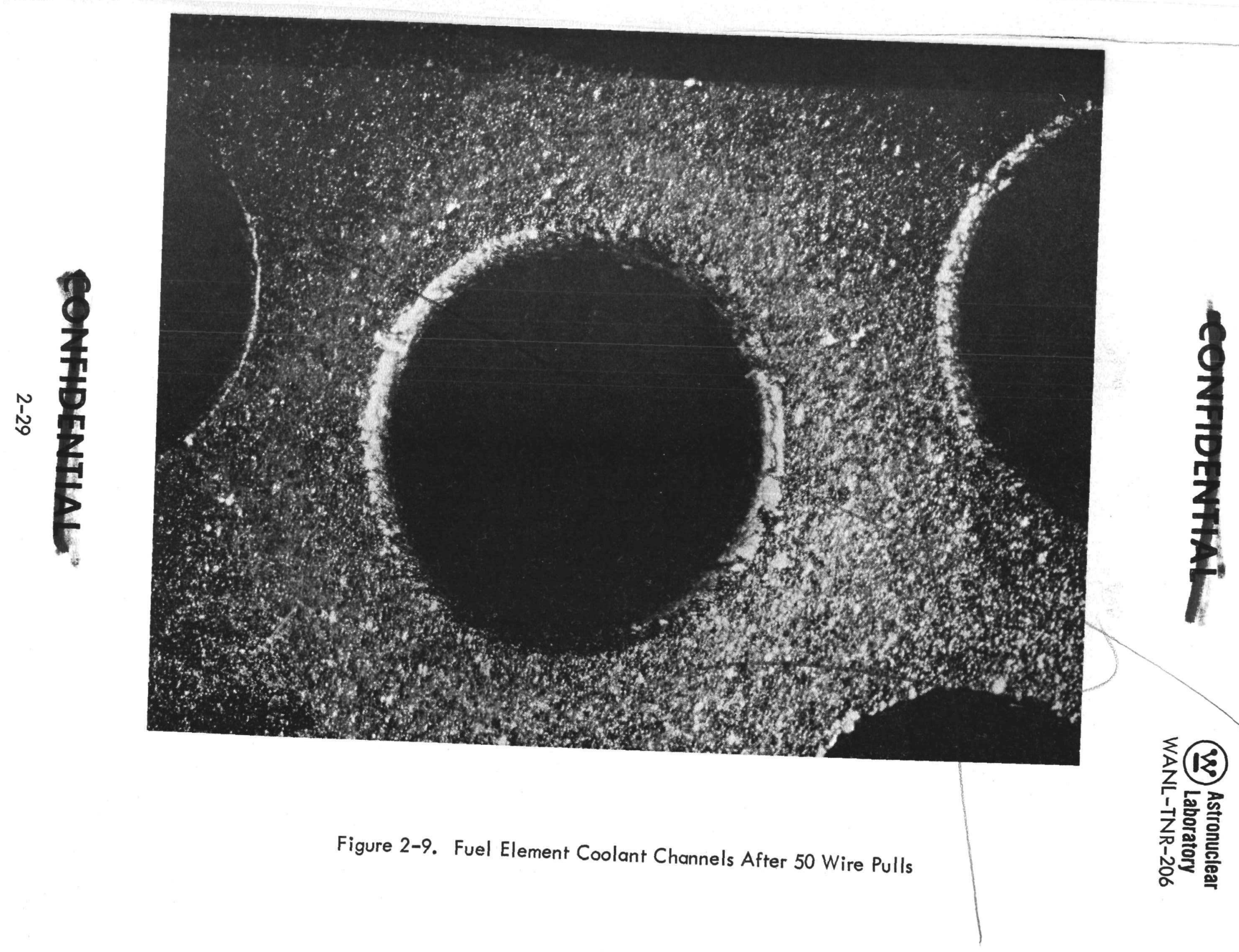


(w) Astronuclear
Laboratory
WANL-TNR-206
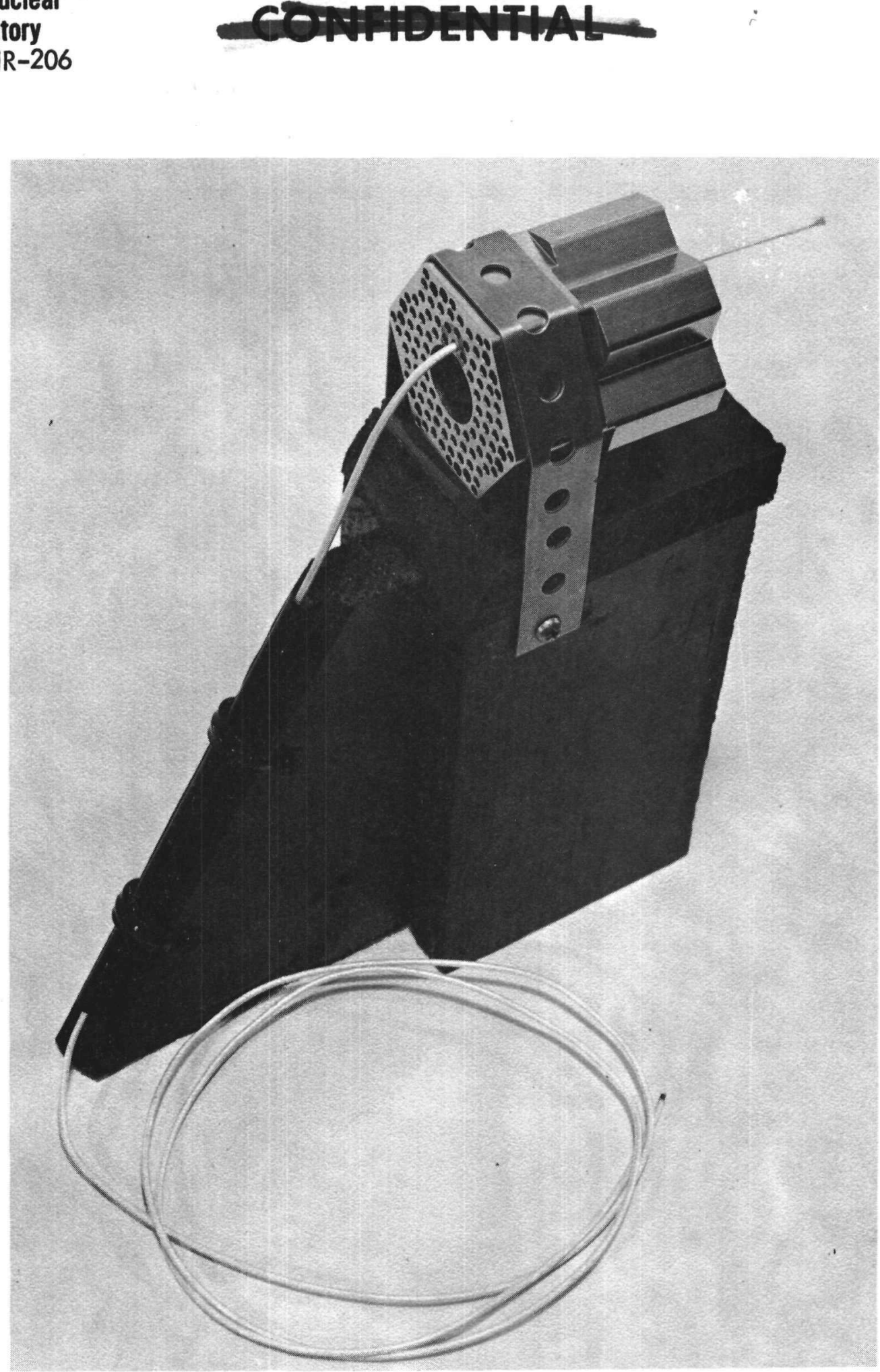

Figure-2-10. Flexible Poison Wire Pull-Test Fixture

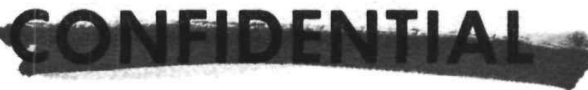




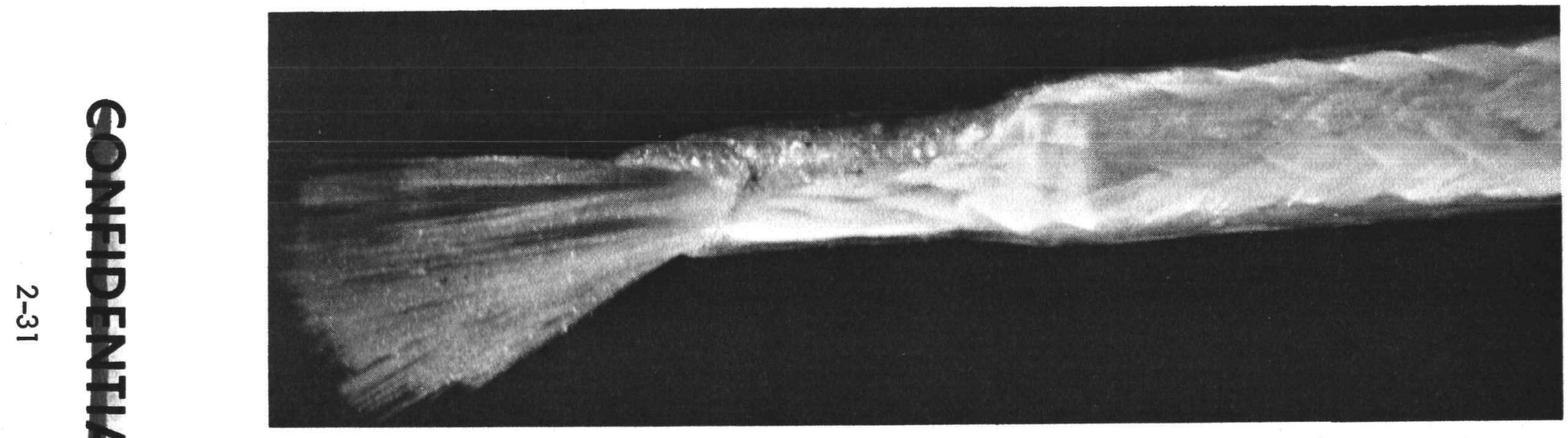

Figure 2-11. Flexible Poison Wire Tip After 50 Pulls

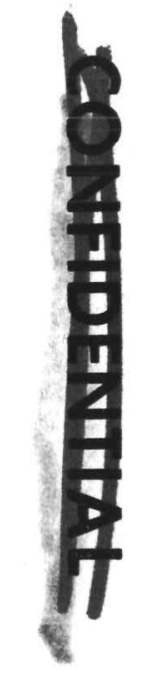

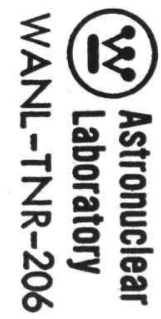




\section{E. DEMONSTRATION WIRE WITHDRAWAL TESTS}

\section{Wire Installation}

Approximately 400 demonstration wires were fabricated as shown in figures 2-1 and

2-4. The nuclear poison, $B_{4} C$, of these wires was simulated by the use of appropriately dimensioned pencil lead material. Various quantities of these wires were inserted as shown in figure 2-12 and installed in an arrangement of NERVA reactor dummy fuel clusters. A complete assembly of wires and apparatus is shown in figure 2-13. The wires were pulled from the clusters to determine the withdrawal forces.

\section{Withdrawal Apparatus}

The apparatus used to withdraw the wires from the dummy fuel clusters was designed and constructed to demonstrate principles and techniques that could be employed to withdraw the wires during flight of the NERVA engine. In essence, the wires were terminated at a retractor head positioned near a simulated engine nozzle throat. A stainless steel tape, 2.54 $\mathrm{cm}$ in width, connected the retractor head unit to a spool on the shaft of a pneumatic motor. Upon admission of air to the motor, the spool wound the tape causing the retractor head to move toward the spool. In this manner, the wires connected to the retractor head were withdrawn from the dummy fuel clusters.

\section{Wire Withdrawal Forces}

Withdrawal test description techniques and results are discussed in detail in Appendix A.

Table B-4 in Appendix A shows the force results from Test 7 which was conducted with 300 wires. This test approximated a uniform distribution of the wires throughout the reactor core. The peak force recorded was $40.4 \mathrm{~kg}$ obtained during the breaking of static friction. This gives a maximum force value of $0.135 \mathrm{~kg} /$ wire. It is possible that the recorded peak force is low due to an inadequate recorder response. Considering this situation, a maximum 


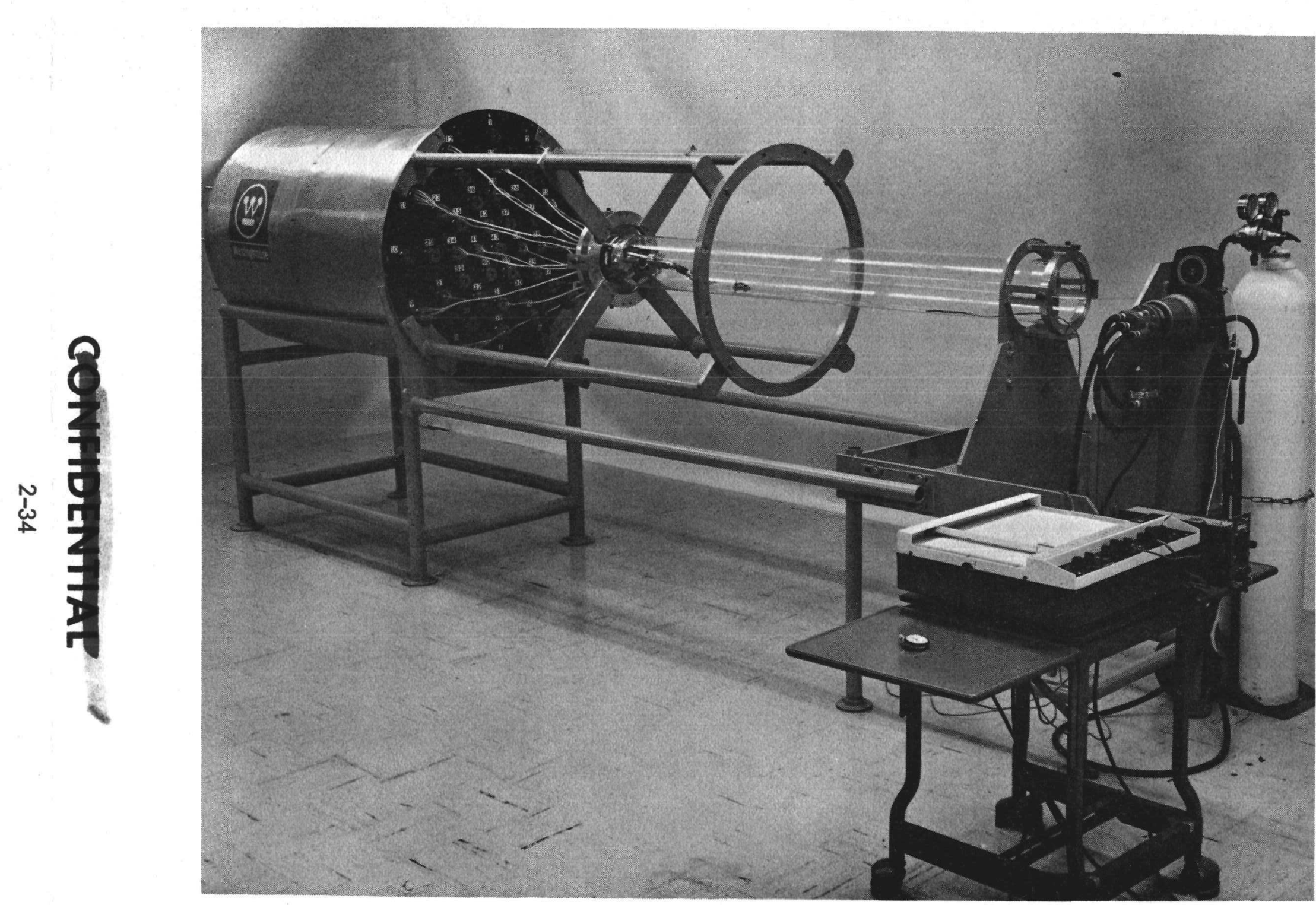

Figure 2-13. Demonstration Wire Withdrawal Assembly 
value of $0.154 \mathrm{~kg} /$ wire was estimated by using the peak force multiplied by 1.25 . With respect to withdrawing 2000 wires, the extrapolated force values (on the basis of 300 wire values) would be $270 \mathrm{~kg}$ measured peak force, $246 \mathrm{~kg}$ maximum sliding friction force, and $308 \mathrm{~kg}$ projected peak force.

\section{F. POISON WIRE RETENTION}

\section{Basis for Wire Groups}

Figure 2-14 is reproduced from Reference 1 and illustrates the distribution of poison wires in the core of the reactor. This distribution approximates a uniform poison pervasion of the reactor core. There are approximately 10 wires per fuel cluster as established by the regular clusters. For convenience in assigning wires to fuel clusters, the nominal number of wires required to establish a bundle will be set at 10. Peripheral clusters will have wire bundles assigned to them which are comprised of smaller numbers of wires. An illustration of a wire bundle is presented in figure 2-4.

\section{Wire Movement Restriction}

The wires must be precisely positioned in the channel of the reactor core since, during installation, the wires must not be inserted too far. The wires must be inserted to a predetermined point which provides adequate tip clearance to assure that there is no possibility of damage to the channel orifices or that the orifices do not become clogged with residue from the wire tip. The tip clearance must not become too large; otherwise the volume of the unpoisoned core wafer at the inlet to the core could become great enough to sustain criticality, independent of the remainder of the core.

Maintaining insertion and preventing random movement of the wires in and out of the fuel channels is much more complicated. The problem centers on providing a structure that will make possible accurate prediction of wire location within close tolerances of movement. Space requirements force this structure to be integrated with the bundling components. 


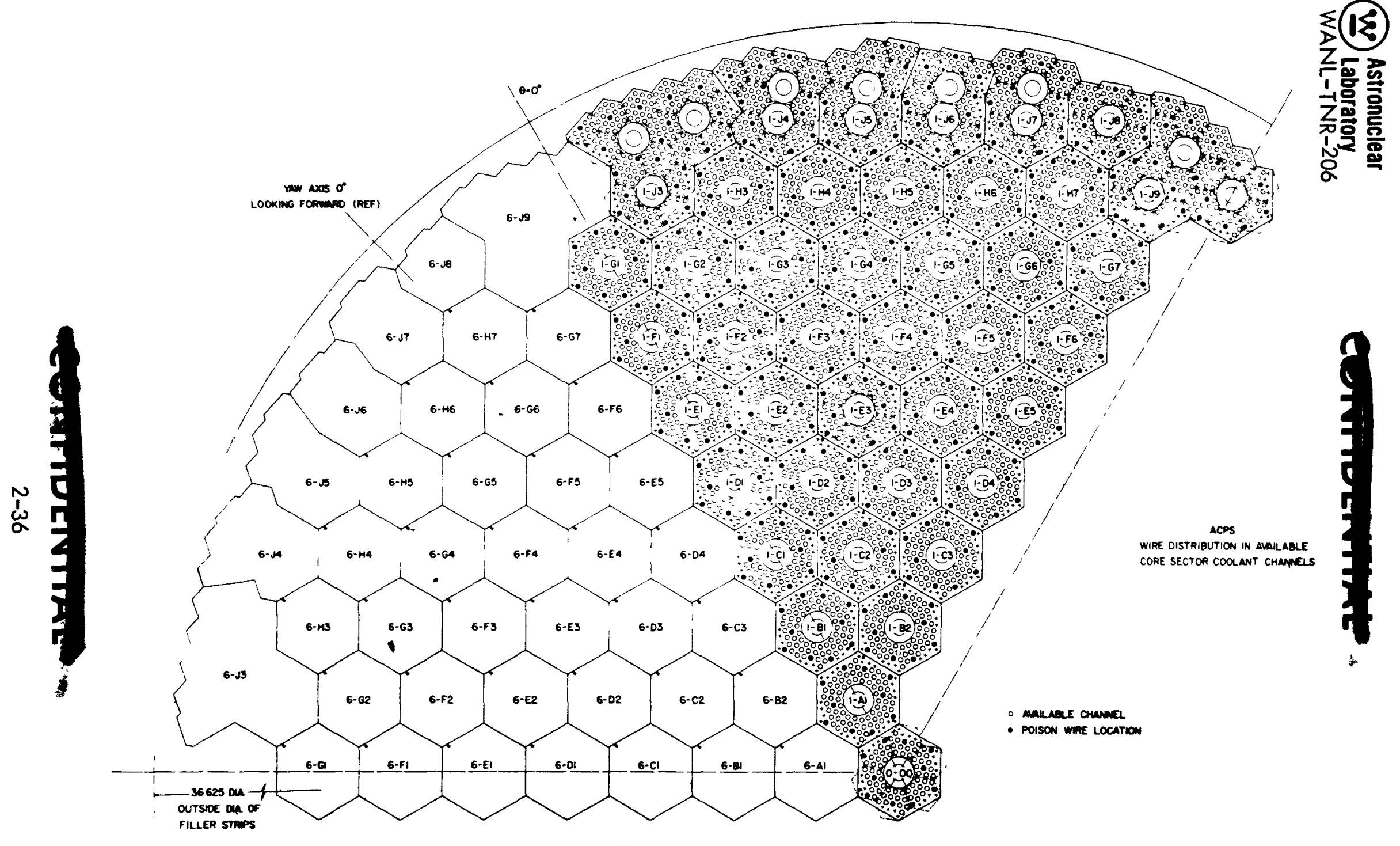

Figure 2-14. ACPS - Wire Distribution in Available Core Sector Coolant Channels 



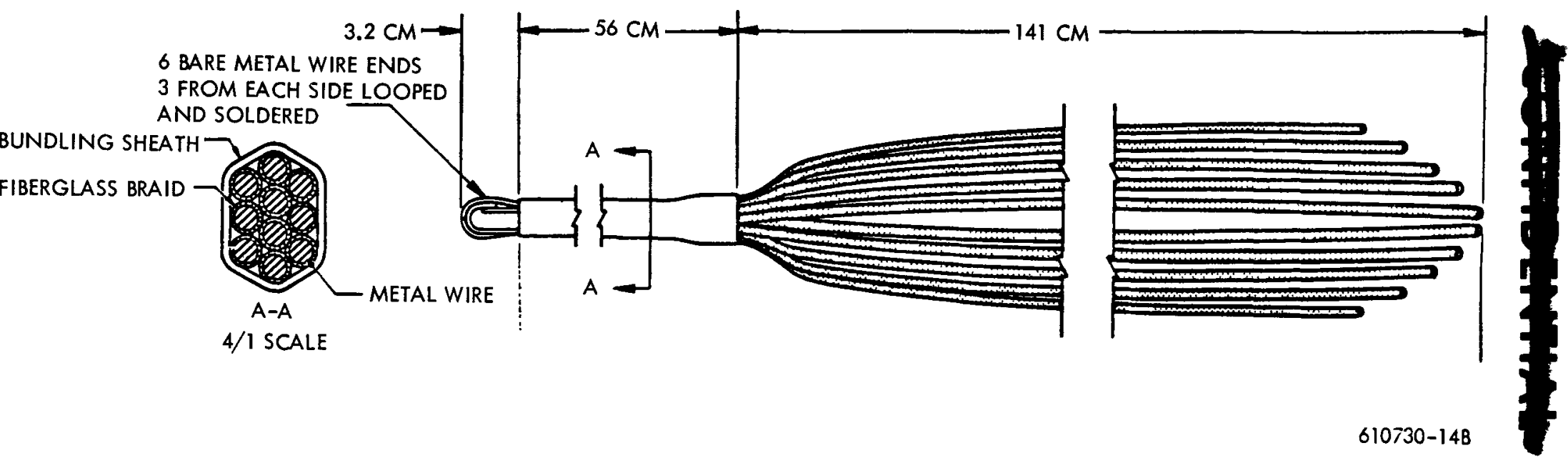

Figure 2-15. Typical Bundle of Poison Wires 
variety of adhesives which are satisfactory for bonding the wires together, the bundle rigidity and stiffness may be regulated over a wide range.

All or part of the bundled length of the wires may be replaced by metal element extensions. These may be partially articulated to provide controlled flexing in specific planes and directions and through a predictable angle. Termination at the actuator end of the bundle will, in all likelihood, be a simple nut or screw which is integral with or bonded to the bundled elements. 


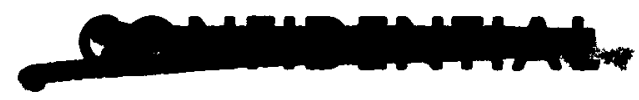

(W) Astronuclear

WANL-TNR-206

\section{CHAPTER III DESIGN CRITERIA FOR THE ACPS}

\section{A. GENERAL INFORMATION}

The design of the poison wire system is based on the loads and environment to which it will be subjected. The following paragraphs define and explain the criteria as they are related to the design, manufacture and operational characteristics of the ACPS. These criteria were developed by the Westinghouse Astronuclear Laboratory (WANL) through coordination with the Space Nuclear Propulsion Office (SNPO) and from requirements established during the Reactor In-Flight Test (RIFT) program. Since the primary purpose of the ACPS is to maintain the reactor subcritical from the time of assembly to the time it will be operated in space, it is essential that the poison wires be positively locked into place under all credible conditions. However, it is also most important that the wires be extracted and the system ejected without complications. Credible accident conditions mentioned in the previous chapter are now discussed with regard to the entire ACPS.

During assembly, the poison wires are inserted into the fuel elements in the specified quantities and bundled according to the clusters which are then placed into the core. The quantity of wires will be sufficient to insure subcriticality of the reactor under conditions of flooding with a hydrogenous liquid and with the control drums in the most reactive (reflective) position. It is not unreasonable to expect flooding from faulty sprinkler systems or storm damage to the shelter, either in assembly, storage, or immersion in water from an accident during shipping. It is also possible that explosions on the launch pad or mission aborts could result in the reactor being dropped into a body of water.

During ground handling operations in loading for shipment, shipping, unloading, installing, and testing, the reactor will experience vibrations, shocks and possible impact due to dropping. For this reason, the design should consider provisions for securing the poison wires in position until the remainder of the ACPS is installed. This is accomplished by components which include the wire terminal retaining plate and which will be installed in the shipping container and locked into place.

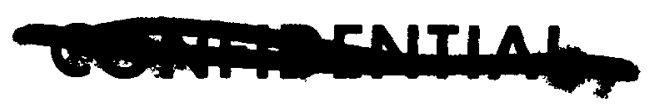


(2)

If a criticality check is conducted at the reactor assembly point and again prior to installation on the flight vehicle, the poison wires must be installed three times and removed twice in the period between assembly and launch. Because of these criticality checks, it is not advisable to install the nozzle and engine system until after the second check and the third insertion of the wires. At this time, the complete ACPS should be installed. Installation of the ACPS prior to this would necessitate removal and reattachment of the nozzle and accessory systems.

In the analysis and evaluation of the systems portion of the ACPS, the three major criteria categories are: 1) operation, 2) load and environment, and 3) credible accidents. The term "credible accidents" is used because there are probably an infinite number of accident conditions that can be postulated and to design for all of them would be impractical. The following accidents are considered credible and have been factored into the ACPS design.

\section{B. EXPOSURE TO FIRE AND HIGH TEMPERATURES}

Fire can occur during shipping due to collision, during storage from burning of the building, or during pre-launch from a Lox Hydrogen explosion. To fulfill the fire criteria, the poison wires are sheathed in a fiberglass encasement which will maintain a high level of tensile strength at extreme temperatures. This material will not burn and it will retard the neutron absorber poison in falling from the reactor. High temperature steel would be selected for use in the design of the reactor shipping wire-retaining fixture and other components of the ACPS to insure maximum protection against inadvertent wire or poison removal.

\section{IMPACT OF REACTOR AND NOZZLE WITH GROUND DUE TO EXPLOSION}

The ejection cylinders of the ACPS are designed to extend beyond the nozzle skirt. From a practical point of view the extension insures that the poison wires will be held in place regardless of the angle of impact of the reactor with the ground or water. The extended part will strike first in a nozzle-down attitude causing the entire ACPS to be driven toward the reactor. This is a desirable action under the circumstances.

During the launch and post-launch phases of a mission the ACPS will experience various combinations of loads and environment. These combinations are postulated on the basis of a 


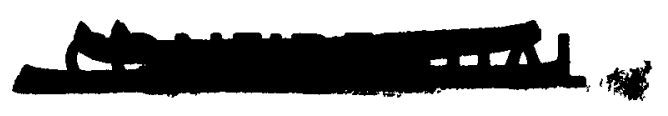

(2) Astronuclear

WANL-TNR-206

three-stage vehicle, and in the sense that the conditions expressed relate specifically to the core and pressure vessel and are assumed to apply to the ACPS structure. The load magnitudes and frequencies will most likely be less than calculated depending upon the interstage structural configuration and the dampening effect of adjacent structures. The load combinations and their reactions from launch vehicle startup to the ACPS ejection are enumerated in the following paragraphs.

\section{Launch Vehicle Startup}

At this point, the reactor will experience engine vibrations producing a steadystate double amplitude, axial displacement of approximately $0.028 \mathrm{~cm}$ at frequencies up to $85 \mathrm{cps}$ along with acoustic vibrations generated by $160 \mathrm{db}$ at $38^{\circ} \mathrm{C}$. The ACPS design should provide that the wires be held in place with a minimum capability for axial displacement. The wire extraction and ejection components are locked into place at the support braces and support platform. See figure 3-1. The protective foam in the cavity of the nozzle will absorb much of the sonic vibrations and provide a dampening effect on the ACPS structural components.

\section{Post Launch}

After launch, the ACPS will experience two critical load conditions. The first load occurs at first stage burnout when the accelerations are $6.0 \mathrm{~g}$ axial and $1.8 \mathrm{~g}$ lateral with the support platform in place. The second load occurs at the second stage burnout when the longitudinal acceleration is $2.8 \mathrm{~g}$ but without the support platform from the preceding stage. The acceleration forces increase gradually up to the maximum at first stage burnout. Axial forces are absorbed by the support platform and the lateral forces are absorbed by the system support braces. The vibratory oscillations at this time are of a minor nature.

Following the first stage separation, the load factors decrease to approximately a third of the maximum load before attaining another peak of approximately $2.8 \mathrm{~g}$, prior to the second stage burnout. At this time, the second stage fuel tank deflects approximately $5 \mathrm{~cm}$ away from the ACPS, due to changes in second stage tank pressure, completely removing the axial reaction supplied by the support platform. The $2.8 \mathrm{~g}$ load will then be absorbed by the retaining fingers at the nozzle throat. Any lateral loads, due to vehicle attitude or vibration, will be absorbed by the support braces.

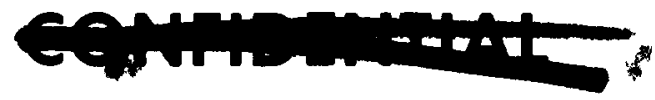



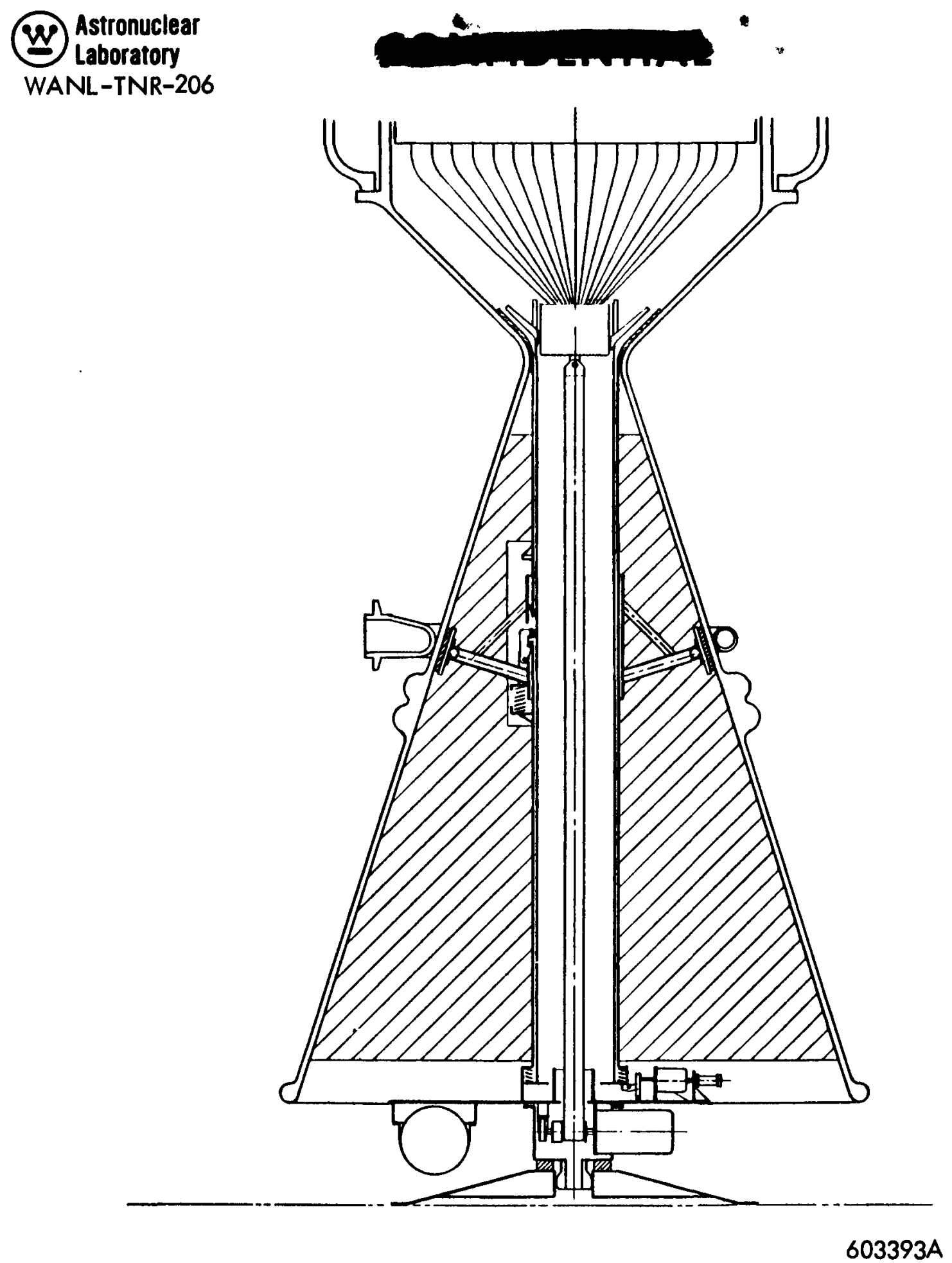

Figure 3-1. ACPS Pre-Launch Condition

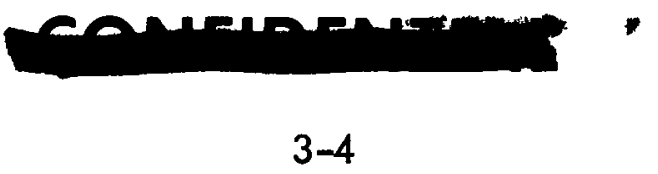




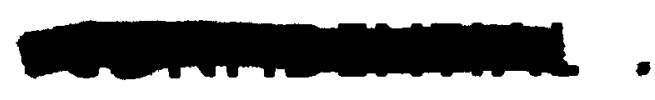

Astronuclear

Laboratory

WANL-TNR-206

\section{Wire Extraction and Ejection Forces}

These forces and reactions are explained in the Support Structure portion of Chapter $V$, System Description. A tabulation of functional data is shown in table 3-1. In addition to being capable of resisting the varied loads imposed upon them, the ACPS structural components should be designed to permit minimum displacement under all conditions. This feature is very important since the numerous release mechan isms in the system must function upon command. Excessive vibratory displacements, if not taken into account, could prevent wire extraction or system ejection.

\section{ADDITIONAL DESIGN CONSIDERATIONS}

The critical functional criteria, such as extreme temperature changes, vacuum conditions, corrosive effects and zero $g$ conditions, primarily affect the electrical circuitry, the gas stowage, the valve systems, the poison wires, and the pneumatic motor. All systems must be operable from $+71^{\circ} \mathrm{C}$ to $-55^{\circ} \mathrm{C}$ and from $795 \mathrm{~mm} \mathrm{Hg}$ to $10^{-8}$ torr. The critical period for these systems begins at the time of wire extraction. Environmental conditions at that time (dependent upon orbital or suborbital release) are postulated to be a 0.0 to $2.0 \mathrm{~g}$ load at a temperature of $-55^{\circ} \mathrm{C}$ and at pressures of ultra-vacuum. The state-of-the-art indicates that pneumatic motors and their attendant energizing systems are capable of operating reliably at the conditions stated above. The poison wires are encased in Teflon and fiberglass. Both of these materials are excellent for maintaining their strength characteristics and stability throughout the launch profile. It is readily acknowledged that there is a need for substantiating experimental data for the above conditions to ensure complete reliability of valves, regulators, lubricants and seals.

The ACPS conceptual design reflects various guidelines which are important to the overall operation of the system.

1) The poison wire material should have a double seal encasement that will not corrode or erode in water. This will provide assurance that the poison material remains in the core in the event of an accident.

2) A poison wire must have characteristics which permit its insertion and removal 
TABLE 3-1

FUNCTIONAL DATA

1) System weight including wires

2) Wire weight including fittings

3) Gas accumulator pressure

4) Pneumatic motor operating pressure

5) Piston lock pin slider spring force

6) Estimated force for wire extraction

7) Nozzle bearing area at support brace

8) Nozzle bearing area at throat retaining fingers

9) System ejection spring force (30 springs)

10) Nozzle reaction at support brace from support platform

11) Calculated system ejection velocity

12) Maximum theoretical impact load on nozzle at support brace ( $2 x$ ejection spring load)

13) Nozzle reaction at support brace from spring ejection force (assume one-half bearing area)

14) Nozzle reaction at support brace during wire extraction

15) Maximum unit load on nozzle throat due to system acceleration at adjacent stage burnout $(2.8 \mathrm{~g})$
$189.0 \mathrm{~kg}$

$45.4 \mathrm{~kg}$

$140 \mathrm{~kg} / \mathrm{cm}^{2}$

$6.3 \mathrm{~kg} / \mathrm{cm}^{2}$

$16 \mathrm{~kg}$

$0.23 \mathrm{~kg} /$ wire

$851 \mathrm{~cm}^{2}$

$174 \mathrm{~cm}^{2}$

$16 \mathrm{~kg} / \mathrm{spring}$

$0.4 \mathrm{~kg} / \mathrm{cm}^{2}$

$160 \mathrm{~cm} / \mathrm{sec}$

$940 \mathrm{~kg}$

$2.2 \mathrm{~kg} / \mathrm{cm}^{2}$

$0.8 \mathrm{~kg} / \mathrm{cm}^{2}$

$3.5 \mathrm{~kg} / \mathrm{cm}^{2}$ 
from the core a minimum of five times without damage to the wire or reactor components. This feature provides flexibility in the programming of criticality tests or assembly procedure.

3. The wire extraction should take place at a rate between 15 and $25 \mathrm{~cm}$ per second and no greater than $25.4 \mathrm{~cm}$ per second. The upper limit restricts the speed of extraction to assure no possibility of damage to the reactor coolant channels. A speed less than the low limit value might require a significant change in a proposed mission profile as a result of delay in the NERVA stage startup.

4) Two separate overt actions are each required to actuate the extraction of the wires and to release the inner locking cylinder. This guards against accidental wire extraction or system ejection.

5) The nozzle surface will be protected from metal to metal contact from the time of installation of the ACPS to its ejection since it is very important to protect the nozzle coolant tubes from being damaged. Dents or cracks may severely affect the heat transfer characteristics of the nozzle.

6) The nozzle reactions from the ACPS loads will always be less than the design capabilities. This again provides insurance for the prevention of damage to the nozzle coolant channels.

7) Weight of the ACPS will be kept to a minimum commensurate with the structural, environmental and operational requirements. Lighter weight requires less propellant to launch the vehicle and also less force to eject the system when required. This in turn reduces the load reactions upon the nozzle.

8) All components of the ACPS will eject from the nozzle.

9) The ACPS concept infers optimum quality control and inspection provisions throughout fabrication, assembly, and installation of the system since structural and functional reliability must be maintained to ensure successful operation.

10) The ACPS will be a complete, self-contained unit without need of auxiliary engine systems for operation.

11) The poison wires will be installed, supported, and retained in the core prior to nozzle installation in order to maintain subcriticality during shipping and handling.

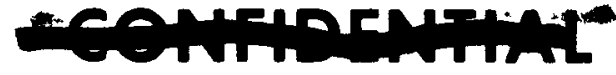


(2) Astronuclear

WANL-TNR-206

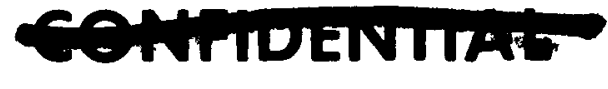

12) After the nozzle attachment, the ejection system can be installed and preparations made for ground handling.

13) The poison wire extraction and system ejection actions shall be compatible with both suborbital and orbital vehicle staging and NERVA engine startup programming.

14) Redundancy provisions have been incorporated for wire extraction and system ejection to add reliability.

15) Nozzle leak checks can be conducted with the wires in place.

16) Indicator signals will be provided to the ground station after each significant step in the ACPS operational sequence.

17) The ACPS shall be designed to ensure maximum positive retention of the poison wires during credible accident conditions. 


\section{CHAPTER IV NEUTRONICS}

\section{CHAPE IV}

This section provides information relating to reactor reactivity under flight accident conditions and the capability of the poison wires to maintain the reactor subcritical under these conditions. A parametria study has been completed to determine the effect of changing $\mathrm{B}_{4} \mathrm{C}$ density, wire diameter, wire length, and number of wires on reactivity under a water flood condition. A critical experiment has been conducted and analyzed to determine experimentally the worth of the poison wires in a flooded reactor. A compacted reactor core has also been evaluated to determine if the poison wires are adequate to maintain the reactor subcritical in this case.

A reactor reactivity of $0.95 k_{\text {eff }}$ based on conservative calculations, is considered to provide an adequate shutdown margin when evaluated under accident conditions which give the highest reactivity value.

\section{A. POISON WIRE REACTIVITY REQUIREMENTS}

The poison wire system is designed to maintain the reactor suberitical under credible accident conditions. The accidents leading to the largest negative reactivity requirements are: 1) water flooding and 2) core compaction.

The reactivity of a water flooded reactor has been previously determined to be $1.56 \mathrm{k}_{\text {eff }}$ by both LASL ${ }^{5}$ and WANL ${ }^{6}$. The calculations performed as part of this study showed that the reactivity of a flooded NERVA type reactor is $1.59 \mathrm{k}_{\text {eff }}$ which is in good agreement with the other calculated values.

Potentially a NERVA reactor can impact upon land following a mission abort prior to removing poison wires. Experiments conducted by LASL $^{7}$ as well as theoretical work by WANL ${ }^{2}$

5

LA-3227-MS, Effects of Adding Hydrogenous Materials to KIWI Reactors, March 1964 (CRD)

6 WANL-TME-713, NRX-A Core Compaction Program, March 1964 (CRD)

7

Private Communication, L. D. P. King, LASL, to J. M. Bridges, WANL, October 1964 
show that the NERVA type reactor under land impact forces will probably not compact sufficiently to cause a significant reactivity increase. The studies show that a reactor impact upon a solid surface will fracture the graphite fuel elements. Under impact forces sufficient to cause significant compaction, the reactor and core vessels will rupture and the fractured fuel elements will be dispersed.

The calculated reactivity of a compacted reactor, with no poison wires, is $1.12 \mathrm{k}_{\text {eff }}$ with the beryllium reflector intact and no flooding, 2) $1.20 \mathrm{k}_{\text {eff }}$ with the beryllium reflector intact and the regions external to the core flooded with water, and 3) $1.16 k_{\text {eff }}$ with the beryllium reflector torn loose by the impact but replaced with water.

Flooding the core with liquid hydrogen results in a reactivity of $1.55 \mathrm{k}_{\text {eff }}$ as reported in WANL-TNR-148. Flooding the core with liquid hydrogen is a highly improbable accident and does not result in greater reactivity than the water flooded core.

\section{B. POISON WIRE REACTIVITY CALCULATIONS}

1. Calculational Methods

The fueled portion of the reactor core was divided into either one or four radial regions, consistent with the regions used for NERVA nuclear analyses at WANL. A single axial core region was used except for the calculations to determine poison wire height effect where in the reactor core was divided into a poisoned and a non-poisoned region. The poison wires were distributed uniformly in the fueled region since previous calculations ${ }^{9}$ have shown that a uniform wire distribution is a more optimum arrangement than grouped or annular arrangements. Loading more wires into the center of the core, or otherwise bundling wires into groups causes "shadowing" effects between wires and reduces their net effectiveness. All basic reactor dimensions, material number densities, and void fractions were obtained from the WANL Nuclear Data Handbook. ${ }^{10}$ The poison wire dimensions and materials are given in Chapter II.

WANL-TNR-148, Safety Analysis Report - NRX Testing, April 1964

WANL-TME-546, Feasibility of a Full Core Nuclear Poison System for use During RIFT Launch Operations, September 1963

10 WANL-TME-840, Reactor Analysis Handbook, February 1965, (CRD) 
The following computer programs were used in the nuclear analyses:

a) NSDM-II (GAM-TNS-QUERY Package) "I - A program to generate multigroup fast and thermal cross sections. It includes both multiple up and down scattering, resonance absorption, and the use of one-element flux depression factors. The program was used to generate nine neutron energy group constants ( 4 fast, 5 thermal), consistent with the type calculations used at WANL to calculate reactivities of NRX reactors. The broad group neutron energy breakdown used in the calculations is given in table 4-1.

b) IOPIC $^{12}-$ A one-dimensional neutron transport program for cylindrical geometry used to solve for cell neutron flux distributions in order to determine poison wire disadvantage factors.

c) ADDICT - A one-dimensional neutron diffusion program, which incorporates both multiple up and down scatter, used for eigenvalue reactivity calculations. Since this is a one-dimensional program, care must be taken to incorporate the correct transverse neutron leakage. This was done for each eigenvalue calculation by a flip-flop iterative technique which involved alternate radial and axial calculations, converging on the correct leakages.

Nine neutron energy groups were used in the calculations in order to eliminate, to a large degree, cross section dependence on spectra variation and thus permitting the use of infinite media spectra calculations. To obtain an estimate of the error due to spectra changes, a clean, dry reactor was analyzed using both infinite media and exact spectra (previously calculated at WANL). The $\delta \mathrm{k}$ difference was found to be 0.0066 . An examination of previous spectral calculations performed at WANL ${ }^{10}$ indicated that the difference should be less for water flooded reactors.

WANL-TME-1091, Improved Nuclear Design Method for NERVA Calculations - NSDM-II, March 1965 (CRD)

IDO-16898, TOPIC - A Fortran Program for Calculating Transport of Particles in Cylinders, April 1964

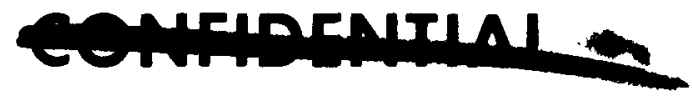


(W) Astronuclear

WANL-TNR-206

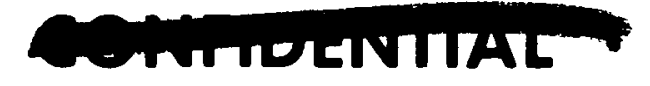

TABLE 4-1

NEUTRON BROAD GROUP ENERGY LEVELS

\begin{tabular}{|cccc|}
\hline Neutron Group & \multicolumn{2}{c|}{ Neutron Energy } \\
\hline 1 & 10 & - & $0.821 \mathrm{mev}$ \\
2 & 821 & - & $5.53 \mathrm{kev}$ \\
3 & 5530 & - & $78.9 \mathrm{ev}$ \\
4 & 78.9 & - & $1.855 \mathrm{ev}$ \\
5 & 1.86 & - & $0.30 \mathrm{ev}$ \\
6 & $0.30-$ & $012 \mathrm{ev}$ \\
7 & 0.12 & - & $0.06 \mathrm{ev}$ \\
8 & 0.06 & $0.02 \mathrm{ev}$ \\
9 & 0.02 & $0.0 \mathrm{ev}$ \\
\hline
\end{tabular}


The cross section library does not presently contain bound hydrogen (for water) slowing down kernels for NSDM II calculations. The spectra weighted ratio of bound to unbound hydrogen scattering cross section in the thermal neutron energy groups was used as a disadvantage factor in the NSDM-II calculations. This scheme was used to obtain the nine group cross section constants in the regions containing no poison wires. Unfortunately, NSDMII permits use of a disadvantage factor for only one element, and thus unbound hydrogen was used in regions containing poison wires. An upper limit on the error involved in the use of unbound hydrogen in the poison wire regions was determined by comparing the reactivity difference for a clean, water flooded reactor using bound and unbound hydrogen cross sections. The $\delta k$ difference was found to be 0.0059 .

A major effort in the analyses was to obtain the disadvantage factors for the poison wires containing $\mathrm{B}_{4}^{10} \mathrm{C}$. These factors must be introduced in the eigenvalue calculations where in the wires are homogenized with the other reactor core materials. The factors were obtained for all nine neutron energy groups from the neutron flux distributions using one-dimensional neutron transport calculations (TOPIC Program) for cylindrical cells. In order to establish upper and lower limits and a "most probable" value of disadvantage factors for the wires, the conditions imposed were:

a) a unit neutron source for each energy group was input at the periphery of the wire,

b) a unit neutron source was input at the periphery of a cell containing a poison section, wire clad, and fueled region but without a fission source within the cell, and

c) only the fission neutron source within the fuel portion of the cell was input.

Table 4-2 lists the results of these calculations for a compacted reactor core. Since use of a fission source within the cell provided a reasonably conservative value for the disadvantage factor, this type of cell calculation was used in all cases.

The disadvantage factors were also found to be sensitive to the neutron energy spectra used in obtaining NSDM-II neutron cross section constants. Table 4-3 lists the disadvantage factors as a result of assuming: 1) an infinite medium neutron energy spectrum and

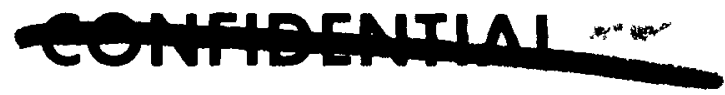


(2) Astronuclear

WANL-TNR-206
Laboratory

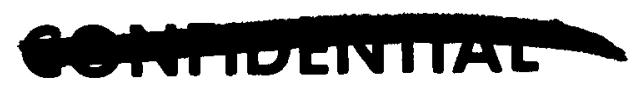

TABLE $4-2$

EFFECT OF NEUTRON SOURCE ON

POISON WIRE DISADVANTAGE FACTORS

Poison Diameter - $0.147 \mathrm{~cm}$

Compocted Reactor

\begin{tabular}{|c|c|c|c|}
\hline $\begin{array}{c}\text { Neutron } \\
\text { Group }\end{array}$ & $\begin{array}{c}\text { Neutron Source at } \\
\text { Wire Boundary }\end{array}$ & $\begin{array}{c}\text { Neutron Source at } \\
\text { Cell Boundary }\end{array}$ & $\begin{array}{c}\text { Fission Neutron } \\
\text { Source in Cell }\end{array}$ \\
\hline 1 & 0.992 & 0.979 & 0.983 \\
2 & 0.998 & 0.996 & 0.989 \\
3 & 0.957 & 0.926 & 0.928 \\
4 & 0.780 & 0.683 & 0.687 \\
6 & 0.208 & 0.157 & 0.157 \\
7 & 0.0872 & 0.0623 & 0.0661 \\
8 & 0.0548 & 0.0379 & 0.0419 \\
9 & 0.0383 & 0.0249 & 0.0292 \\
\hline
\end{tabular}


TABLE 4-3

EFFECT OF NEUTRON ENERGY SPECT RUM ON

POISONWIRE DISADVANTAGE FACTORS

Poison Diameter - $0.147 \mathrm{~cm}$

Flooded Reactor

\begin{tabular}{|c|c|c|}
\hline $\begin{array}{c}\text { Neutron } \\
\text { Group }\end{array}$ & $\begin{array}{c}\text { Infinite Medium } \\
\text { Neutron Energy } \\
\text { Spectrum }\end{array}$ & $\begin{array}{c}\text { Homogenized Reactor } \\
\text { Neutron Energy } \\
\text { Spectium }\end{array}$ \\
\hline 1 & 0.978 & 0.981 \\
2 & 0.992 & 0.976 \\
3 & 0.934 & 0.892 \\
4 & 0.706 & 0.453 \\
5 & 0.157 & 0.117 \\
6 & 0.0653 & 0.0555 \\
7 & 0.0413 & 0.0371 \\
8 & 0.0390 & 0.0249 \\
9 & 0.0162 & 0.0132 \\
\hline
\end{tabular}


2) an energy spectrum associated with a homogenized core and poison wires. The correct value should lie between these two limits. The homogenized core energy spectrum provided the more conservative disadvantage factors, and thus this type calculation was used in all cases.

The effect of poison wire diameter and $\mathrm{B}_{4}^{10} \mathrm{C}$ density on disadvantage factors is shown in table 4-4. It was found for the range of cases considered the cell areas were sufficiently large that the disadvantage factors were independent of the number of wires.

Eigenvalue reactivities were calculated with a one-dimensional neutron diffusion computer program. An iterative technique between radial and axial direction calculations was used to converge on the correct transverse leakage. Generally, two iterations were sufficient to obtain nearly identical eigenvalues. A typical series of eigenvalues resulting from alternate radial-axial neutron diffusion calculations is shown in table 4-5.

Reactivity differences between cases were obtained by the relationship:

$$
\beta \delta \rho=\frac{k_{0}\left(k_{1}-k_{2}\right)}{k_{1} k_{2}}
$$

where $\beta \delta \rho$ is the fractional reactivity change $(\delta k)$ and $k_{0}$ is the calculated eigenvalue for the critical case $\left(k_{\text {eff }}=1\right)$. The calculated eigenvalue for the just critical reactor was determined indirectly by calculating the clean, dry PAX reactor (Critical Experiment Mock-up of NERVA Reactor) with no control rods $(k=1.017)$ and comparing it to the experimentally determined $k$ of 1.055 . The $\delta k$ difference between the two cases is 0.0353 by the above relationship and $k_{0}$ calculated for the just critical reactor is 0.966 .

A homogeneous poison wire distribution in the fueled element was used for all calculations. As previously discussed, this provides a near optimum use of poison wires. The relative worth of poison wires as a function of radial position has been determined previously and is shown in figure 4-1.

13

WANL-TME-603, Selection of Material, Number and Distribution of Poison Wires for the Anti-Criticality Poison System, November 1963 
TABLE 4-4

POISON WIRE DISADVANTAGE FACTORS FOR

VARIOUS POISON DLAMETERS ANO DENSITIES

\begin{tabular}{|l|c|c|c|c|c|c|c|c|c|c|}
\hline Diameter & Density & \multicolumn{8}{|c|}{ Neutron Energy Group } \\
\hline$(\mathrm{cm})$ & (percent) & 1 & 2 & 3 & 4 & 5 & 6 & 7 & 8 & 9 \\
\hline 0.137 & 90 & 0.9825 & 0.9772 & 0.8980 & 0.4718 & 0.1255 & 0.5958 & 0.03977 & 0.02669 & 0.01418 \\
0.147 & 90 & 0.9815 & 0.9756 & 0.8915 & 0.4526 & 0.1171 & 0.05552 & 0.03707 & 0.02487 & 0.01305 \\
0.157 & 90 & 0.9804 & 0.9741 & 0.8851 & 0.4347 & 0.1097 & 0.05198 & 0.03470 & 0.02329 & 0.01236 \\
0.147 & 85 & 0.9821 & 0.9769 & 0.8972 & 0.4690 & 0.1238 & 0.05876 & 0.03924 & 0.02633 & 0.01382 \\
0.147 & 80 & 0.9827 & 0.9782 & 0.9030 & 0.4865 & 0.1313 & 0.06241 & 0.04168 & 0.02797 & 0.01468 \\
\hline
\end{tabular}

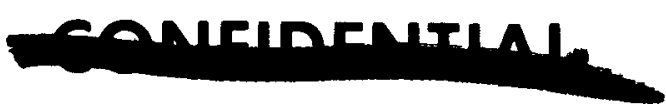




\section{TABLE 4-5}

EIGENVALUE AND BUCKLING ITERATIONS FOR 2600 WIRES

$0.147 \mathrm{~cm}$ DIAMETER AND 90 PERCENT DENSITY (FULLY FLOODED)

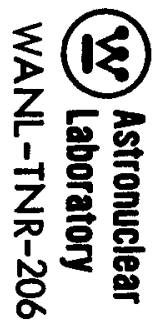

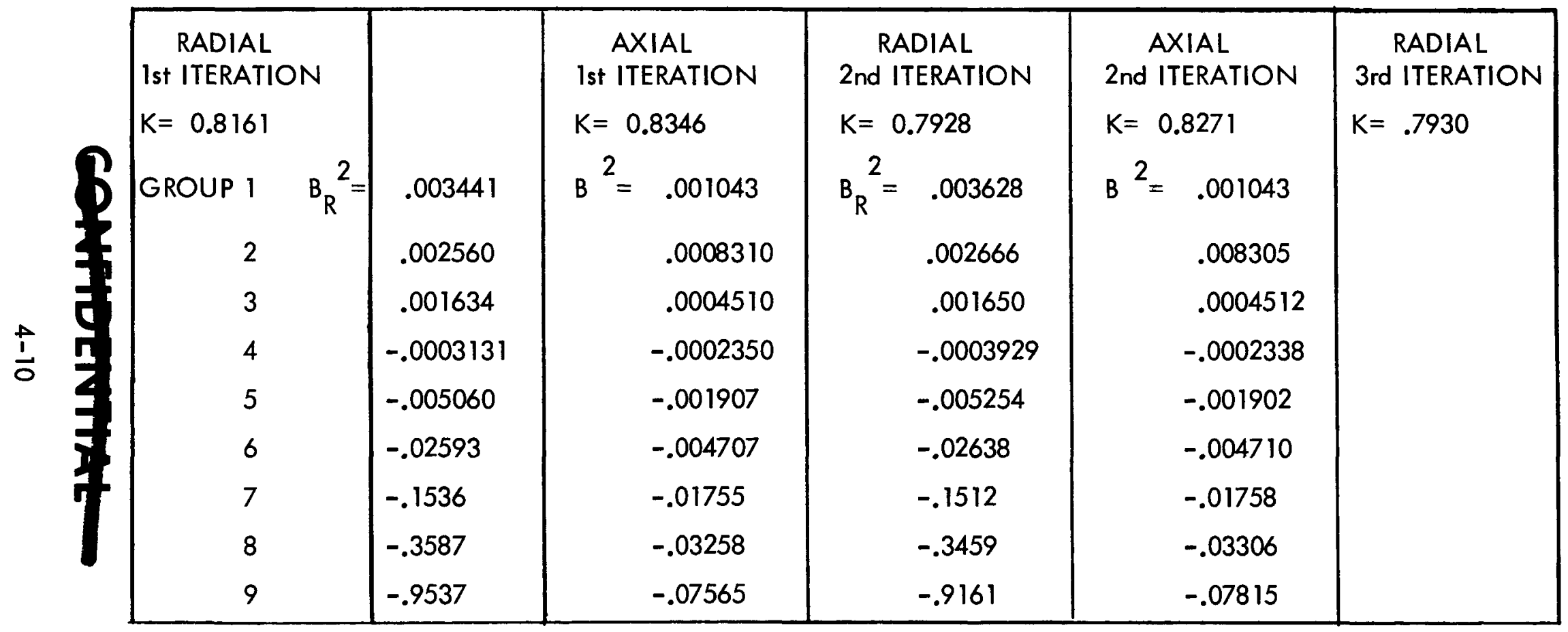




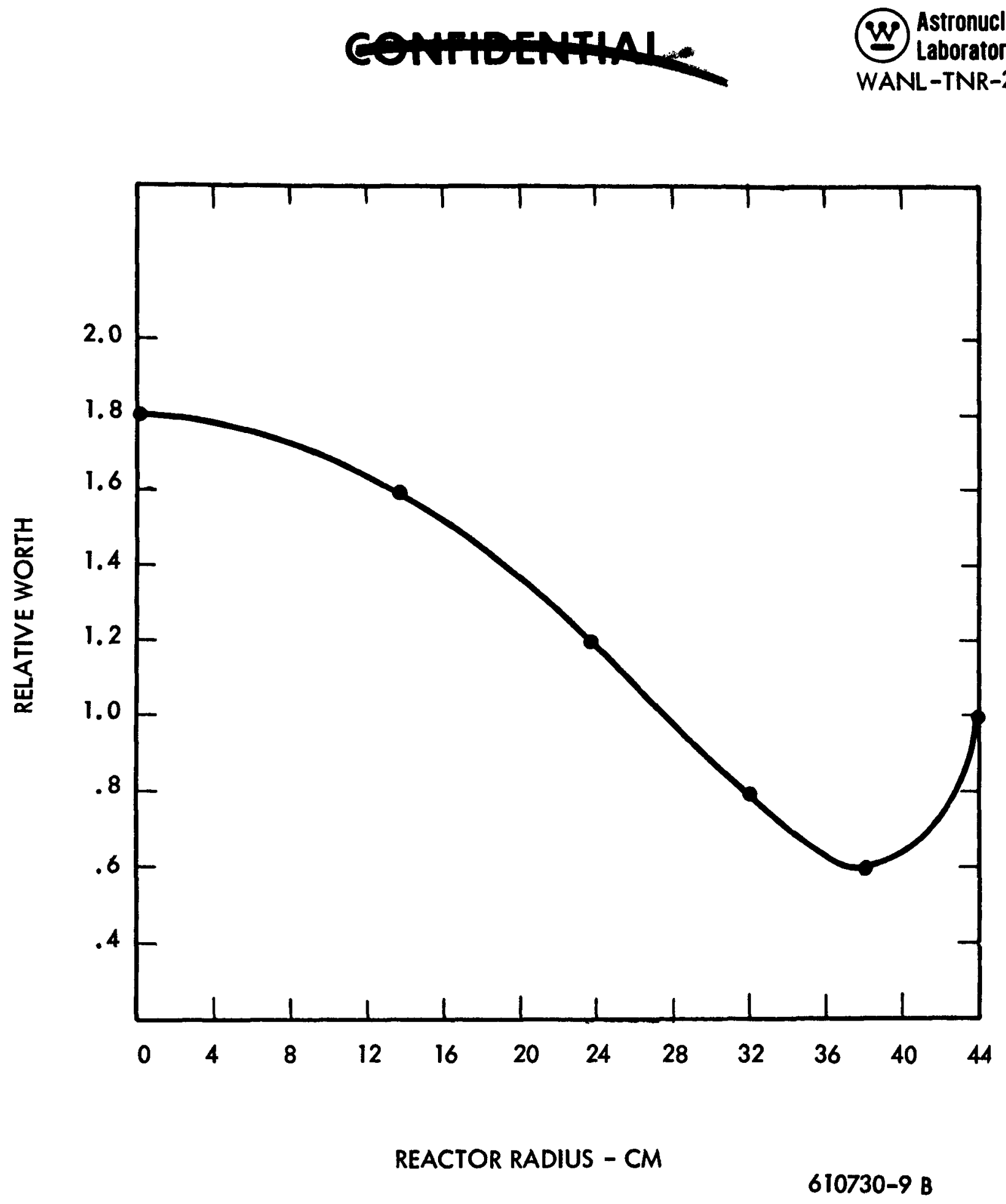

Figure 4-1. Radial Worth of Poison Wires - Flooded Reactor

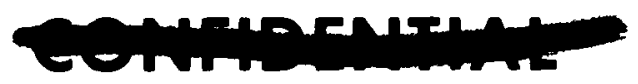




\section{WANL-TNR-206}

\section{REACTIVITY EFFECTS}

\section{Flooded Reactor}

The effect of poison wire density, diameter, number of wires, and wire height on reactivity has been determined. Table 4-6 provides a list of cases considered.

Figure 4-2 shows reactivity ( $k_{\text {eff }}$ ) as a function of $\mathrm{B}_{4}^{10} \mathrm{C}$ diameter, density, and number of wires. Dashed lines indicate extrapolated values obtained by simplified calculations rather than the computer code. It can be seen that reactivity is relatively insensitive to $\mathrm{B}_{4}^{10} \mathrm{C}$ over the range of 80 to 90 percent theoretical density. The maximum reactivity differential over that spread in density is less than $0.02 \Delta k$. A 10 percent change in the number of wires in the range of 2000 to 2200 wires results in about a $0.04 \Delta \mathrm{k}$ change in reactivity, whereas changing $\mathrm{B}_{4}^{10} \mathrm{C}$ diameter from 0.137 to $0.157 \mathrm{~cm}$ results in approximately a $0.08 \Delta \mathrm{k}$ change in reactivity. The number of wires required to maintain a reactivity of 0.95 with a fully flooded core and full length wires is shown in figure 4-3. An allowance of 100 wires should be made to compensate for the errors in calculations discussed previously.

The effect of wire insertion height for 2600 and 1800 wires is shown in figures 4-4 and 4-5. Figure 4-6 shows the number of wires required to maintain the reactivity of a fully flooded sector at $0.95 \mathrm{k}_{\mathrm{eff}}$ as a function of wire height and diameter $\left(\mathrm{B}^{10} \mathrm{C}\right.$ density, 90 percent theoretical). In the latter figure, the dashed curves are obtained from interpolated values and they should be considered as approximations only. An examination of these figures shows that moving 2600 wires, of the sizes considered, 20 to $25 \mathrm{~cm}$ out of the core gives rise to a critical region above the wires. One thousand eight hundred $B_{4} C$ wires of $0.137 \mathrm{~cm}$ diameter are not adequate to assure a subcritical reactor under full flood conditions, whereas 0.147 and 0.157 $\mathrm{cm}$ diameter wires need to be pulled 15 to $30 \mathrm{~cm}$ out of the core before a critical configuration is attained.

For the NRX type reactor, it would appear that 2000 wires containing 85 percent theoretical density $\mathrm{B}_{4}^{10} \mathrm{C}$ of $0.147 \mathrm{~cm}$ diameter provides' a reasonably conservative design basis to maintain a fully flooded reactor core at or below $0.95 \mathrm{k}_{\mathrm{eff}}$.

\section{Compacted Reactor}

In order to determine the adequacy of the poison wires to maintain a compacted

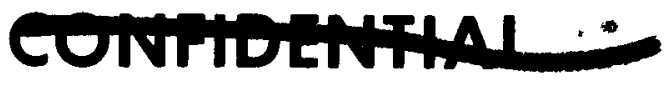


TABLE $4-6$

FLOODED CORE REACTIVITY CALCULATIONS

\begin{tabular}{|c|c|c|c|c|}
\hline $\begin{array}{l}\text { Case } \\
\text { No. } \\
\end{array}$ & $\begin{array}{l}{ }^{10}{ }_{4} \mathrm{C} \text { Density } \\
\% \text { Theoretical }\end{array}$ & $\begin{array}{c}\text { Diameter * } \\
(\mathrm{cm})\end{array}$ & $\begin{array}{c}\text { Number of } \\
\text { Wires }\end{array}$ & $\begin{array}{c}\text { Wire Height } \\
(\mathrm{cm}) \\
\end{array}$ \\
\hline 1 & 90 & 0.157 & 2600 & 132 \\
\hline 2 & 90 & 0.147 & 2600 & 132 \\
\hline 3 & 90 & 0.137 & 2600 & 132 \\
\hline 4 & 85 & 0.157 & 2600 & 132 \\
\hline 5 & 85 & 0.147 & 2600 & 132 \\
\hline 6 & 85 & 0.137 & 2600 & 132 \\
\hline 7 & 80 & 0.157 & 2600 & 132 \\
\hline 8 & 80 & 0.147 & 2600 & 132 \\
\hline 9 & 80 & 0.137 & 2600 & 132 \\
\hline 10 & 90 & 0.157 & 2200 & 132 \\
\hline 11 & 90 & 0.147 & 2200 & 132 \\
\hline 12 & 90 & 0.137 & 2200 & 132 \\
\hline 13 & 90 & 0.157 & 1800 & 132 \\
\hline 14 & 90 & 0.147 & 1800 & 132 \\
\hline 15 & 90 & 0.137 & 1800 & 132 \\
\hline 16 & 90 & 0.157 & 1800 & 126 \\
\hline 17 & 90 & 0.157 & 2600 & 120 \\
\hline $18 \& 31$ & 90 & 0.157 & $2600 \& 1800$ & 114 \\
\hline $19 \& 32$ & 90 & 0.157 & $2600 \& 1800$ & 108 \\
\hline $20 \& 33$ & 90 & 0.157 & $2600 \& 1800$ & 102 \\
\hline 21 & 90 & 0.147 & 2600 & 126 \\
\hline $22 \& 34$ & 90 & 0.147 & $2600 \& 1800$ & 120 \\
\hline $23 \& 35$ & 90 & 0.147 & $2600 \& 1800$ & 114 \\
\hline $24 \& 36$ & 90 & 0.147 & $2600 \& 1800$ & 108 \\
\hline $25 \& 37$ & 90 & 0.137 & $2600 \& 1800$ & 102 \\
\hline 26 & 90 & 0.137 & 2600 & 126 \\
\hline $27 \& 38$ & 90 & 0.137 & $2600 \& 1800$ & 120 \\
\hline $28 \& 39$ & 90 & 0.137 & $2600 \& 1800$ & 114 \\
\hline $29 \& 40$ & 90 & 0.137 & $2600 \& 1800$ & 108 \\
\hline $30 \& 41$ & 90 & 0.137 & $2600 \& 1800$ & 102 \\
\hline
\end{tabular}

* Diameter of Neutron Absorbing Material 


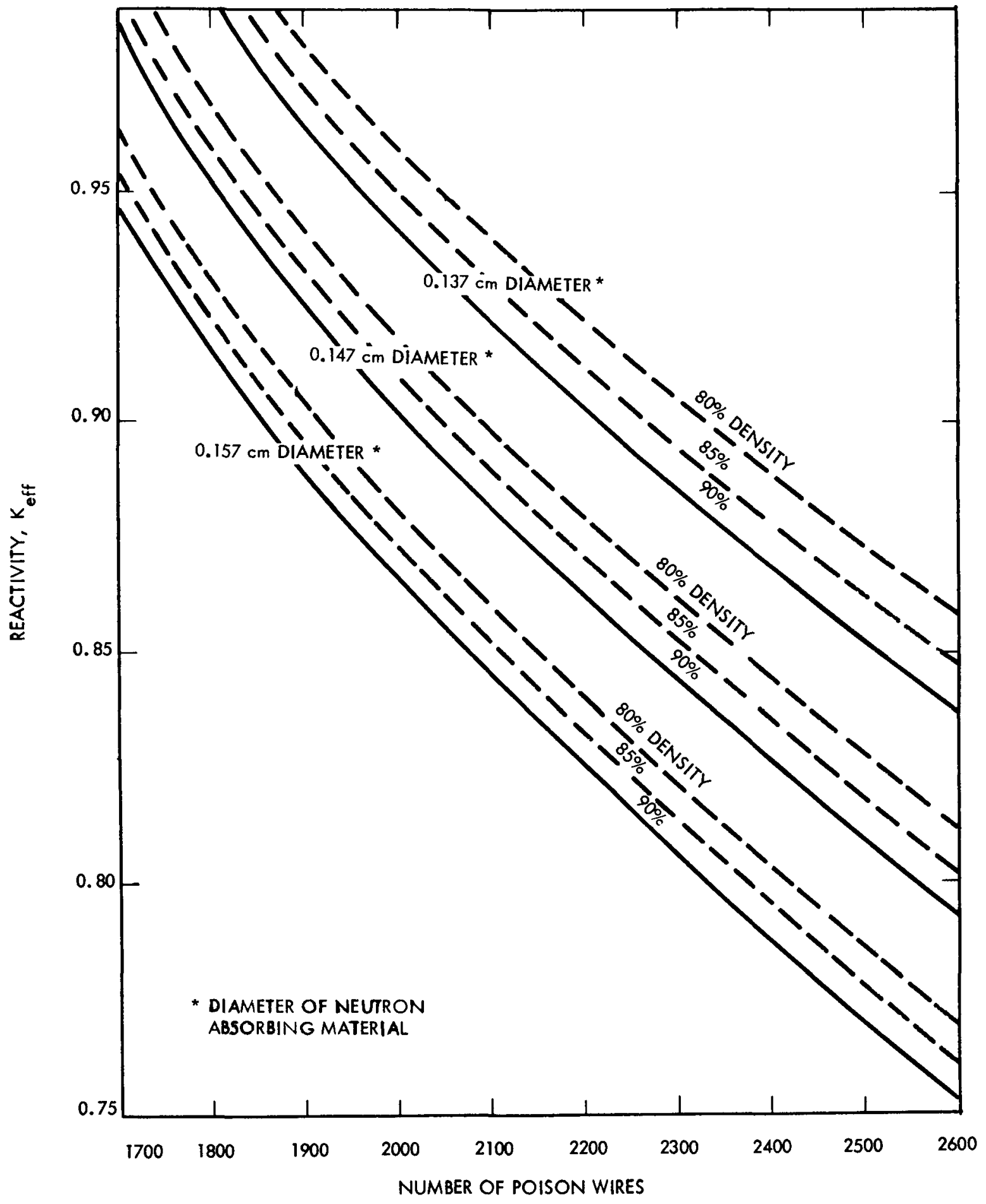

Figure 4-2. Reactivity Variation Effects of Poison Wire Diameter and Density 


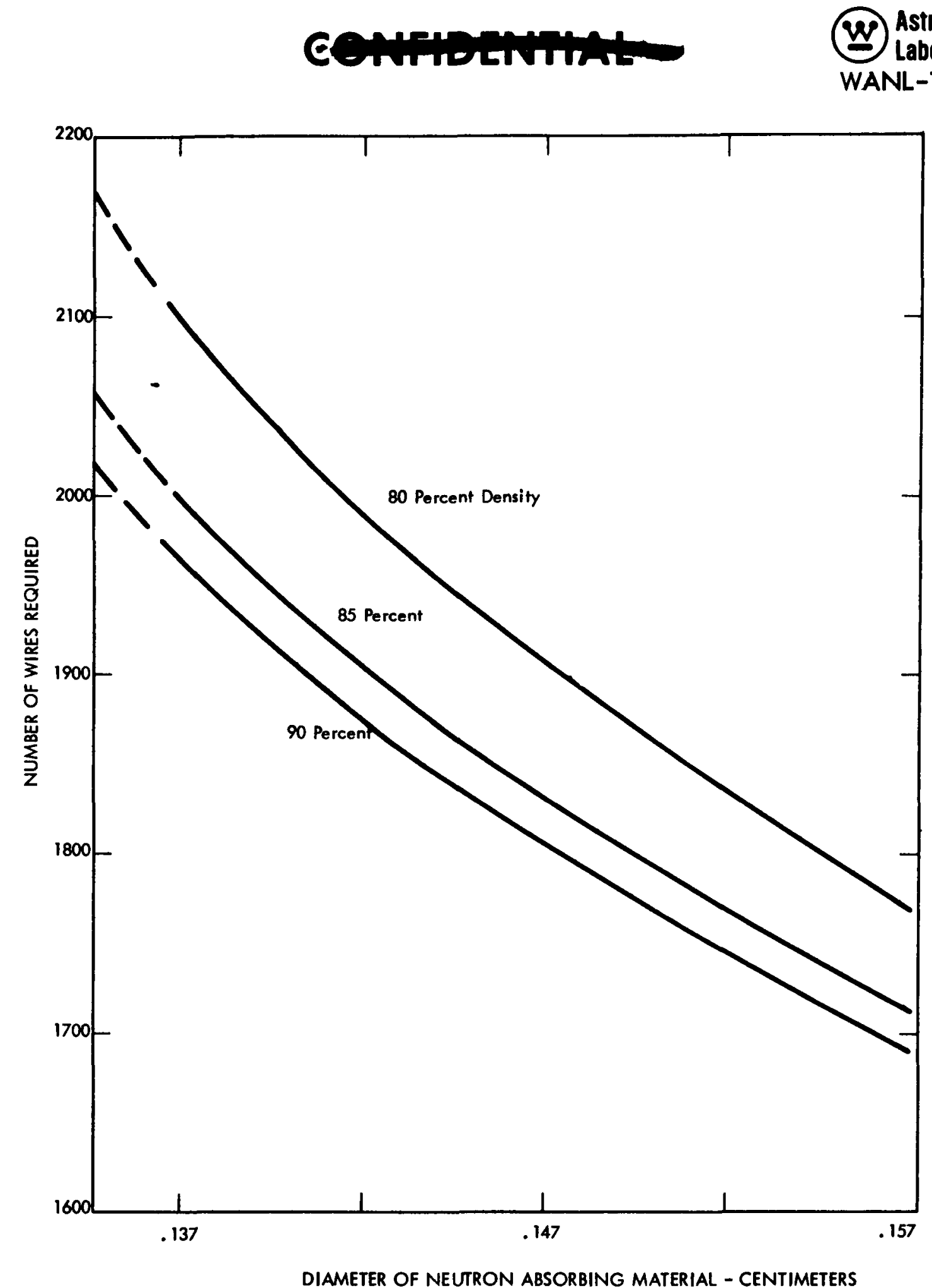

DIAMETER OF NEUTRON ABSORBING MATERIAL - CENTIMETERS

610730-3 A

Figure 4-3. Poison Wires Required for $0.95 K_{\text {eff }}$ Versus Diameter and Density 
(W) Astronuclear

WANL-TNR-206

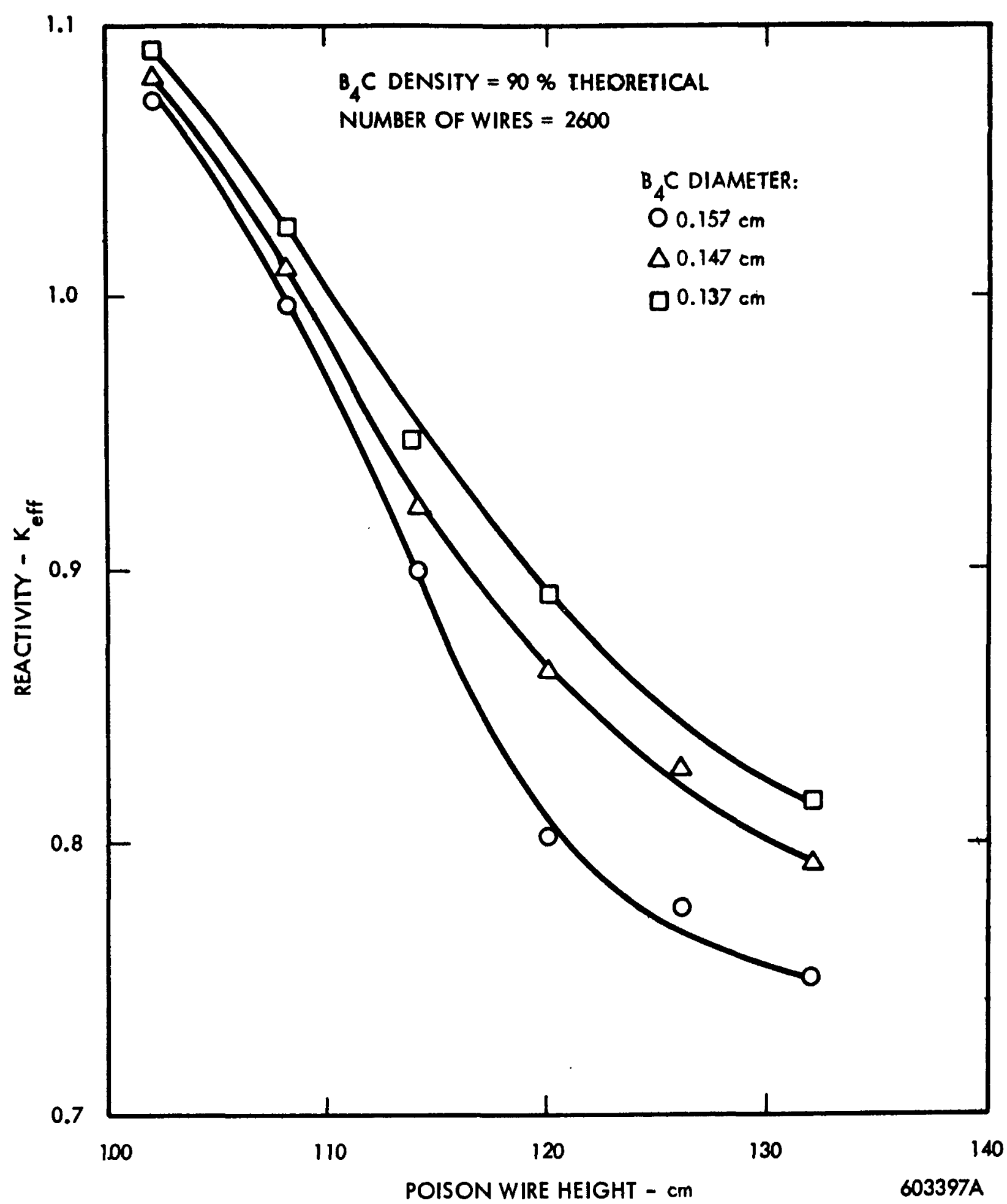

Figure 4-4. Reactivity Versus Poison Wire Height

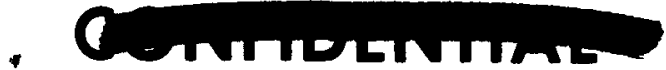




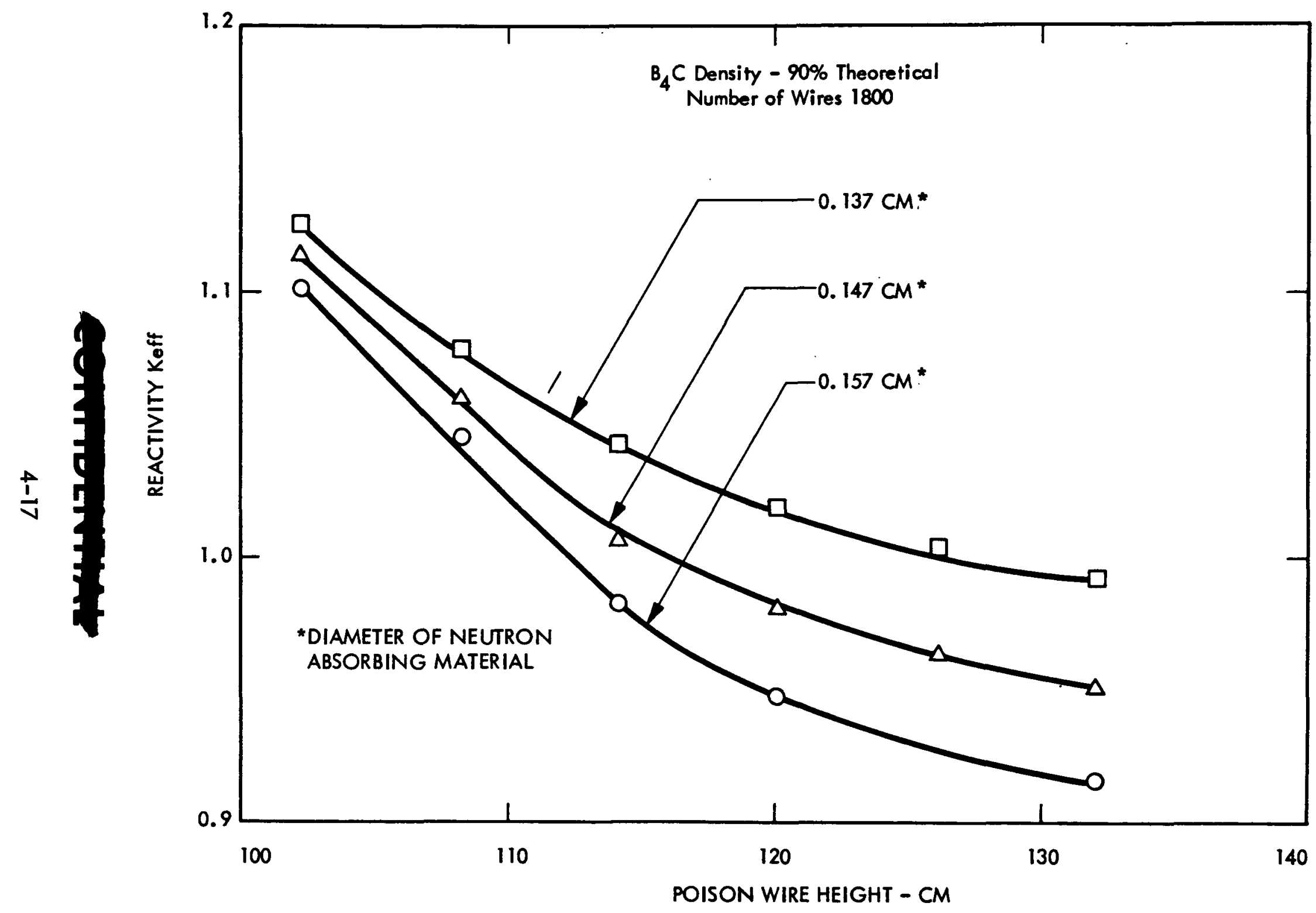

Figure 4-5. Reactivity Versus Poison Wire Height and Diameter

$610730-2$ A

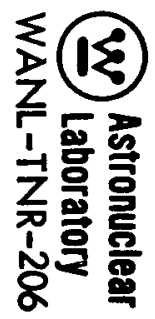


(2) Astronuclear

WANL-TNR-206

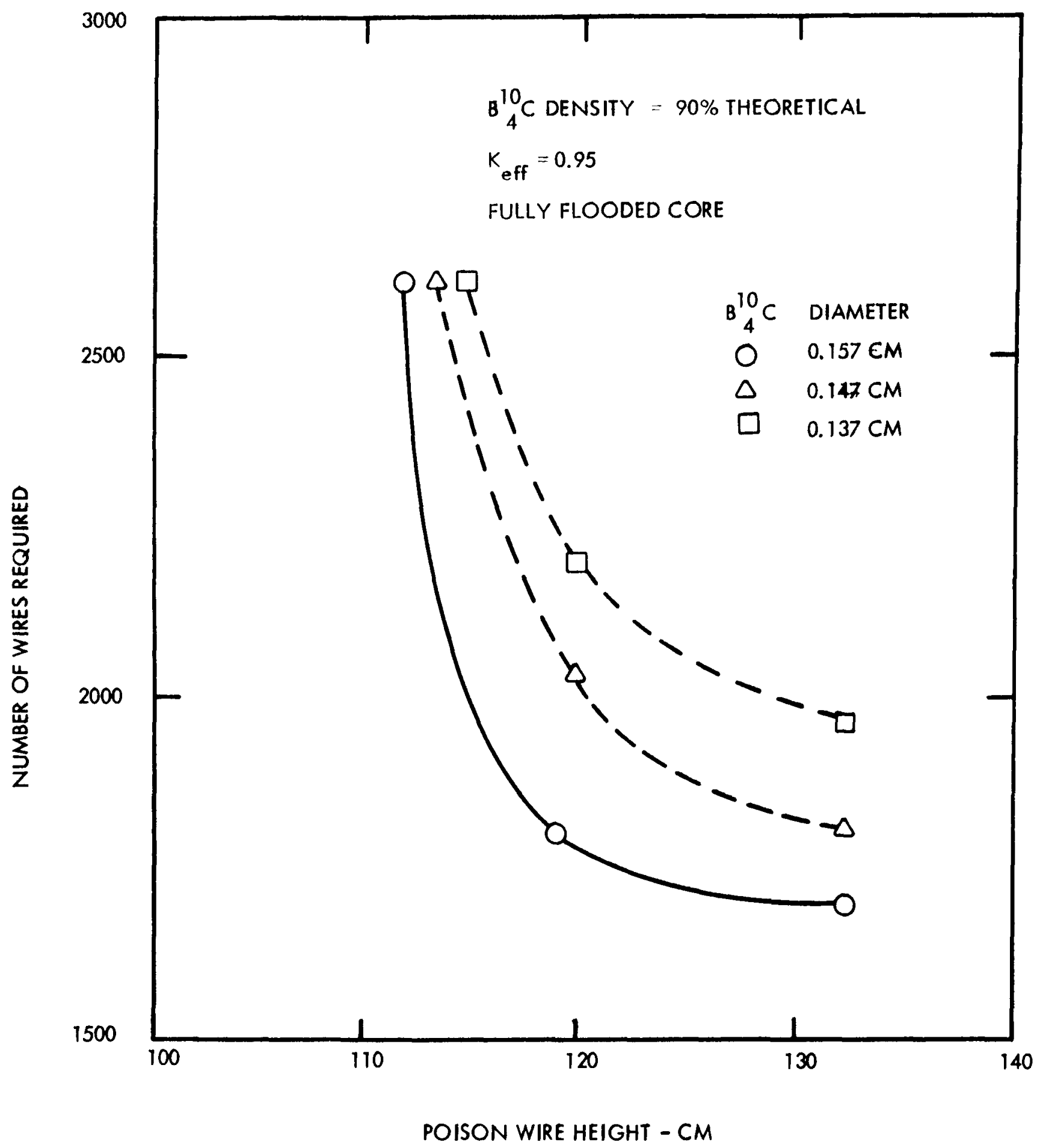

Figure 4-6. Number of Wires Required for $0.95 \mathrm{~K}_{\text {eff }}$ Versus Diameter and Height

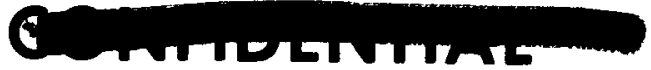




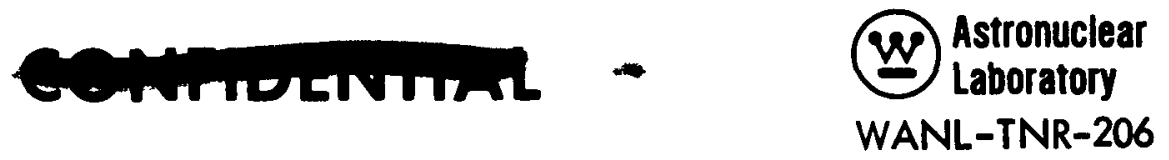

core in a subcritical state, three conditions were assumed to be 1 ) the beryllium reflector is compacted but no water flooding occurs, 2) the beryllium reflector is compacted and water flooding takes place, and 3) the beryllium reflector is torn loose and is replaced with water. Wire parameters for these cases are a $0.147 \mathrm{~cm} \mathrm{~B} C$ diameter, ${ }_{4}^{10} \mathrm{C}$ density of 90 percent, and a total of 2600 wires.

The reactivity of the compacted reactor with 1) a compacted beryllium reflector with no water flooding is $0.62 \mathrm{k}_{\text {eff' }}$ 2) a compacted beryllium reflector with water flooding is $0.72 k_{\text {eff' }}$ and 3 ) the beryllium reflector torn loose and replaced with water is $0.62 k_{\text {eff }}$ In the latter two cases, the reactor core was also reflected axially with water.

The calculations show that designing a poison wire system to maintain a water flooded reactor subcritical will provide ample shutdown margin for a compacted core.

3. Experimental and Analytical Poison Wire Worth

A series of tests were performed in the PAX critical facility to experimentally determine poison wire worth; see Appendix B. The worth of the poison wires was also determined analytically by essentially the same procedures as outlined in the previous chapters. The calculations gave conservative values of poison wire worth as is shown in table 4-7. This table presents the average poison wire worth, in cents, obtained experimentally and analytically. One dollar (100 cents) of poison wire worth is equivalent to $0.0071 \Delta \mathrm{k} / \mathrm{k}$ in the PAX critical reactor. The approximate total reactivity worth of the poison wires can be obtained by multiplying the worth of the individual wire by the number of wires in the reactor and dividing by the relative radial worth of the wires in the particular location where wire worth was determined.

The relative radial worth of the wires in the PAX-C experiment as compared to the average worth over the entire core is slightly less than 1.8; see figure 4-1. However, the important fact to be obtained from the PAX experiments is the degree of conservatism in the calculated wire worth versus experimentally determined values. The calculated values of poison wire worth were expected to be conservative since disadvantage factors were determined with a neutron energy spectrum associated with a homogenized core and poison wires. An iterative procedure, as discussed previously, between cell disadvantage factor calculations and cross-sectional calculations should result in a greater accuracy of analytical values for

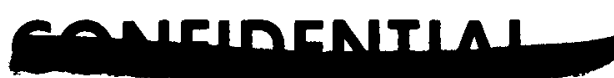


TABLE 4-7

POISON WIRE WORTH

PAX EXPERIMENTAL VS. ANALYTICAL VALUES

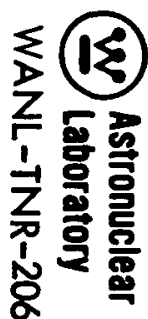

\begin{tabular}{|c|c|c|c|c|c|c|c|c|}
\hline \multirow[b]{2}{*}{ Case Number } & \multicolumn{2}{|c|}{$\begin{array}{l}{ }^{10}{ }^{10} \mathrm{C} \text { Wires } \\
\text { Per Element }\end{array}$} & \multicolumn{2}{|c|}{$\begin{array}{c}\mathrm{CH}_{2} \text { Rods } \\
\text { Per Element }\end{array}$} & \multicolumn{2}{|c|}{ Core Inventory } & \multicolumn{2}{|c|}{${ }_{B}^{10} C$ Worth, $x$} \\
\hline & 0 -Cluster & A-Row & 0 -Cluster & A-Row & $\begin{array}{l}\text { Total } \\
{ }_{B}^{10}{ }_{4} \mathrm{C}\end{array}$ & $\begin{array}{l}\text { Total } \\
\mathrm{CH}_{2}\end{array}$ & $\begin{array}{l}\text { PAX } \\
\text { Experimental } \\
\text { Value }\end{array}$ & $\begin{array}{l}\text { Analytical } \\
\text { Value }\end{array}$ \\
\hline 1 & $1-0$ & 0 & 0 & 0 & $6-0$ & 0 & -5.94 & -4.1 \\
\hline 2 & $1 / 2-0$ & 0 & 0 & 0 & $6-3$ & 0 & -5.8 & -3.9 \\
\hline 3 & $1-2 / 3$ & 0 & 18 & 0 & $6-4$ & 108 & -10.9 & -7.4 \\
\hline 4 & $1-1 / 3-1$ & 0 & $17-2 / 3$ & & $8-6$ & 106 & -10.1 & -6.9 \\
\hline 4 & $1-1 / 2-1-4 / 9$ & $1-1 / 2$ & $17-1 / 2$ & $17-1 / 2$ & $63-61$ & 735 & -9.25 & --- \\
\hline 5 & $1-1 / 3-1$ & $1-1 / 4$ & $17-1 / 2$ & $17-2 / 3$ & $50-48$ & 742 & -12.6 & -9.2 \\
\hline 6 & $1-1 / 3-1$ & $1-1 / 3$ & $17-2 / 3$ & $17-2 / 3$ & $56-54$ & 742 & -11.7 & -8.5 \\
\hline 7 & $1-2 / 3$ & $1-1 / 3$ & $17-2 / 3$ & $17-2 / 3$ & $54-52$ & 742 & -12.6 & -9.3 \\
\hline 8 & $2 / 3-1 / 3$ & $1-1 / 3$ & $17-2 / 3$ & $17-2 / 3$ & $52-50$ & 742 & -13.4 & --- \\
\hline 9 & $1 / 3-0$ & $1-1 / 3$ & $17-2 / 3$ & $17-2 / 3$ & $50-48$ & 742 & -13.9 & -- \\
\hline
\end{tabular}


poison wire worth. Agreement between experimentally and analytically determined values of wire worth is reasonably good. The analytical values are 25 to 35 percent below the experimental values. As shown in Appendix B, the experimental error in wire worth determination is approximately 10 percent. Thus, the difference between experimentally and analytically determined poison wire worths could be as low as 15 to 25 percent.

A more exact determination of poison wire worth is not warranted at this state of the ACPS development. It is evident that the calculations are sufficiently conservative so that a high degree of confidence can be placed on 2000 wires containing 85 percent theoretical density $(0.147 \mathrm{~cm}$ diameter). This number of wires is adequate to provide at least a 5.0 percent $\triangle k$ shutdown margin for a fully flooded NERVA type reactor. Future estimates on poison wire worth may show that a reduction in the number of poison wires is feasible. 


\section{CHAPTER V SYSTEM DESCRIPTION}

\section{A. ACPS COMPONENT SECTION}

\section{A. ACPS COMPONENT SECTION}

The ACPS is basically a mechanical spring actuated system, with the exception of the pneumatic motor which is used for initiating wire extraction. The principle of operation utilizes relative movement of an inner and outer cylinder and the mass momentum generated by instantaneous release of pre-compressed springs. Proper operation is highly dependent upon generating the required acceleration and velocity at each spring release to actuate succeeding mechan isms or eject the system as required. A self contained winding tape actuator derives its power and control from components completely independent of the NERVA engine components which are designed primarily for other purposes. This independence permits greater freedom in selecting suitable and efficient components.

The ACPS can be readily divided into nine distinct sections, illustrated in figure 1-1, and are listed as follows:

1) Poison wires and support

2) Wire retention system

3) Piston

4) Inner locking cylinder

5) Outer ejection cylinder

6) Locking mechanisms and springs

7) Poison wire extraction system

8) Control system

9) Support structure

The following paragraphs describe each section of the conceptual ACPS. A complete explanation of the operational sequence is contained in a separate section of this document.

1. Poison Wires

Poison wires are long, slender, flexible rods intended for insertion into selected reactor core coolant channels. The wires contain a neutron absorbing material, boron carbide,

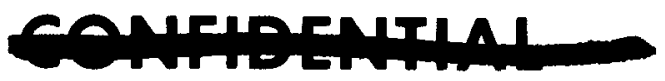


enriched with the effective isotope of boron of atomic weight 10. A sufficient number of poison wires distributed throughout the core volume assure that the reactor cannot attain criticality. Poison wire criteria, construction and utilization are described in detail in Chapter II of this report; a representative poison wire is illustrated in figure 2-1 and 2-2.

\section{Wire Retention System}

During reactor ground handling, storage, testing and flight operation, it is imperative that the poison wires be maintained in the core without slippage. If the wires are allowed to penetrate the fuel element coolant channels beyond the prescribed length, there is a possibility of damaging the flow restriction orifices. If the wires are partially withdrawn from the channels, the subcriticality margin is reduced.

The retention plate is basically a circular plate with wire attachment fittings spaced to accommodate the wire bundles. For the flight configuration, this plate (head) is an integral part of the piston structure. (See figure 5-1.) Since it is mandatory that the poison wires be installed in the core from the time of reactor assembly and prior to nozzle attachment, a dummy retention plate is provided, with rigid supports, to maintain wire immobility during handling and shipping. Both plates will be made of 301 stainless steel to meet the fire exposure criteria as described in Chapter III, Section B of this report.

\section{Piston}

The piston, as illustrated in figure 5-2, is a composite structure, circular in shape, with the wire retention plate on top and a support plate on the bottom. It is secured inside the inner locking tube by means of the spring loaded locking pins. Teflon " $O$ " rings attached to upper and lower plates provide the sliding surface and prevent piston cocking within the cylinder. The spring mechanism, the pin release lever and the pre-pressurized redundant system for activating the pin release are internally mounted in the piston. To fulfill fire exposure criteria, 301 stainless steel was chosen as the most suitable material.

\section{Inner Locking Cylinder}

The inner cylinder is a machined circular tube of stainless steel with variable thickness and is approximately 2.1 meters long. (See figure 1-1.) It serves two primary purposes in

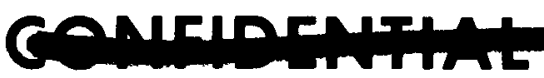




\section{COINFIDENIIAL}

(20) Astronuclear

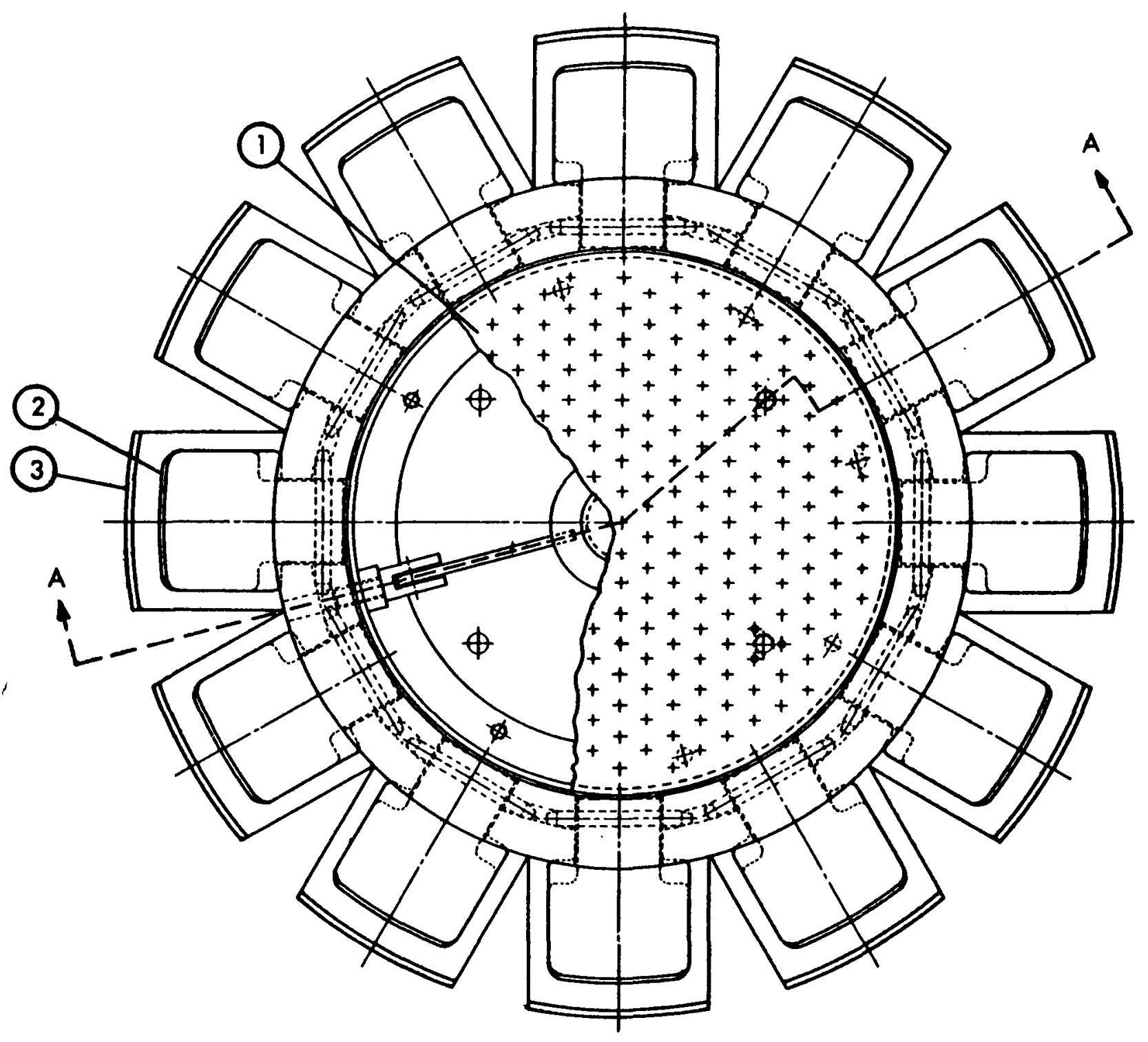

1. WIRE RETAINER PLATE

2. RETAINING FINGERS

(3.) FLEXIBLE PADS

$603389 A$

Figure 5-1. Plan View of Retaining Plate and Retaining Fingers 


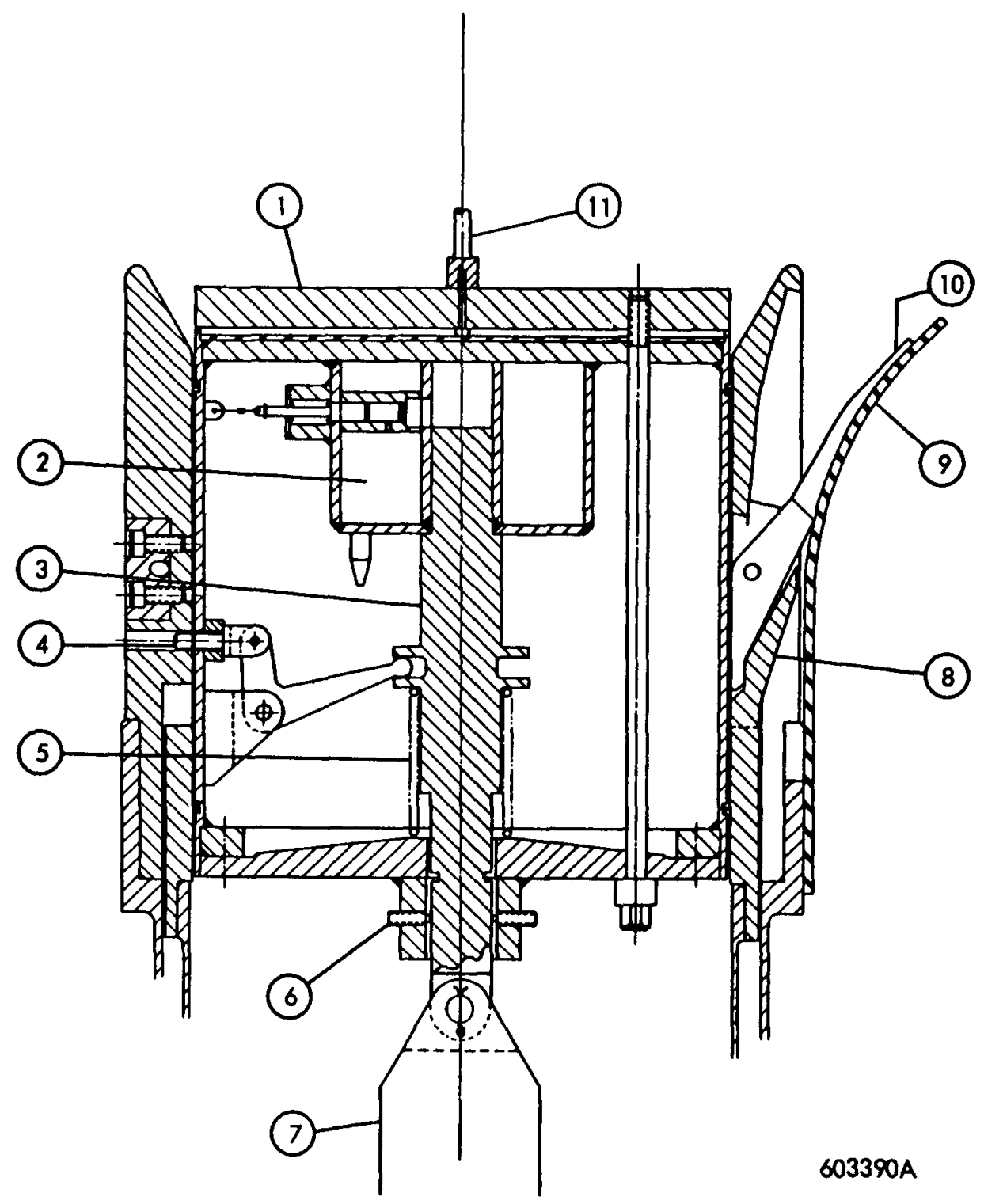
(1) Wire retainer plate
(7) WIRE EXTRACTION TAPE
(2) PRE-PRESSURIZED REDUNDANT SYSTEM
3. SLIDER SHAFT
(8) INNER LOCKING TUBE
4. PISTON LOCKING PIN
9. PADDING
5. PRELOADED SPRING
6. SLIDER LOCK PINS
10. RETAINING fingers
(11) WIRE BUNDLE ATTACHMEINT

Figure 5-2. Detail Cross Section A-A of Piston 
the overall operation of the ACPS. First it provides a locking mechanism for the retainer fingers and secondly, when actuated, it provides the force for unlatching the ejection tube lever. Locking latches are placed around the periphery of both the inner and outer cylinder at their lower extremities. The latches prevent relative movement between the two cylinders and also lock the pre-compressed inner cylinder actuating spring. The only way the inner cylinder can actuate, after it has been locked into place, is to release the latches. After this is accomplished, the actuator spring drives the inner cylinder downstream from the nozzle throat, relative to the outer cylinder. After a travel of approximately $3.8 \mathrm{~cm}$, bumpers machined onto the inner cylinder strike the retention levers, unlocking the whole system.

\section{Outer Ejection Cylinder}

The outer cylinder fits around the inner cylinder with a gap of approximately 0.25 $\mathrm{cm}$ between them. It is essentially a circular stainless steel machined tube with cutouts and thickness variations where required. See figure 1-1. It serves three important functions: 1) It provides support for the throat retaining fingers, gas accumulator, pneumatic motor and inner cylinder locking latches. 2) It anchors the piston locking pins. 3) It drives the support brace, the protective foam and the complete ACPS out of the nozzle when actuated. Actuation is initiated by the ejection impulse from the inner cylinder impact of the retention lever and release of the throat retaining fingers. After the retention lever is released, the system ejection springs are released and movement of the outer cylinder is relative to all other components of the system. The mass momentum generated by the outer cylinder impacts the support braces and ejects the entire system.

The entire ACPS is prevented from moving out of the nozzle under flight vehicle acceleration by the throat retaining fingers. The loading is transmitted to the nozzle throat wall surface through the pressure exerted by the retaining fingers and padding. These items, 9 and 10 , are illustrated in figure 5-2.

The reactor nozzle assembly had been pressure tested during the current NRX ground test series to pressures which exceed the magnitude exerted by the retaining fingers and padding. To pressure test the nozzle assembly, an expandable plug is employed to seal the throat area of the nozzle. In order to develop forces which hold the plug in place under internal

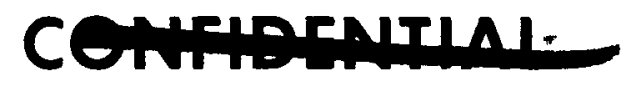


WANL-TNR-206

assembly pressure, a flexible rubber-like material on the outer plug surface is compressed. causing the flexible material to conform to the surface irregularities and to the annular volume between the plug mandrel and the nozzle wall. Aerojet-General Corporation drawings 293700 and 293701 show the plug that is employed to seal the nozzle throat.

\section{Locking Mechanisms and Springs}

The ACPS operates as a self energized mechanical release system highly dependent upon reliable spring locking mechanisms. The design requirements include provisions for devices in which the locks are positive in order to prevent accidental release, and, at the same time, be responsive to release signals without complications.

There are three primary spring and lock systems designed into the ACPS. See figure 1-1. These, in the order of sequential system actuation, are the piston lock slider spring, the inner locking tube ejection spring, and the outer tube system ejection spring. The piston lock slider spring is pre-loaded to approximately nine $\mathrm{g}^{\prime} \mathrm{s}$, taking into consideration the mass of the piston structure and terminal fittings. This operation is performed in order to prevent unlocking due to launch acceleration forces. Its prime function is to maintain the piston locked in the desired position which in turn prevents movement of the wire terminal retainer plate. The actuation of this lock is very essential if the poison wires are to be extracted. Therefore, a pressurized redundant system capable of overcoming the spring is provided to prevent the pins from returning to a lock position if the redundant system is used. In the design evaluation the locking pins are notched so that a relatively low pressure produced by release of propellant through the NERVA engine can shear them if all other systems fail.

The inner locking tube ejection springs are also pre-loaded and locked into place by a series of latches. The springs are designed to eject the inner locking tube with sufficient initial velocity to unlatch the system ejection lever and at the same time be capable of locking the throat retaining fingers in place under all conditions of force and vibration. It is very important that the actuation of these springs can be controlled closely in order to prevent premature accidental release of the latches. This system differs from the piston lock system in that release of the pins initiates a chain reaction culminating in the ejection of the entire

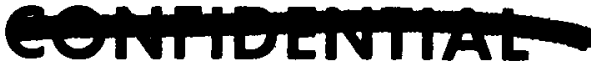


system. To preclude any credible accident, the latch mechanisms must be armed by a separate ground signal before the spring release mechanism is operable. This requires two separate overt actions to unlock the latches, one to engage and arm the mechanism and one to release the latches. Provisions are made for two methods of release, one electrically via a solenoid and one by a pneumatic cylinder. The release of these springs thrusts the inner locking tube downstream from the nozzle throat, unlocking the throat retaining fingers by its movement away from the area and releasing the system ejection lever by impacting it. Approximately 30 springs of $4.5 \mathrm{~kg}$ capacity each will be required for this action. This part of the ejection sequence is considered to be the most critical. Extraordinary caution will be exercised in this area during design and assembly to ensure a positive and reliable operation.

The system ejection springs are pre-loaded and are by far the largest and most heavily loaded springs in the system. The primary functions of these springs are to dislodge the support braces and eject the complete system out of the nozzle. Since it is most important to dislodge the support braces, the spring forces are designed for twice the static requirements. This does not take into account the impact factor which may be as much as three times the static force. Approximately 30 springs, spaced equally around the outer periphery, with an average force of $16 \mathrm{~kg}$ per spring, will be utilized. These springs are contained in a housing and locked into place with four cam-latch spring loaded ejection levers. If more than four are required to insure a uniform spring release or to reduce the unit lever load, the system is adaptable to additional levers. The operation of this system is dependent upon a successful actuation of the inner locking tube system.

\section{Poison Wire Extraction System}

The extraction system is composed of a pneumatic motor, an energizing gas storage accumulator, an arming clutch mechanism, a winding spool, and the pull tape. The system will be mounted on a plate welded to the lower portion of the outer ejection tube. The pneumatic motor will be of a special design utilizing the lightest weight materials and sealed from the elements. 
The conceptual design shows that the accumulator will be of the aircraft type, using a stainless steel body and a siliconized rubber bladder pressurized to $140 \mathrm{~kg} / \mathrm{cm}^{2}$ for either nitrogen or helium. Two separate and independent regulator systems are mounted to the accumulator; one actuates the wire extraction motor and the other is connected to the redundancy system for releasing the inner locking springs.

The arming mechanism which engages the motor shaft will be of a clutch type actuated by an electric signal. The pull tape will be made from a nickel cobalt alloy with a high yield and ultimate strength. Tests indicate yield strengths up to $19,700 \mathrm{~kg} / \mathrm{cm}^{2}$ and ultimate strengths to $25,900 \mathrm{~kg} / \mathrm{cm}^{2}$ for this material. A tape approximately $0.025 \mathrm{~cm}$ thick and $5 \mathrm{~cm}$ wide will be adequate for use in extracting the wires. Elgiloy or Haver tapes exhibit strength and unusual ductility in the operating range of the ACPS temperature and possess characteristics which will fulfill the requirements for poison wire extraction. The spool will be in the range of 5 to $7.5 \mathrm{~cm}$ in diameter and will be machined from an aluminum forged block. A pillow block will be supplied if necessary to support the motor shaft. See figure 1-1.

The pneumatic motor spool-winding tape principle was proven during tests conducted to establish withdrawal force conditions with respect to the demonstration wire. Figure 2-13 shows the entire assembly and figure 5-3 provides a better view of the motor and tape assembly.

\section{Control System}

The control system is described as any piece of equipment that signals, actuates or regulates the function of the ACPS components. Figure 5-4 is a schematic of the control system as presently designed. The steps are numbered in sequence of operation, and dotted lines indicate the ultimate routes of the functions which will be required if the redundant system is utilized.

The ACPS control not only includes that portion of the system mounted on the NERVA rocket, but also a ground control station. Communications between the rocket and the ground station are accomplished by means of a two-way radio link or transceiver. The transceiver on the rocket will receive the control signals in coded form from the ground station, decode them, and present them in a form necessary to operate the various ACPS control

\section{CONTIDENITAL :}




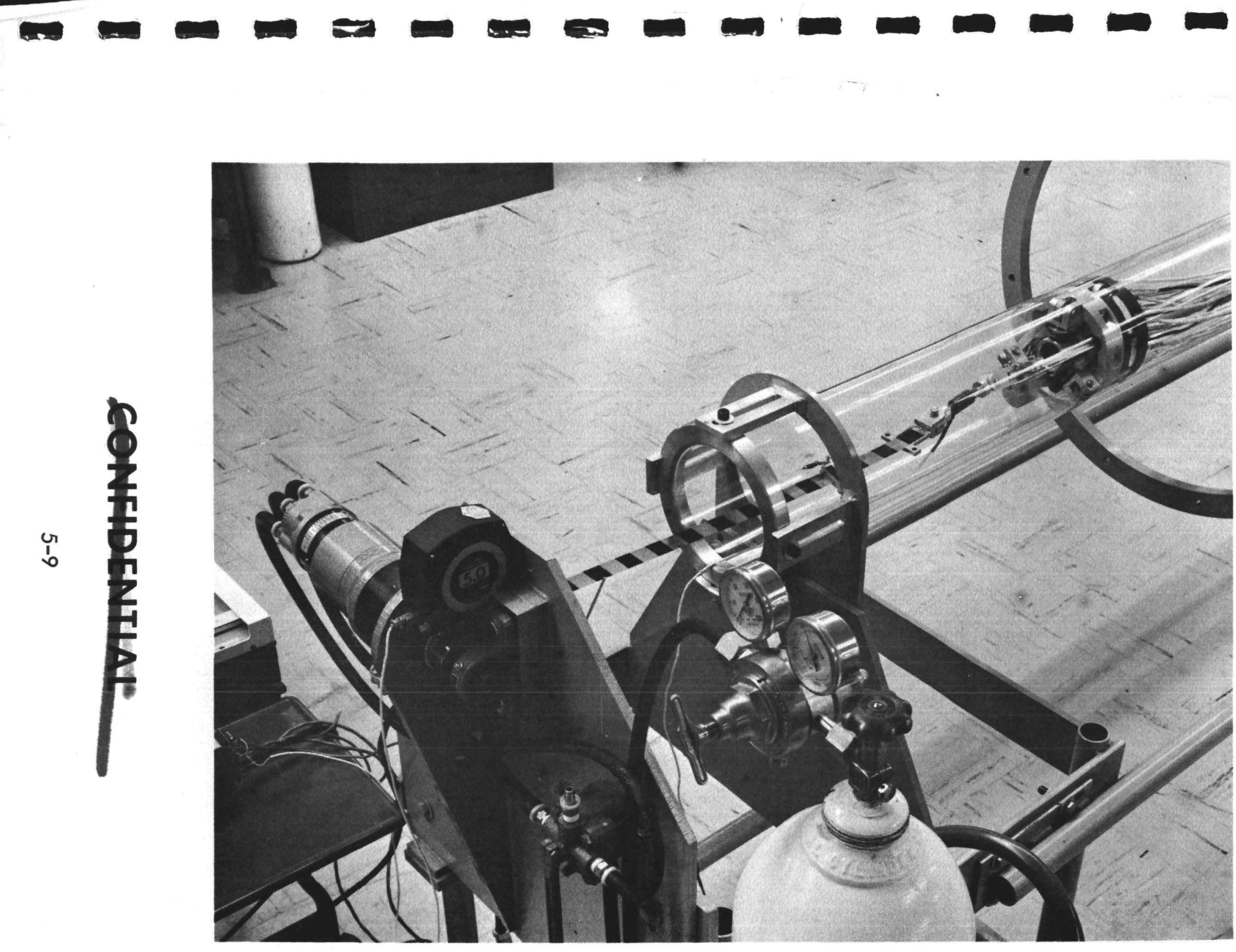

Figure 5-3. Assembly of Pneumatic Motor and Withdrawal Tape

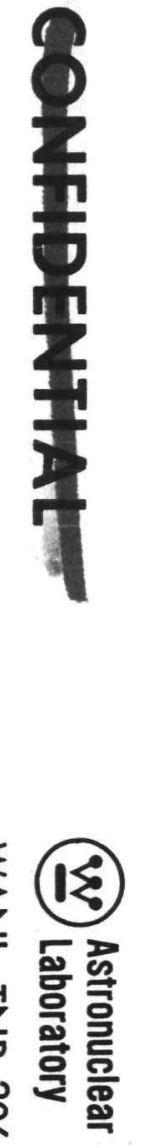




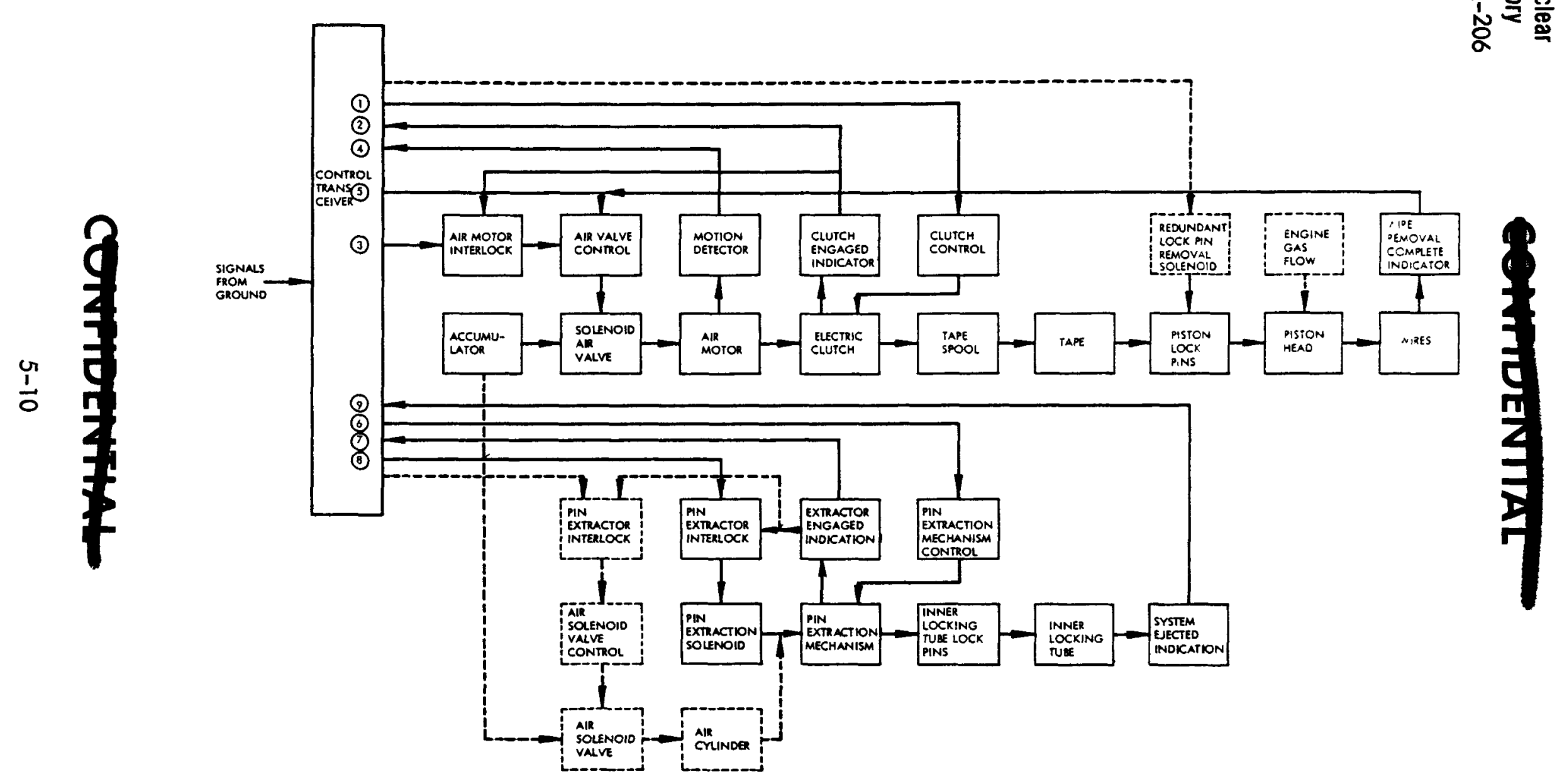

Figure 5-4. Block Diagram of the Control System 
functions. Indication signals will be returned to the ground station in a similar fashion. This transceiver, which may be a part of a large communication system for other NERVA engine control functions, will be capable of rejecting all spurious signals. The ACPS control functions will be initiated at the ground station by contact closures and all "operation complete" indications will be verified by lamp.

The ACPS control system aboard the rocket will be composed of low voltage dc circuitry, with all "operation complete" indications generated by contact closures actuated by signals from the transceiver. There are no servo or feedback loops. This was done to increase the reliability and to simplify the circuitry by minimizing the number of components. This type of system relinquishes as much of the control function as possible to the ground station and its operators, a feature which provides maximum flexibility.

\section{Support Structure}

ACPS support structures are the components that support or react the system loads due to launch and wire extraction and are independent of the system functional requirements. There are two major support structures in ACPS, 1) the support braces and 2) the system support platform. The design of both structures was interrelated due to a mutual load apportionment. The support braces are a series of stainless steel tubes with welded curved plates (to conform with the nozzle curvature) covered with a siliconized rubber pad molded to fit the contour of the nozzle flow tubes. The brace structure is locked into the outer ejection tube and is adjustable in the axial direction. This permits a position variation in relation to the support platform in order to control the allocation of load reactions. Additional brace adjustment is provided by a ball connection to the pads. The support platform will have a lateral guide tube built in for the sole purpose of preventing horizontal pivoting and movement of the system due to lateral acceleration and vibrations. The surface of the platform will be covered with a hard durometer siliconized rubber pad which will allow the system to translate axially about 0.25 to $0.6 \mathrm{~cm}$ during maximum acceleration of the flight vehicle. The schematics in figures 5-5 to 5-8 indicate the installation loads and reactions to be expected at the critical loading points on the support structure. In conjunction with the illustrations, table 2-2 lists functional data pertinent to the system.

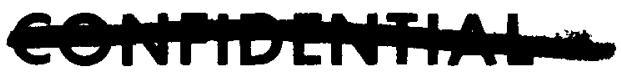


(20) Astronuclear

WANL-TNR-206

(1) RETAINING FINGERS

(2) INNER TUBE

(3) OUTER TUBE

(4) EXTRACTION TAPE

(5) FLEXIBLE PAD

(6) EJECTION LEVER

7. SUPPORT BRACE

8) OUTER EJECTION SPRING

(9) FLEXIBLE PLASTIC FOAM

(10) INNER EJECTION SPRING

(11) ACCUMULATOR

(12) GUIDE TUBE

(13) SUPPORT PLATFORM

(14) TOP OF PRECEDING STAGE

(15) FLEXIBLE PAD

(16) PNEUMATIC MOTOR

(1) INNER TUBE RELEASE MECHANISM

(18) PISTON

19 FLEXIBLE PAD

(20) POISON WIRE BUNDLES

\author{
MECHANISM
}

4
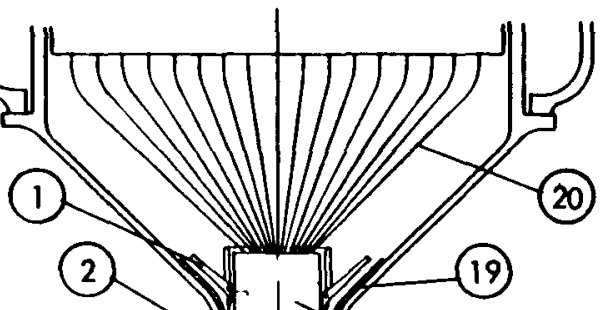

(3) 18

\section{(5)}

(4)

(6)

8

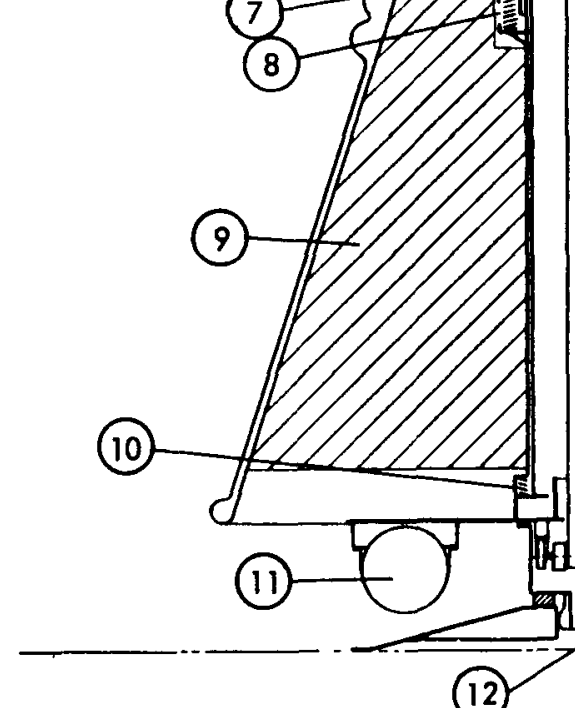

(12)

(13)

(14)

$603102 A$

CONDITIONS:
A. PRE-LAUNCH-1.0 g LOAD
C. RETAINING FINGERS FREE OF THROAT PAD
B. ACPS WEDGED INTO NOZZLE \& SUPPORT PLATFORM
D. SUPPORT BRACES \& PLATFORM PADS REACT WEDGE LOADS

Figure 5-5. ACPS Pre-Launch Condition 

(1) RETAINING FINGERS
(2) SUPPORT BRACES
(3) SUPPORT PLATFORM PAD
(4) GUIDE TUBE

D

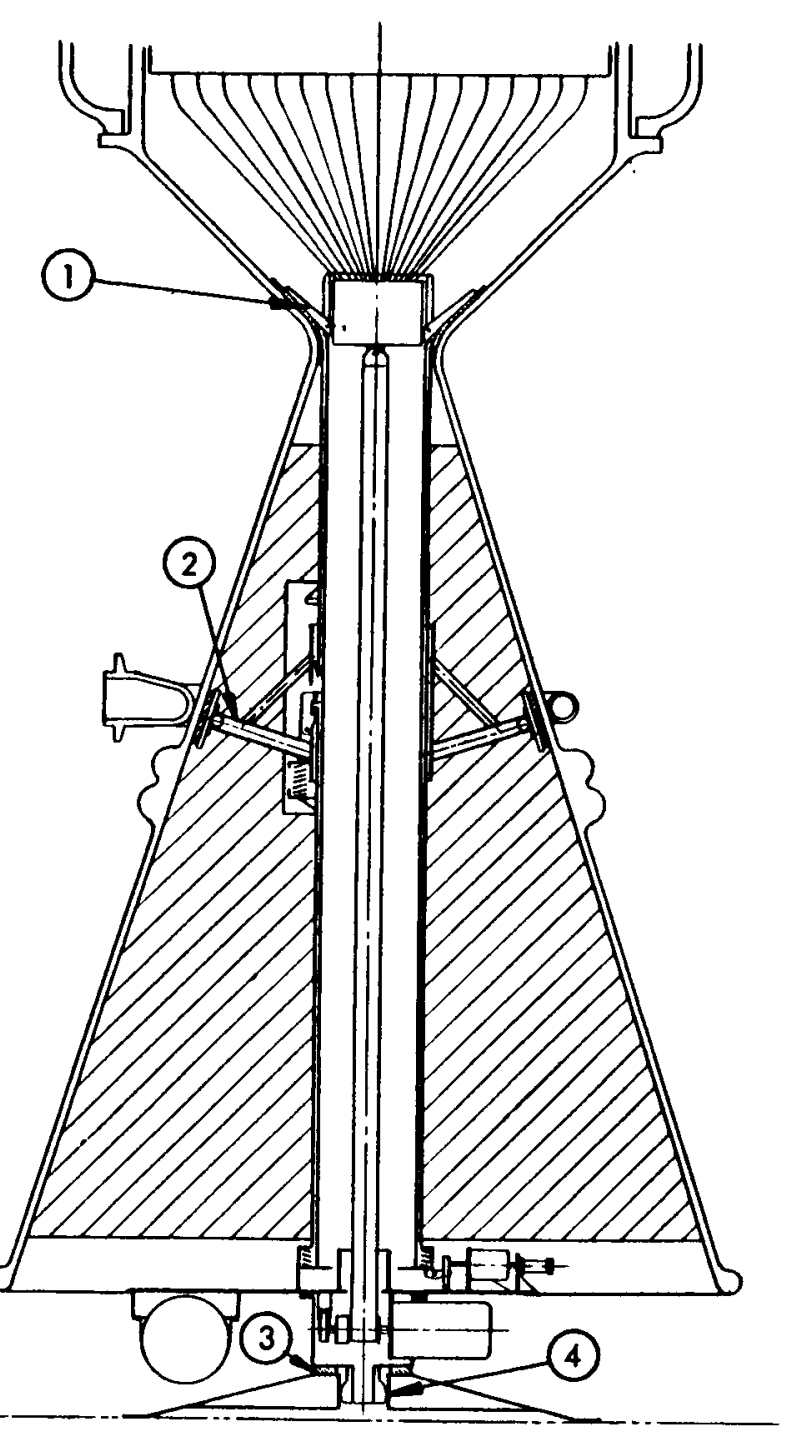

603103A

CONDITIONS:
A. MAX. ACCELERATION FORCE OF $6.0 \mathrm{~g}$ JUST PRIOR TO IST STAGE BURNOUT
D. SUPPORT BRACE INITIAL AXIAL LOADS RELIEVED - ZERO REACTION
B. SUPPORT PLATFORM PADS DEFLECTED TO REACT PORTION OF AXIAL LOAD
E. LATERAL LOADS OF $1.8 \mathrm{~g}$ REACTED BY SUPPORT BRACES AND GUIDE TUBE
C. RETAINING FINGERS REACT PORTION OF AXIAL LOAD

Figure 5-6. ACPS - Maximum Acceleration Condition

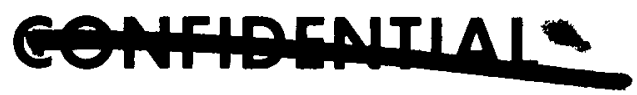


(W)

Astronuclear

Laboratory

WANL-TNR-206

(1) RETAINING FINGERS

(2) SUPPORT BRACES

(3) SUPPORT PLATFORM

(4) GUIDE TUBE

(5) SECOND STAGE

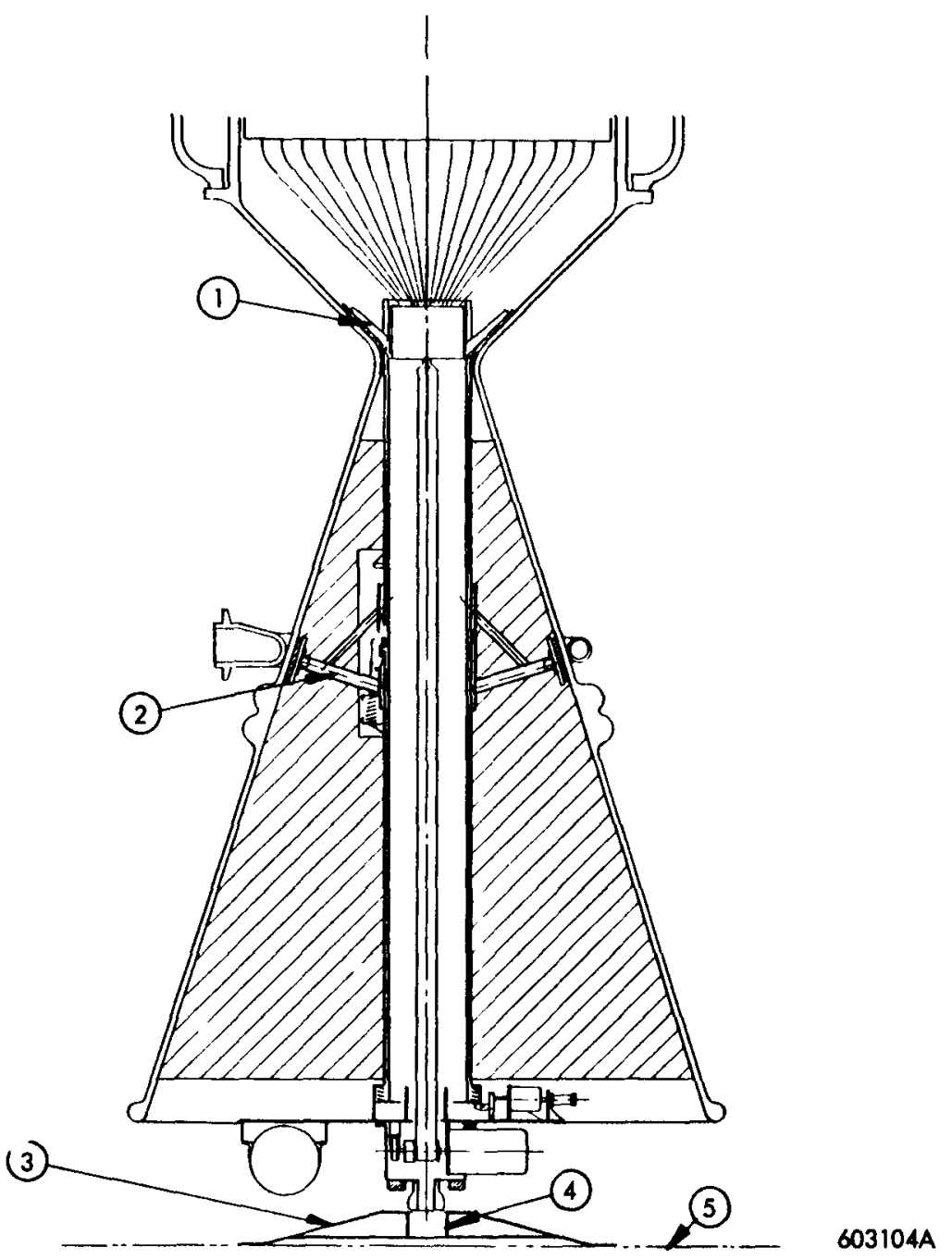

CONDITIONS:

A. JUST PRIOR TO 2ND STAGE BURNOUT

B. 2ND STAGE TANK WITH SUPPORT PLATFORM DEFLECTS 5 CM. AWAY FROM ACPS

C. RETAINING FINGERS REACT $2.8 \mathrm{~g}$ LOAD

D. SUPPORT BRACE REACTS LATERAL ACCELERATIONS

E. ACPS COMPLETELY FREE FROM GUIDE TUBE

Figure 5-7. ACPS - At Second Stage Burnout

\section{REINFIDENITAL:}


(1) POISON WIRES

(2) SUPPORT BRACES

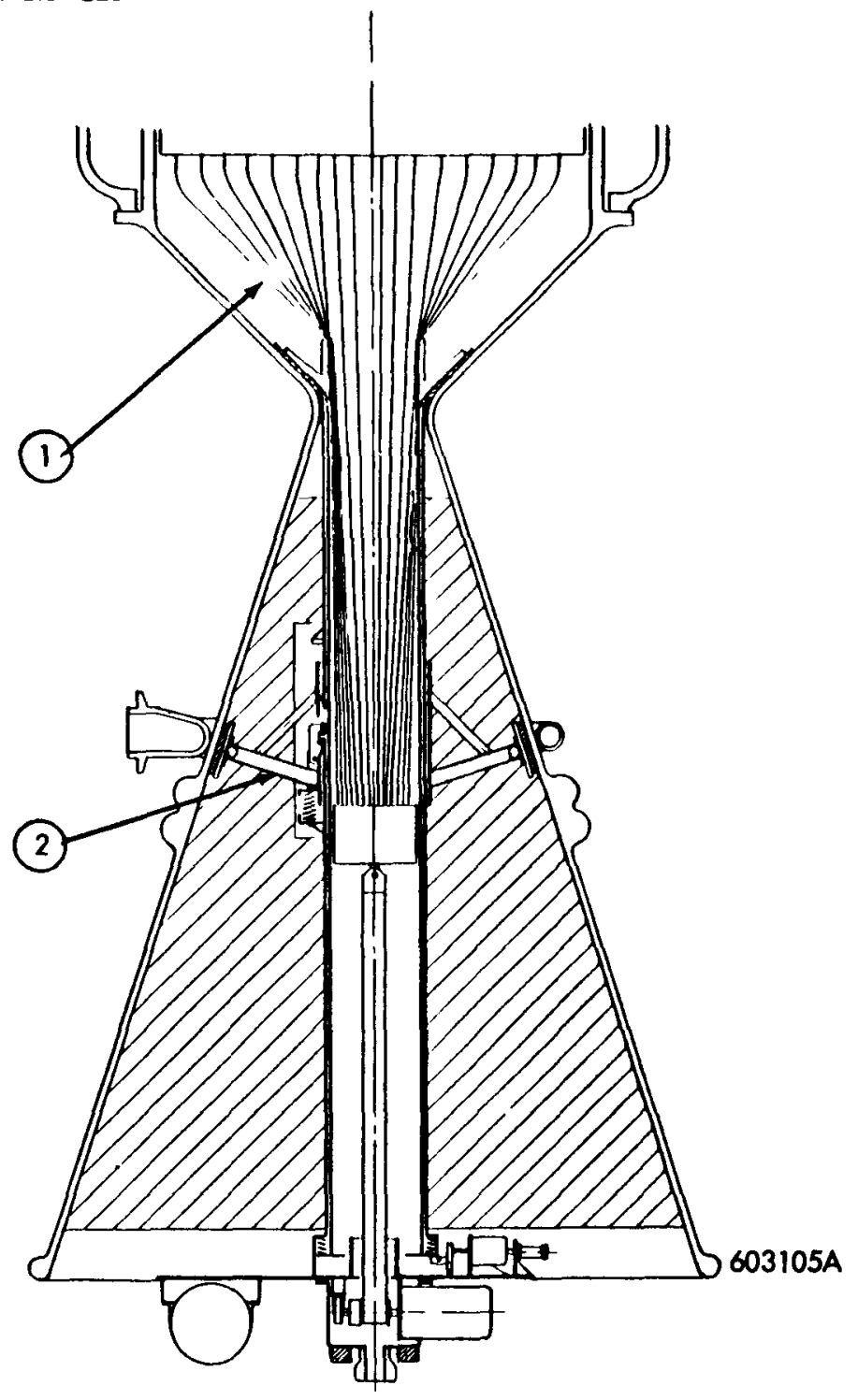

CONDITIONS:

A. 2ND STAGE SEPARATED

B. ZERO ' $G$ " LOADS

C. POISON WIRES BEING EXTRACTED

D. EXTRACTION LOADS REACTED PRIMARILY BY SUPPORT BRACES

Figure 5-8. ACPS - Wire Extraction Conditions

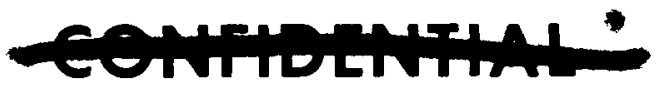


At the final installation of the system on the launch vehicle, the support braces will be resting on a platform located on the second stage propellent tank. In order to stabilize the ACPS under dynamic operating conditions, the braces will receive part of their support from the second stage. Such a concept has the following advantages:

1) Increase in system stabilizing before and after launch.

2) Dampening of vibrational effects on the ACPS and nozzle.

3) Reduction of the reaction loads of the ACPS on the nozzle during maximum acceleration of the rocket.

4) Inherent compensation for temperatures and pressure changes.

5) Positive maintenance of the alignment of the ACPS.

6) Compensation for inter-stage structural contractions.

Immediately prior to the preceding stage burnout, it is postulated that the fuel tank upon which the system platform support is attached will deflect $5.0 \mathrm{~cm}$ away from the ACPS. Also, an instantaneous load factor of 2.8 is expected on the NERVA (S-N) stage. Without the platform support, this load will be absorbed by the retaining fingers on the nozzle throat, figure 5-7. The support brace pads will remain in contact with the nozzle wall with no appreciable load (greater than $1.0 \mathrm{~g}$ ) on them. The platform guide tube is so designed that the ACPS will be completely free of lateral restraint after the $5.0 \mathrm{~cm}$ movement of the platform. The $2.8 \mathrm{~g}$ load occurs simultaneously with the $5.0 \mathrm{~cm}$ movement but is a momentary occurrence lasting only a fraction of a second.

Following separation of the preceding stage, the nuclear stage will be programmed for operation. At this time, the poison wires will be withdrawn from the reactor core.

As a conservative estimate, $308 \mathrm{~kg}$ is presumed as the force required to break static friction for extraction of the poison wires. This value was derived from ground withdrawal tests. Furthermore, this value is conservative because the nuclear stage will, in all likelihood, be in a condition near "zero-g". Consequently, frictional force influences should be lower than those of the horizontal ground pull tests because no directed weight-force causes the wires to align against the reactor core coolant channel walls. 
The withdrawal forces will be reacted through the support brace pads bearing against the nozzle wall, figure 5-8. Maximum unit reaction loads on the nozzle wall due to wire extraction are approximately $0.8 \mathrm{~kg} / \mathrm{cm}^{2}$ Maximum unit loads are excited on the nozzle wall at the brace during ACPS ejection. Unlatching of the outer ejection lever releases the system ejection springs (a total spring load of approximately $469 \mathrm{~kg}$ ) driving the support braces against the nozzle wall. To take into account the effect of an instantaneous spring release, the nozzle reaction loads are considered double the spring load. Only one half the brace pad area was considered in calculating the unit load. This, in effect, provides a factor of four times the nominal spring load on the nozzle wall or approximately $2.2 \mathrm{~kg} / \mathrm{cm}^{2}$.

To insure against possible damage to the nozzle coolant channels, a pliable padding will be bonded onto all ACPS surfaces that contact the nozzle. In addition, polyurethane foam buns wrapped in polyethylene or Teflon sheets will be installed between the nozzle and the ACPS support components.

\section{B. REDUNDANT SYSTEMS}

Due to the ACPS requirements for a positive retention system and an equally positive extraction and ejection system, alternate methods for these operations would be provided. A summary of redundancy provisions are:

1) A pre-pressurized system to release the piston lock pins in the event the pneumatic motor arming mechanism or the pneumatic motor becomes inoperative.

2) Notched piston lock pins which will shear at a low engine flow if the primary system fails to operate. This can be considered a backup system for wire extraction.

3) A pneumatic cylinder for extracting the inner locking tube pins. In normal operation an electrically operated solenoid will extract the pins. 
(W) Astronuclear
Laboratory

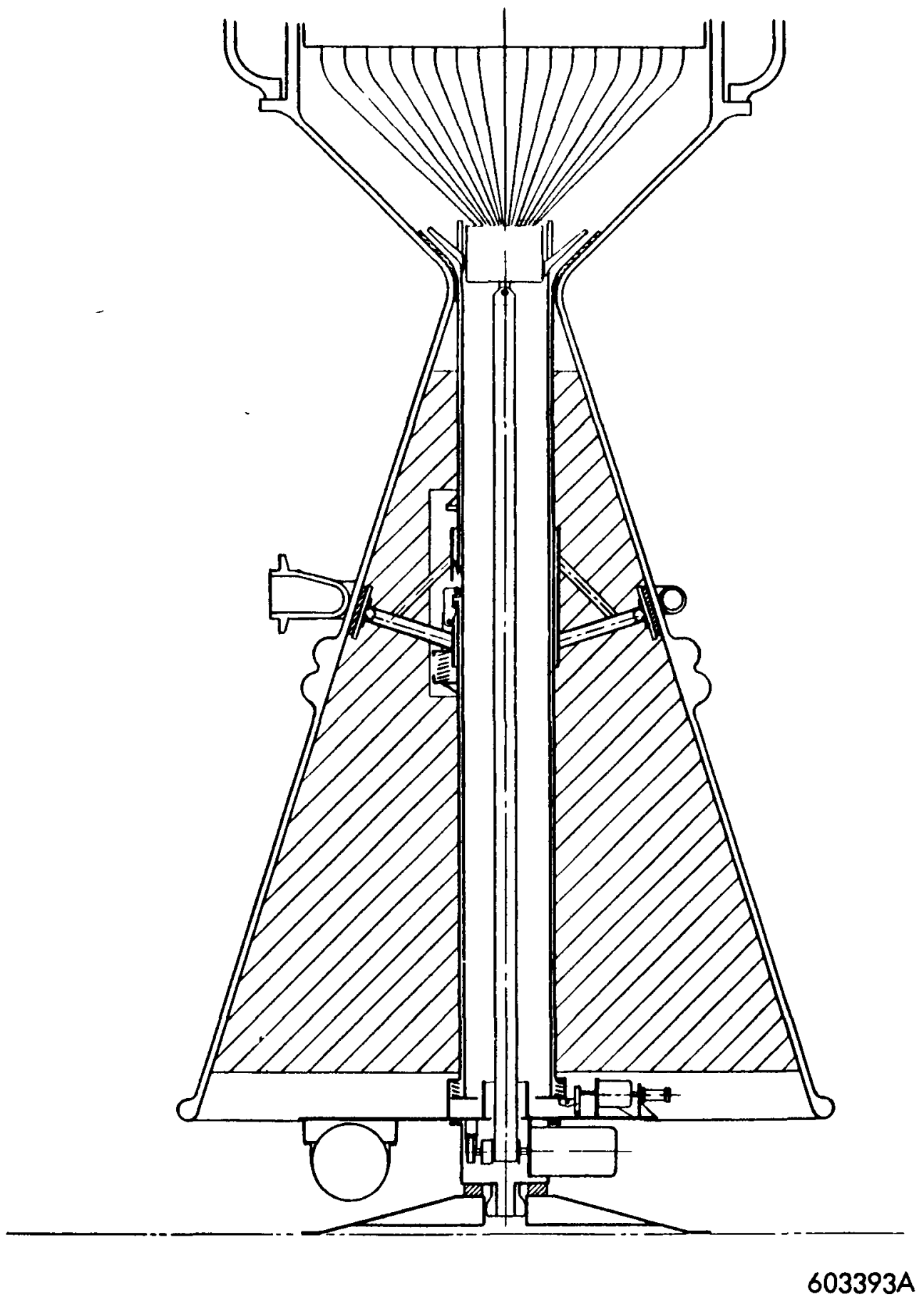

Figure 6-2. Pre-Launch In Ejection Sequence

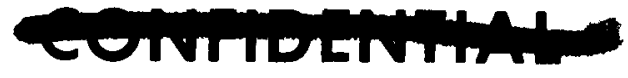




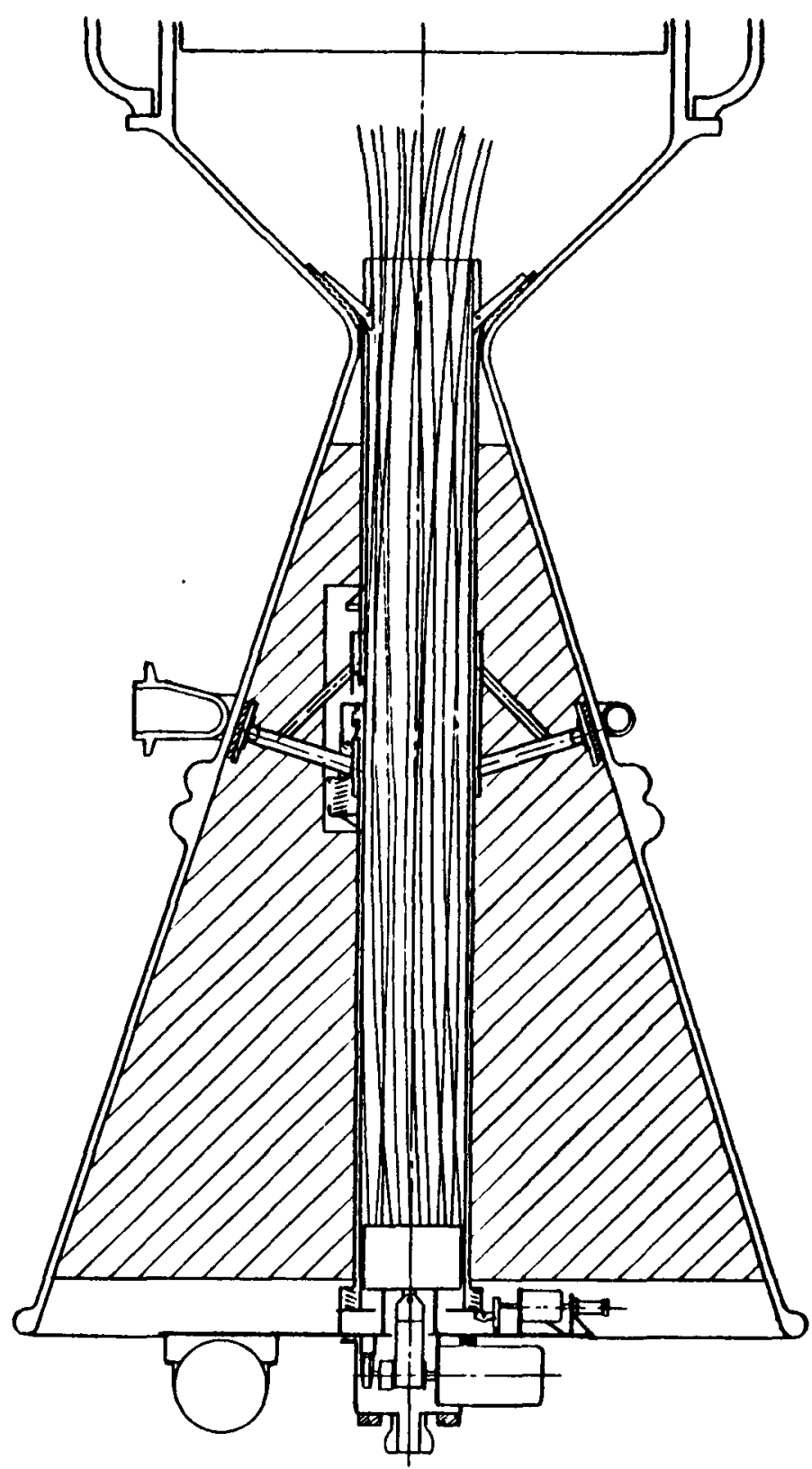

$603106 A$

CONDITIONS:
A. SECOND STAGE SEPARATED
C. WIRES EXTRACTED AND STORED
B. SYSTEM LOCKED IN PLACE
D. ZERO "G"

Figure 6-3. Wires Stored in ACPS Ejection Sequence

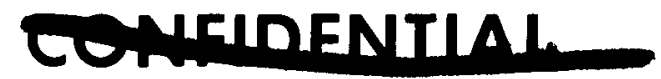


(2) Astronuclear

WANL-TNR-206

\section{COIVTILLIVITAL}

(1) INNER LOCKING TUBE SPRINGS

(2) RETAINING FINGERS

(3) EJECTION LEVERS

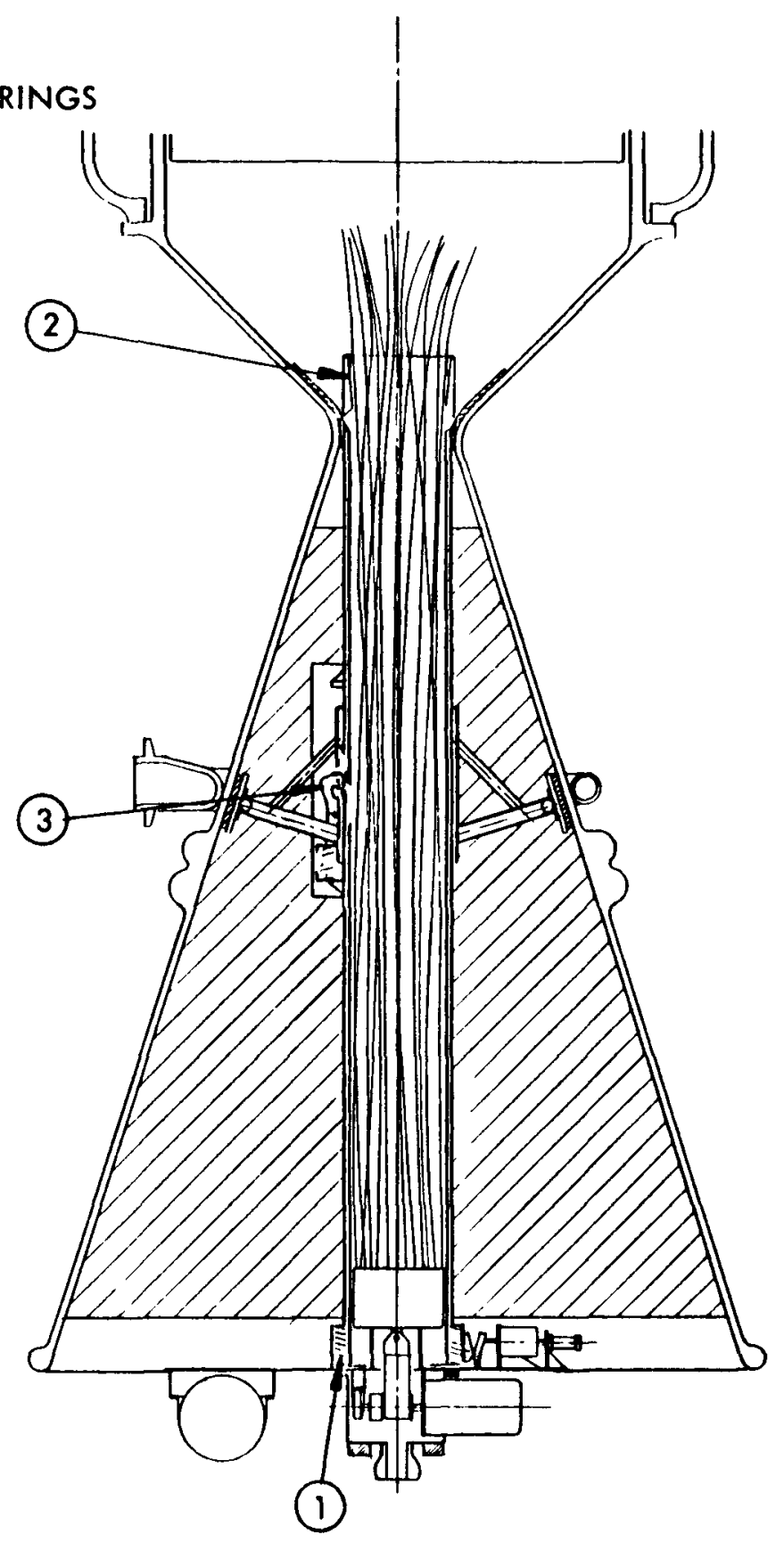

CONDITIONS:

A. INNER LOCKING TUBE SPRINGS RELEASED

B. RETAINING FINGERS RELEASED

C. OUTER EJECTION LEVER IMPACTED

Figure 6-4. Release Initiated in ACPS Ejection Sequence

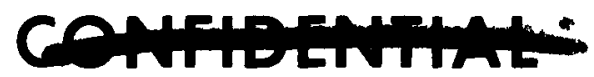



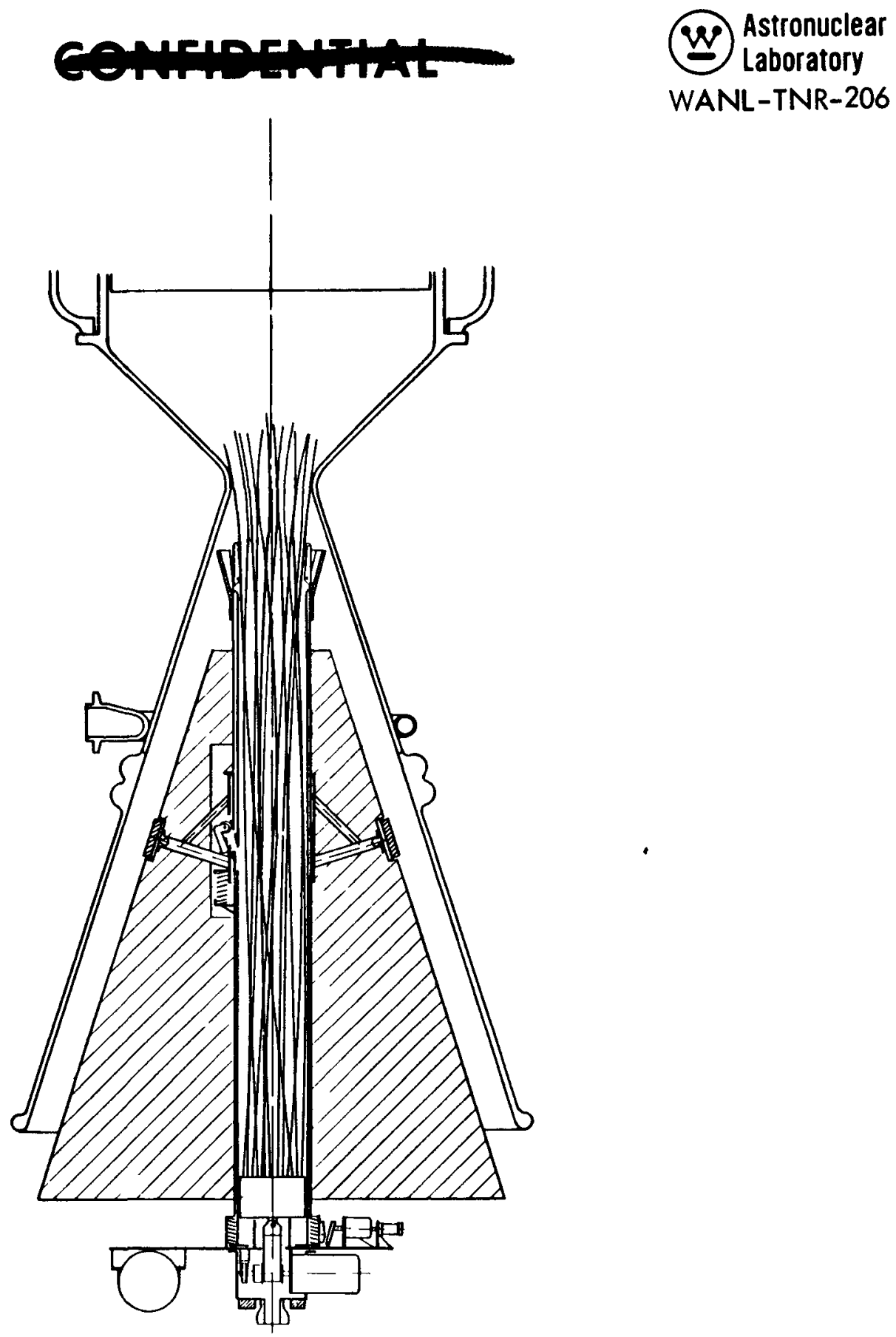

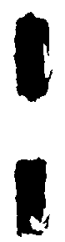

WANL-TNR-206 


\section{CHAPTER VII RELIABILITY OF THE ANTI-CRITICALITY POISON WIRE SYSTEM}

\section{A. RELIABILITY}

Due to the nature of the ACPS, its usage, and the environment in which it must operate, the reliability goals established must equal or exceed those established for the NERVA engine subsystem. In a complex design of this type, there are areas in which further development and testing are required. A preliminary reliability design review indicated that emphasis should be placed on a further study of the following sections:

1) The electrical circuitry and control system.

2) A quality control program for the manufacturing process.

3) Provisions for inspection during installation.

4) The development of a material for retaining finger and support system pads which must be capable of exposure to extreme environmental conditions.

5) Dynamic testing of poison wire support structures.

6) Environmental tests for actuating components.

A thorough reliability analysis complete with numerical values can only be obtained from a detailed design. The conceptual stage in which the ACPS now exists presents many obvious limitations. However, with respect to further effort required, direction and insight can be gained from a qualitative reliability review. Tables 7-1 and 7-2 provide this qualitative evaluation. 
TABLE 7-1

ACPS QUALITATIVE RELIABILITY EVALUATION

COMPONENTS SECTION

\begin{tabular}{|c|c|c|c|c|c|c|}
\hline ITEM ' & $\begin{array}{l}\text { WEIGHT } \\
\text { (L.BS.) }\end{array}$ & MATERIAL & $\begin{array}{l}\text { ANALYYSIS } \\
\text { VALIDITY }\end{array}$ & $\begin{array}{c}\text { DESIGN AND } \\
\text { SYSTEM COMPLEXITY }\end{array}$ & $\begin{array}{l}\text { DEVELOPMENT } \\
\text { EFFORT }\end{array}$ & $\begin{array}{l}\text { SAFEGUARDS } \\
\text { COMPATIBILITY }\end{array}$ \\
\hline 1. Complete Syctem & 189.0 & & & $\begin{array}{l}\text { Proven principles and } \\
\text { devices }\end{array}$ & $\begin{array}{l}\text { Mechanical synchro- } \\
\text { nization and timing } \\
\text { problems }\end{array}$ & Minimum influence \\
\hline 2. Poison Wires & 45.4 & Non-metalic & Good & $\begin{array}{l}\text { Basic fabrication } \\
\text { established }\end{array}$ & $\begin{array}{l}\text { Retention in reactor } \\
\text { and nozzle }\end{array}$ & Primary component \\
\hline $\begin{array}{l}\text { 3. Wire support } \\
\text { Piston }\end{array}$ & 4.7 & S.S. & Good & $\begin{array}{l}\text { Close tolerance } \\
\text { machining to minimize } \\
\text { friction }\end{array}$ & Minimum & $\begin{array}{l}\text { Mandatory for } \\
\text { anchoring poison } \\
\text { wires }\end{array}$ \\
\hline 4. Outer Ejection Tube & 26.2 & S.S. & Good & $\begin{array}{l}\text { Close toleronce } \\
\text { mochining required }\end{array}$ & $\begin{array}{l}\text { Structural and } \\
\text { mechanical tests }\end{array}$ & $\begin{array}{l}\text { Required to eject } \\
\text { system independently }\end{array}$ \\
\hline 5. Inner Locking tube & 14.4 & S.S. & Good & Some as above & Same as above & $\begin{array}{l}\text { Locks system refainer } \\
\text { fingers }\end{array}$ \\
\hline $\begin{array}{l}\text { 6. Throot Locking } \\
\text { Fingers }\end{array}$ & 5.5 & 5.5. & Good & $\begin{array}{l}\text { Contour surface to } \\
\text { match nozzle tubes will } \\
\text { be difficult }\end{array}$ & Minimum & $\begin{array}{l}\text { Retains system and } \\
\text { wires in ploce until } \\
\text { ejection }\end{array}$ \\
\hline 7. Flexible Podding & 1.2 & $\begin{array}{l}\text { Siliconized } \\
\text { Rubber }\end{array}$ & Fair & $\begin{array}{l}\text { Molding problems and } \\
\text { temperature effects }\end{array}$ & $\begin{array}{l}\text { Extensive environ- } \\
\text { mental testing to } \\
\text { determine flexibility }\end{array}$ & $\begin{array}{l}\text { Protects nozzle } \\
\text { coolont tubes }\end{array}$ \\
\hline $\begin{array}{l}\text { 8. System Levers } \\
\text { and Locks }\end{array}$ & 0.7 & S.S. & Good & & Minimum & \\
\hline $\begin{array}{l}\text { 9. Ejection Springs, } \\
\text { Housing and } \\
\text { Associated Hardware }\end{array}$ & 18.9 & $\begin{array}{l}\text { Piono wire } \\
\text { and S.S. }\end{array}$ & Good & $\begin{array}{l}\text { Installation and retention } \\
\text { problems }\end{array}$ & $\begin{array}{l}\text { Uniform load release } \\
\text { mechan ism tests }\end{array}$ & $\begin{array}{l}\text { Provides force to } \\
\text { eject system }\end{array}$ \\
\hline $\begin{array}{l}\text { 10. System Brace and } \\
\text { Support Structure }\end{array}$ & 13.8 & Aluminum & Excellent & & & $\begin{array}{l}\text { Include interface } \\
\text { with nozzle wall }\end{array}$ \\
\hline $\begin{array}{l}\text { 11. Pull Tape, Pulley and } \\
\text { Aseociated Hardware }\end{array}$ & 0.9 & $\begin{array}{l}\text { Elgiloy tope, } \\
\text { aluminum } \\
\text { pulley }\end{array}$ & Excellent & Atrochment problems & Minimum & $\begin{array}{l}\text { Attached to piston } \\
\text { for extracting poison } \\
\text { wires }\end{array}$ \\
\hline $\begin{array}{l}\text { 12. Accumulator and } \\
\text { Support Structure }\end{array}$ & 19.8 & $\begin{array}{l}\text { S.S. and } \\
\text { Aluminum }\end{array}$ & Good & $\begin{array}{l}\text { Actuation and contral } \\
\text { problems }\end{array}$ & $\begin{array}{l}\text { Dynamic and environ } \\
\text { mental experiments }\end{array}$ & $\begin{array}{l}\text { Provides pressure to } \\
\text { actuate air motor }\end{array}$ \\
\hline $\begin{array}{l}\text { 13. Air Mator and } \\
\text { Support Structure }\end{array}$ & 13.6 & $\begin{array}{l}\text { Special } \\
\text { design motor } \\
\text { and aluminum } \\
\text { supports }\end{array}$ & Good & $\begin{array}{l}\text { Similar systems opera- } \\
\text { tive in space required } \\
\text { close cooperation with } \\
\text { vendor }\end{array}$ & $\begin{array}{l}\text { Dynamic and environ } \\
\text { mental integrity tests }\end{array}$ & $\begin{array}{l}\text { Actuates the pull } \\
\text { tape for pulling } \\
\text { poison wires. }\end{array}$ \\
\hline $\begin{array}{l}\text { 14. Piston Redundant } \\
\text { System }\end{array}$ & 2.4 & S.S. & Good & $\begin{array}{l}\text { Temp. and dynamic } \\
\text { conditions can trigger } \\
\text { system }\end{array}$ & $\begin{array}{l}\text { Environmental and } \\
\text { dynamic tests }\end{array}$ & $\begin{array}{l}\text { Provides alternate } \\
\text { wire extroction } \\
\text { method }\end{array}$ \\
\hline $\begin{array}{l}\text { 15. Arming cylinder and } \\
\text { miscellaneous clutch } \\
\text { and mechan isms }\end{array}$ & 7.1 & $\begin{array}{l}\text { S.S. } \\
\text { Aluminum }\end{array}$ & Good & $\begin{array}{l}\text { Systems actuation and } \\
\text { integration }\end{array}$ & $\begin{array}{l}\text { Environmental and } \\
\text { dynamic tests }\end{array}$ & $\begin{array}{l}\text { Provides locking and } \\
\text { releasing mechonisms }\end{array}$ \\
\hline 16. Prolective foom & 14.4 & Polyurethane & & & $\begin{array}{l}\text { Flexibility and } \\
\text { compression tests }\end{array}$ & $\begin{array}{l}\text { Protects nozzle } \\
\text { structure }\end{array}$ \\
\hline
\end{tabular}




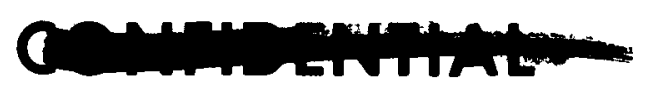

(2) Astronuclear

WANL-TNR-206

TABLE 7-1 (Continued)

\section{REMARKS}

1. Mechanical lock and release provide high reliability - latest wire pull test data indicates a need for $50 \%$ of preliminary estimated loads.

2. Termination and structure of wire-bundling in convergent portion of nozzle requires definition.

3. Provisions for minimum friction using Teflon sliding surfaces makes this highly reliable.

4. Tube locks and ejects system when required.

5. Provides the actuating force to unlock outer ejection tube.

6. Most suitable area at nozzle throat for system retention.

7. Problems may arise in ejection sequence where pads could interfere and cause deceleration of system.

8. Locks and releases system for ejection in space.

9. Uniform release is a must to prevent hang up during release.

10. Maintains axial and lateral stability of system.

11. High strength Elgiloy reduces weight.

12. Carried to make system completely independent of reactor systems.

13. Proven principles will allow for motor design at reduced weight.

14. Safety feature if accumulator system air motor system fails.

15. Chronological arming and release of actuation systems must be coordinated to obtain optimum ejection speeds. 
TABLE $\quad 7-2$

ACPS QUALITATIVE RELIABILITY EVALUATION OPERATION SECTION

\begin{tabular}{|c|c|c|c|}
\hline EFFECTS OF SEPARATION & UNIFORMITY OF OPERATION & CONSTRUCTION & COMPLEXITY \\
\hline $\begin{array}{l}\text { Mechan ical release utilizing spring } \\
\text { forces is a good positive method of } \\
\text { separation. } \\
\text { VIBRATION EFFECTS }\end{array}$ & $\begin{array}{l}\text { 1) Wire extraction procedure very } \\
\text { positive and smooth } \\
\text { 2) Ejection sequence depends highly } \\
\text { upon successful mechanism opera- } \\
\text { tion when required. } \\
\text { ADJUSTMENTS }\end{array}$ & $\begin{array}{l}\text { 1) Close tolerance components are } \\
\text { required to maintain rigid support } \\
\text { 2) Close tolerances required for } \\
\text { ejection sequence to be success- } \\
\text { fully completed. } \\
\text { OTHER INERTIAL FORCES }\end{array}$ & $\begin{array}{l}\text { 1) Major consideration is to } \\
\text { design the mechanism that } \\
\text { can be assembled into a } \\
\text { workable system under the } \\
\text { required conditions. } \\
\text { 2) The forces, flexibility, } \\
\text { weight, timing, and actua- } \\
\text { ting mechanisms must be all } \\
\text { coordinated to a precise } \\
\text { degree. } \\
\text { HAZARDS }\end{array}$ \\
\hline $\begin{array}{l}\text { 1) System vibration can bind } \\
\text { levers and locks. } \\
\text { 2) Misalignment of system can } \\
\text { prevent ejection. } \\
\text { 3) Piston lock pins can prevent } \\
\text { wire extraction. }\end{array}$ & $\begin{array}{l}\text { 1) Alignment fixtures must be used } \\
\text { during installation. } \\
\text { 2) Component design should allow } \\
\text { for adjustment. }\end{array}$ & Not Significant. & $\begin{array}{l}\text { 1) Capable of preventing } \\
\text { reactor criticality under } \\
\text { all credible accident } \\
\text { conditions. }\end{array}$ \\
\hline
\end{tabular}


TABLE 7-2 (Continued)

FAILURE MODES

1) Tape failure unlikely-- high margin of sofety.

2) Malfunction of sensing or actuating control mechanism-faulty design fabrication, installation or calibration.

3) Faulty installation of system components difficult; accessibility and visibility poor in nozzle throat. Inspection is difficult.

4) Flexible pad freezing when contacted by Liquid Hydrogen-development and test program required.

5) System ejection failure due to binding of lock pins, pressure controls on accumulator or air motor, insufficient velocity generated by tube mass and release lever binding. Requires careful design, manufacturing and installation.

6) Accidental initiation of ejection sequence due to vibratory or acceleration forces on actuating mechanism. Requires careful design and experimental testing.

7) Component structural failures-proper analysis and choice of material.

INTERACTIONS

TEMPERATURE EFFECTS

PRESSURE EFFECTS

) Electronic telemetering equipment must be integrated with the overall sequential operation.

Extensive development and testing required.
1) Low temperature effects on structural components can cause brittleness and failure.

2) Lubrication problems on moving mechanism at low temperature.

3) Design must accomodate contraction of materials due to low temperature.
1) Effects on accumulator controls and velocity at which gas is released must be considered.

2) Effect of pressure on air motor operation. This can be controlled by design. 


\begin{abstract}
APPENDIX A
The pull test mechanism of figure $A-1$ was constructed to provide a means for applying and determining wire withdrawal forces. Following the insertion of flexible wire bundles into fuel clusters, as shown in both figures $A-1$ and $A-2$, air from the cylindrical steel "bottle" was permitted to flow through the hand-operated valve to drive the pneumatic motor. A flexible steel tape winding up on a spool fastened to the pneumatic motor shaft caused the retractor head to move through the guide tube toward the winding spool. Since the wire bundles were connected to the retractor head, the flexible wires were withdrawn from the fuel clusters.

A transducer load cell located between the flexible steel tape and the retractor head provided a signal proportional to the withdrawal force. Upon amplification, this signal produced an ordinate or $Y$-axis force deflection of the pen trace on the $X-Y$ recorder. A distance transducing potentiometer which was connected by means of a wire to a point on the steel tape near the retractor head, provided a signal proportional to the withdrawal distance. This was employed to deflect the pen in the abscissa or X-axis direction.

A Program Sheet, figure A -2, provided a record of wire bundle locations for each withdrawal test. Cluster locations of this figure are presented as the view an observer would see looking into the nozzle in a direction upstream of the propellant discharge. Cluster numbers 1 through 43 were arbitrarily assigned for reference purposes. Table A-1 lists the location of wires for the eight tests that were conducted.

The $X-Y$ recorder trace for Test 7 is shown in figure $A-1$. This trace is a good representation of the patterns of force behavior which were common to all tests. During a wire withdrawal, it was noted that the sequence of the various types of behavior could be segregated into distinct portions (zones) of the wire withdrawal distance. The various patterns of behavior
\end{abstract}

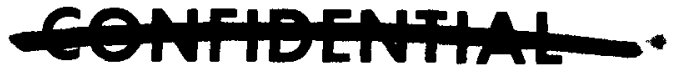




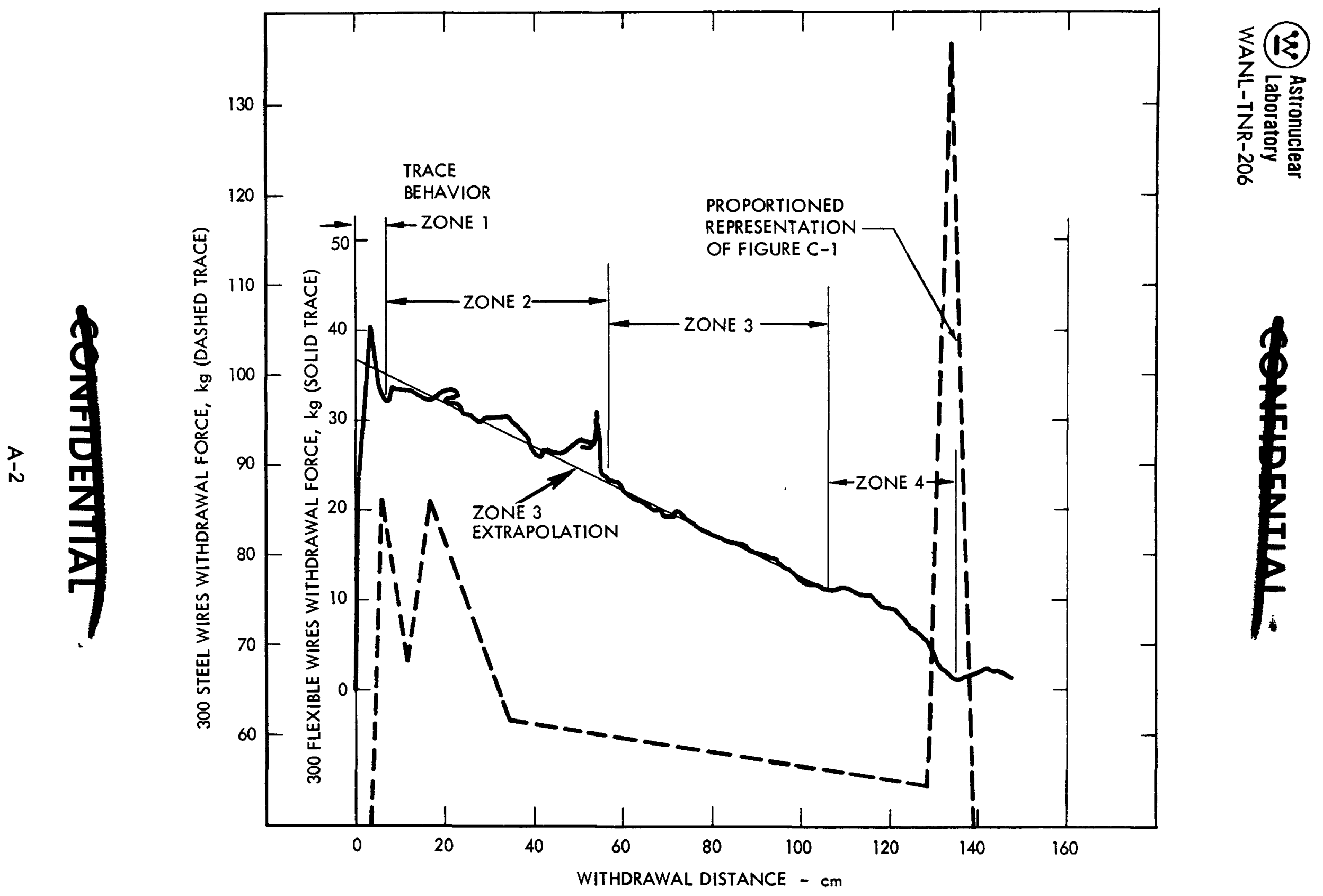

Figure A-1. Typical Wire Withdrawal Recorder Tract - Test No. 7 
TEST NO.

DATE
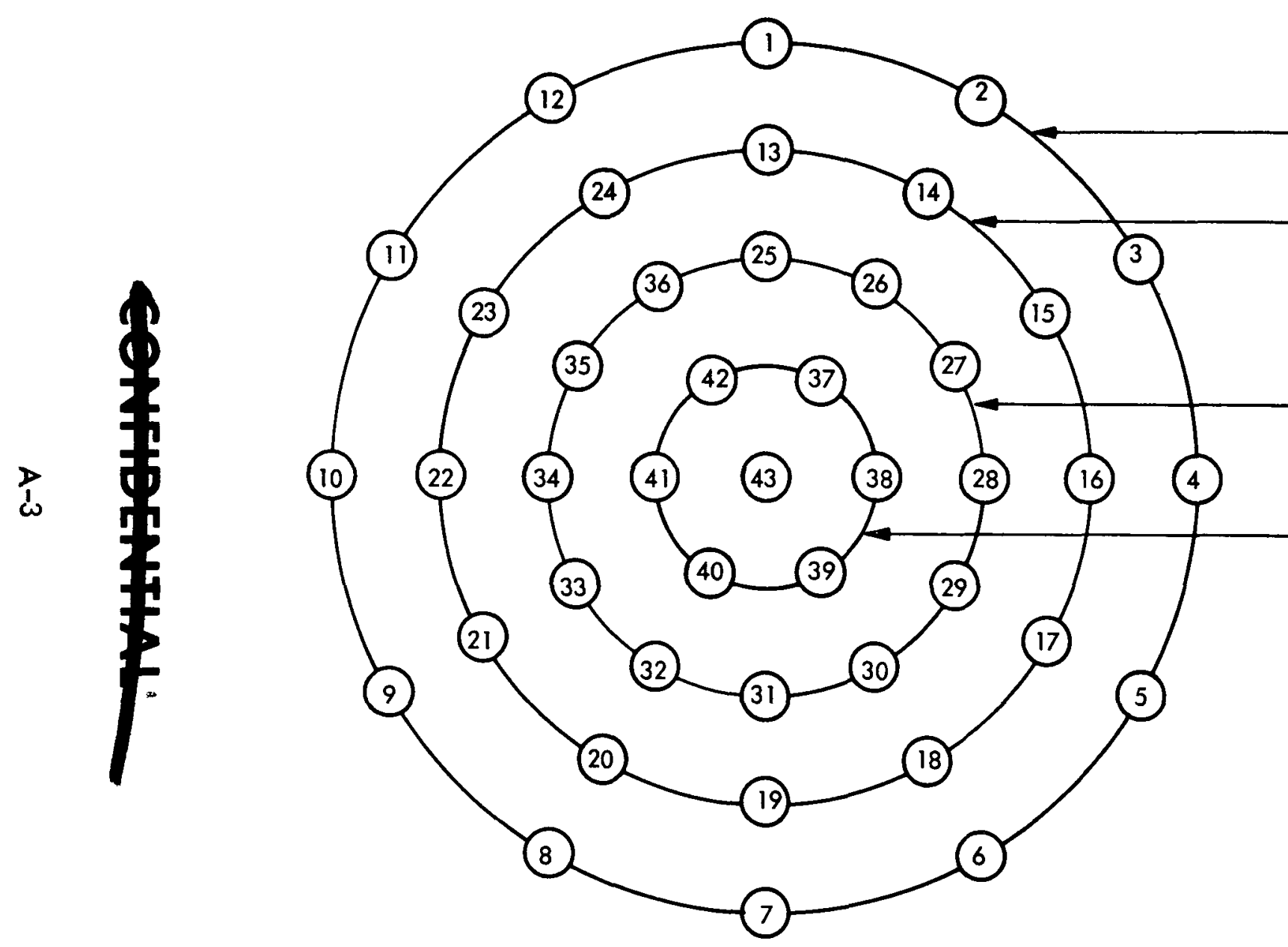

ONLY CLUSTERS DESIGNATED ARE TO BE USED. $82.5 \mathrm{CM}$. DIA. 61.0 CM. DIA. 40.7 CM. DIA. 20.3 CM. DIA.

NO. OF TESTS REQUIRED TIME PERIOD FOR TEST MATERIAL BEING TESTED

NO. OF CLUSTERS NO. OF WIRES PER CLUSTER TOTAL NO. OF WIRES

Figure A-2. Poison Wire Pull Test Program 
TABLE $A-1$

INSTALLATION OF FLEXIBLE WIRES FOR WITHDRAWAL TESTS

\begin{tabular}{|c|c|c|c|c|c|}
\hline $\begin{array}{c}\text { TEST } \\
\text { NUMBER }\end{array}$ & $\begin{array}{c}\text { TOTAL } \\
\text { WIRES } \\
\text { WITHDRAWN }\end{array}$ & $\begin{array}{c}\text { NUMBER } \\
\text { OF } \\
\text { CLUSTERS }\end{array}$ & $\begin{array}{l}\text { NUMERICAL } \\
\text { DESIGNATION } \\
\text { OF CLUSTERS } \\
\text { UTILIZED * }\end{array}$ & $\begin{array}{l}\text { CLUSTER } \\
\text { DIAMETER } \\
\mathrm{cm}\end{array}$ & $\begin{array}{l}\text { WIRES } \\
\text { INS ERTED } \\
\text { IN EACH } \\
\text { CLUSTER }\end{array}$ \\
\hline 1 & 120 & 12 & $1-12$ & 82.5 & 10 \\
\hline 2 & 120 & 12 & $13-24$ & 61.0 & 10 \\
\hline 3 & 120 & 12 & $25-36$ & 40.7 & 10 \\
\hline \multirow[t]{2}{*}{4} & \multirow[t]{2}{*}{70} & 6 & $37-42$ & 20.3 & 10 \\
\hline & & 1 & 43 & Center & 10 \\
\hline \multirow[t]{3}{*}{5} & \multirow[t]{3}{*}{360} & 12 & $1-12$ & 82.5 & 10 \\
\hline & & 12 & $13-24$ & 61.0 & 10 \\
\hline & & 12 & $25-36$ & 40.7 & 10 \\
\hline \multirow[t]{4}{*}{6} & \multirow[t]{4}{*}{360} & 8 & $2,3,5,6,8,9$, & 82.5 & 10 \\
\hline & & 4 & $1,4,7,10$ & 82.5 & 20 \\
\hline & & 12 & $13-24$ & 61.0 & 10 \\
\hline & & 8 & $\begin{array}{c}25,27-29,31, \\
33-35\end{array}$ & 40.7 & 10 \\
\hline \multirow[t]{4}{*}{7} & \multirow[t]{4}{*}{300} & 12 & $1-12$ & 82.5 & 10 \\
\hline & & 9 & $13,15-17,19$, & 61.0 & 10 \\
\hline & & 6 & $25,27,29,31$, & 40.7 & 10 \\
\hline & & 3 & $37,39,41$ & 20.3 & 10 \\
\hline \multirow[t]{4}{*}{8} & \multirow[t]{4}{*}{200} & 8 & $1,3-5,7,9-11$ & 82.5 & 10 \\
\hline & & 6 & $13,15,17,19$, & 61.0 & 10 \\
\hline & & 4 & $25,28,31,34$ & 40.7 & 10 \\
\hline & & 2 & 38,41 & 20.3 & 10 \\
\hline
\end{tabular}

* Cluster numbers correspond to those shown in Figure $A=2$ 
are delineated on the trace of figure $A-1$.

Zone 1 is the wire withdrawal distance in which the applied force overcomes wire resistance due to static friction. The static friction occurs through a distance of approximately $5 \mathrm{~cm}$. The wire and the bundle are not loaded by the pulling force simultaneously; thus, wires near the center of the reactor core and directly in line with the extraction mechan ism start exit movement immediately as removal forces are applied. Wires near the outer periphery of the core are somewhat delayed in extraction due to the angle at which the force is applied and to bending in the bundle section of the wires. This zone is graphically illustrated in all test plots by the high initial peak loading and by a rapid drop to sliding friction conditions.

Zone 2 is typically illustrated on test number 7 shown in figure A-1. It is characterized by the relatively small erratic fluctuation in the sliding frictional forces shown on the recording plot. This zone occurs immediately following the initial peak load and continues to an extraction distance of $55 \mathrm{~cm}$. This fluctuation is caused by the irregular cross-sectional configuration of the bundle portion of the wires rubbing the retaining ring at the simulated nozzle throat. Zone 2 terminates as soon as the flexible wires reach the initial portion of the extraction plot. The bundling arrangement for these wires was designed to give a general geometrical configuration for the pull test. It is possible to eliminate this erratic force characteristic in the final bundling design. The force required in this zone is dependent upon the rigidity of the bundling. The bundling in turn would be determined by test analysis of the force required to maintain the wires in the reactor during launch of the vehicle.

Zone 3 of the plot occurs when the only frictional forces present are those of the wires rubbing the retaining ring during their extraction. This zone extends from the end of zone 2 to approximately $105 \mathrm{~cm}$ of pull head movement. It is characterized by the smoothest portion of the force plot and shows that the frictional force connected with the wire extraction is a linear function of the length of wire remaining in the reactor core.

With the establishment of the inverse relationship between the length of poison wires in the core and the sliding frictional forces required for extraction, a straight line extrapolation was drawn back to the origin of the plot in figure A-1. This line should closely approximate

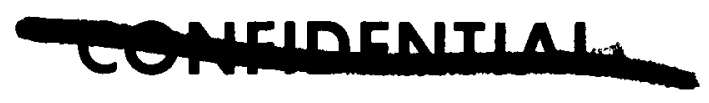


(2)

Astronuclear

Laboratory

WANL-TNR-206

the maximum sliding frictional forces involved in the extraction of the wires. For test No. 7, this force was approximately $37 \mathrm{~kg}$. The peak recorded force was $31 \mathrm{~kg}$ or about $5 \mathrm{~kg}$ required to overcome the static frictional forces. This is a 13.5 percent increase over the sliding frictional forces. This graphical procedure established at lower limits can be used to determine the maximum resistance for other arrangements of wires. The apparent value of maximum sliding friction resistance occurring at the initiation of withdrawal would always be less than the maximum force required to brake static friction. Although the latter type of peak force actually occured near the initiation of withdrawal in zone 1, it was delayed since movement does not begin simultaneously for all the wires.

Zone 4 extends from the end of zone 3 to the completion of the wire extraction. An increase in the bending moment occurs as the wires near the exit of the reactor core due to the angle at which the outer wires are extracted. The wires used for the pull tests were of a uniform length and caused the wires of the outer radius to exit first. This uneven exit sequence was the reason for the force variations evidenced over some distance of the extraction plot of zone 4.

Indications similar in nature to those of zones 1 and 4 have been reported in Reference 2. In this reference, the information pertained to forces produced in pulling stainless steel wires from an arrangement of fuel clusters.

Figure C-1 of Reference 2 showed a typical trace obtained upon pull testing 555 stainless steel wires. The connected dashed lines superimposed on figure A-1 are a simplified representation of figure $\mathrm{C}-1$ which has been proportioned from 555 to 300 wires. These dashed lines connect prominences of the solid line trace in Reference 2 which have been multiplied by 300/ 555 to proportion the values to 300 wires.

These proportioned values can be compared directly with the trace of figure $A-1$ since the number of wires represented is the same. The comparison especially illustrates the dramatic reduction of forces in zone 4 resulting from the use of the flexible poison wire.

In comparison to the behavior in zones 1, 2, and 4, the pull force pattern for zone 3 of each test trace was apparently produced by a minimum number of different influences acting upon the wires. The resistance and behavior exhibited in zone 3 was attributed to the sliding 
friction between the wires and fuel element coolant channel and between the peripheral wires and the circular lip at the end of the guide tube, figure A-3.

Table A-2 lists the values obtained for each withdrawal test which indicated a significance with respect to test record pen-trace zones $1,2,3$, and 4 .

Test 7 provided data for a withdrawal with the largest number of wires approximating a uniform wire distribution throughout the cluster arrangement cross section. Since this distribution is analogous to that presumed for the reactor, it was desirable to use test 7 as the bas is for determining withdrawal force requirements of the ACPS.

To establish the degree of uncertainty of test 7 results, various combinations of results from the other tests were compared with the appropriate value of test 7 . Obtaining consistency on the basis of the reasons previously stated, the specific type of value extracted from the different tests is the derived maximum force due to sliding friction, table A-2. The combination of test result values are adjusted to a 300 wire basis to facilitate comparison with the test 7 value.

Results of some of the tests are related to a particular radius of withdrawal and obtained on the basis of a different number of wires than that inserted at the particular radius for withdrawal in test 7. To sum a value of this nature into the total force to be compared, it must be multiplied by the ratio of the number of test 7 wires at the particular radius to the number of wires withdrawn at the time the value under revision was obtained. This manipulation is indicated in table A-3.

Table A-3 provided three comparisons with the desired test 7 value, lines 1, 4, and 9. Line 1 shows extremely close agreement between the test 8 value and the modified test 7 value. This indicates that the measured withdrawal force per wire is not sensitive to the total number of wires removed since the type of distribution of wires in the cluster arrangement cross sections is the same for any two tests compared.

Results of combinations entering values of lines 4 and 9 are respectively 4.1 and 8.1 percent different from the rest 7 value. This agreement is quite reasonable considering that the results of combinations of lines 4 and 9 include an undetermined resistance produced by friction in bending the wire over the guide tube leading edge as shown in figure A-3. This type of

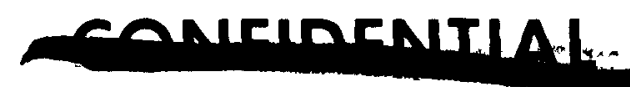




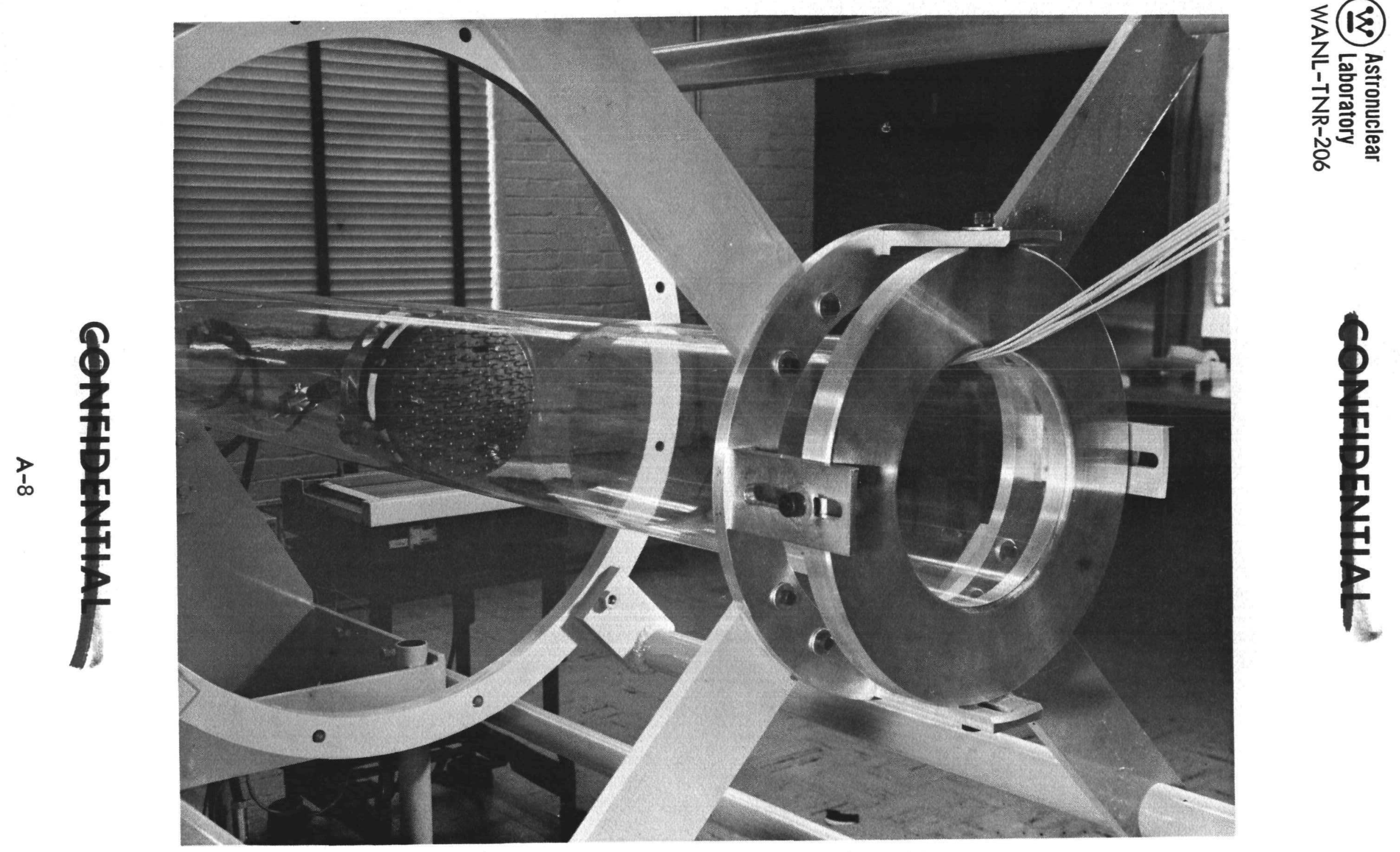

Figure A-3。 Guide Tube Inlet 
TABLE A-2

SIGNIFICANT WITHDRAWAL TEST FORCE VALUES

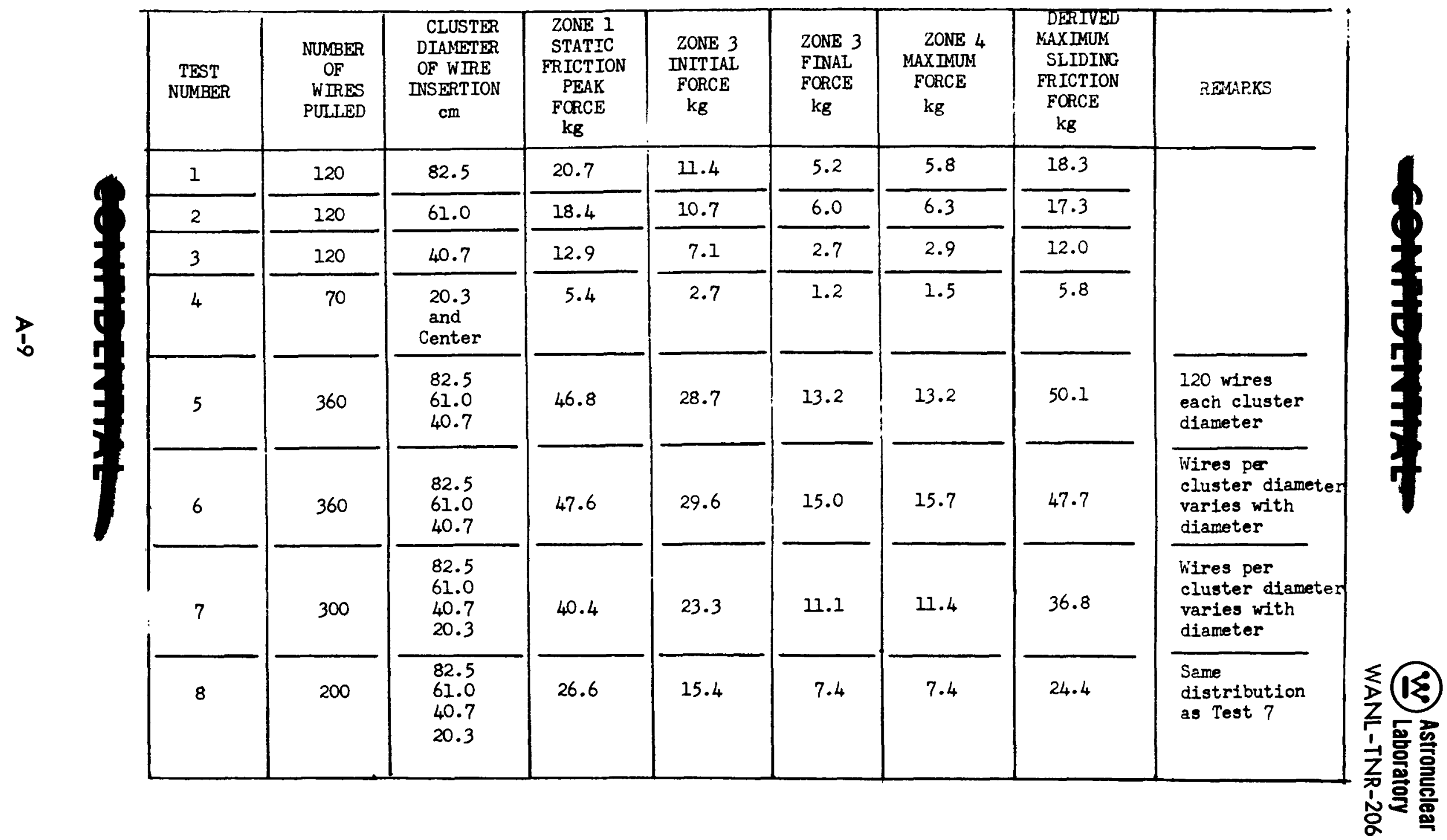


TABLE A-3

CORRELATION OF TEST RESULTS

\begin{tabular}{|c|c|c|c|c|c|c|c|c|c|}
\hline Line & $\begin{array}{c}\text { Test Providing } \\
\text { Derived } \\
\text { Maximum } \\
\text { Sliding } \\
\text { Friction } \\
\text { Force }\end{array}$ & $\begin{array}{c}\text { (A) } \\
\text { Derived } \\
\text { Maximum } \\
\text { Sliding } \\
\text { Friction } \\
\text { Force, } \\
\text { kg }\end{array}$ & $\begin{array}{c}\text { Radius, } \mathrm{R}_{w w}, \\
\text { of } \\
\text { Wire } \\
\text { Withdrawal, } \\
\mathrm{cm}\end{array}$ & $\begin{array}{l}\text { (B) } \\
\text { Wires } \\
\text { at } \\
R_{\text {Ww }} \\
\text { for } \\
\text { (A) }\end{array}$ & $\begin{array}{l}\text { (c) } \\
\text { Wires } \\
\text { at } \\
\mathrm{R}_{\text {ww }} \\
\text { for } \\
\text { Test } 7\end{array}$ & $\begin{array}{c}\text { (D) } \\
\text { Contribution } \\
\text { toward } \\
\text { comparison } \\
\text { Value } \\
=\frac{(A) \times(C)}{(B)} \\
\mathrm{kg}\end{array}$ & $\begin{array}{c}\text { (E) } \\
\text { Test } 7 \\
\text { Value of } \\
\text { (A) to } \\
\text { Compare } \\
\text { with } \\
\text { (D) Summation } \\
\mathrm{kg}\end{array}$ & \begin{tabular}{|c}
$(F)$ \\
Difference, \\
(D) Summation \\
Less \\
$(E)$
\end{tabular} & $\begin{array}{c}\begin{array}{c}\text { Percent } \\
\text { Difference }\end{array} \\
\frac{(E) \times 100}{(E)}\end{array}$ \\
\hline 1 & 8 & 24.4 & $\begin{array}{l}\text { Distribution } \\
\text { same as } \\
\text { Test } 7\end{array}$ & $\begin{array}{l}200 \\
\text { for } 4 \\
\text { radii }\end{array}$ & $\begin{array}{l}300 \\
\text { for } 4 \\
\text { radii }\end{array}$ & $\begin{array}{c}36.6 \\
\text { summation }\end{array}$ & 36.8 & -0.2 & -0.54 \\
\hline 2 & 6 & 47.7 & $\begin{array}{l}\text { Distribution } \\
\text { same as } \\
\text { Test } 7\end{array}$ & $\begin{array}{l}360 \\
\text { for } \\
\text { outer } \\
3 \text { radi }\end{array}$ & $\begin{array}{l}270 \\
\text { for } \\
\text { outer } \\
3 \text { radij }\end{array}$ & 35.8 & -- & -- & -- \\
\hline 3 & 4 & 5.8 & $\begin{array}{l}10.2 \text { and } \\
\text { center } \\
\text { cluster }\end{array}$ & 70 & 30 & 2.5 & - & -- & -- \\
\hline 4 & $6 \& 4$ & - & - & - & - & $\begin{array}{c}38.3 \\
\text { sumation }\end{array}$ & 36.8 & 1.5 & 4.1 \\
\hline 5 & 1 & 18.3 & 41.2 & 120 & 120 & 18.3 & - & -- & -- \\
\hline 6 & 2 & 27.3 & 30.5 & 120 & 90 & 13.0 & - & -- & -- \\
\hline 7 & 3 & 12.0 & 20.4 & 120 & 60 & 6.0 & - & - & -- \\
\hline 8 & 4 & 5.8 & $\begin{array}{l}10.2 \text { and } \\
\text { center } \\
\text { cluster }\end{array}$ & 70 & 30 & 2.5 & - & - & - \\
\hline 9 & $1,2,3,4$ & - & -- & - & - & $\begin{array}{c}39.8 \\
\text { summation }\end{array}$ & 36.8 & 3.0 & 8.1 \\
\hline
\end{tabular}

* See Figure A-2 for pictorial representation and Tables A-1 and A-2 for wire location and distribution. 
resistance existed for test 7 also, but this undetermined resistance varies nonlinearly from combination to combination of results.

That is, the sum of resistance values due to guide tube inlet friction of any of the combinations, line 4 or 9, would not equal the same value for test 7 even if all had been determined. The summing of parts does not equal the total in this situation since the number of wires in contact with the inlet edge of the guide tube remains nearly constant and varies in percentage between large and small numbers of wires withdrawn. Also there is a physical limitation on the number of wires that can seat side-by-side over the inlet edge. The guide tube inlet edge bending resistance probably accounts for most of the force measured in zone 4 of figure $A-1$. 


\section{APPENDIX B}

\section{PAX-C REACTOR CORE, ACPS FLEXIBLE POISON WIRE MEASUREMENTS}

\section{A. INTRODUCTION}

During the performance of the critical experiments conducted on the PAX $C$, a series of measurements were performed to determine the reactivity worths of flexible poison wires in simulated flooded core conditions. The measurements employed flexible poison wires whose composition was boron carbide enriched in the $B^{10}$ isotope to about 87 percent. The wires were fabricated as part of the program to develop an ACPS for the NERVA program.

\section{B. SUMMARY AND CONCLUSIONS}

From the measurements that were obtained with the $B_{4}^{10} C$ wires in various arrays and under various degrees of simulated flooding, it appears that the wires are very capable of preventing an accidental criticality due to core flooding. This can be inferred from figure $B-1$ which shows that with an effective 89.7 percent water flooding in the 000 and A-row clusters, the net reactivity change of the flooded-poisoned region is negative if more than $53 \mathrm{~B}_{4}^{10} \mathrm{C}$ wires are inserted into this region. It was found that the dry worth of the $B_{4}^{10} C$ wires in the 000 cluster was about -5.8 cents per wire which is about 4.3 times as much as the standard $B_{4} C$ poison wire. In a flooded condition (89.4 percent water) the $\mathrm{B}_{4}^{10} \mathrm{C}$ worth in the 000 cluster is between -11.7 and -13.9 cents depending on the number of poison wires in the core.

From the measurements it was also noted that the PAX-C incremental drum worth was reduced from about 7.5 cents per degree at its peak to about 6.9 cents per degree when the 000 and A-row clusters were flooded and poisoned. This is a reduction in the incremental worth of about eight percent.

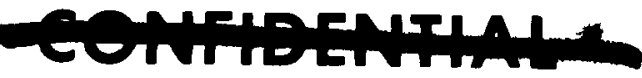


WANL-TNR-206

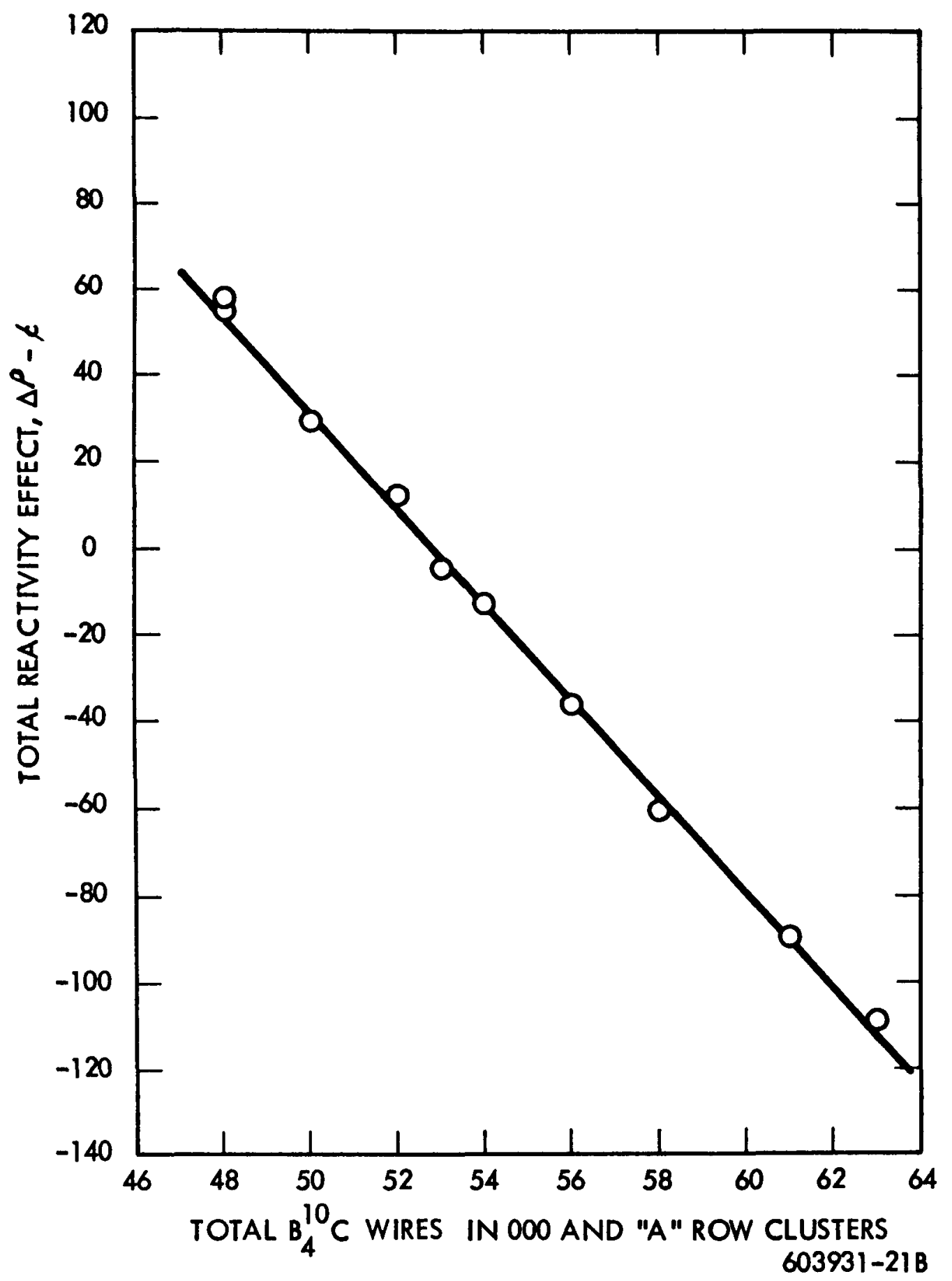

Figure B-1. Effect on Core Reactivity as a Function of Density - PAX-C 


\section{EXPERIMENTAL METHODS AND DETAILS}

In this series of measurements, the reactivity effect on the PAX-C core was determined with various flexible ${ }^{10}{ }_{4}^{10}$ poison wire arrays and for various degrees of simulated core flooding with water. The poison wires used in the measurements were enriched in the $B^{10}$ isotope to approximately 87 percent, and the core flooding was mocked-up using polyethylene rods whose chemical composition was $\mathrm{CH}_{2}$. A description of the flexible poison wires and the polyethylene rods is given in table $B-1$. Only the central region of the core was utilized in these measurements.

The actual measurement techniques employed during the experiment were similar to those used in previous PAX-C reactivity determinations. That is, the reactivity effect produced by the insertion or removal of a known amount of poison and/or polyethylene was measured using the standard period technique. In using this technique, the reactivity change is determined by measuring the reactor period before and after the change and then determining the reactivity change by converting the two period measurements to reactivity values and subtracting.

\section{RESULTS AND ANALYSIS}

The major objective of this series of experiments was to determine the effectiveness of boron carbide poison wire enriched in the $B^{10}$ isotope under various degrees of core flooding by water. Since it was not feasible to mock-up the flooding and poisoning conditions over the entire PAX-C core, a series of experiments were designed wherein flooding conditions were mocked-up in the center section of the PAX-C core, and the effects on the core reactivity studied. In conducting the experiments in this manner, the experimental data obtained can be used as a check of the analytical techniques employed to calculate the degree of subcriticality under various flooding and poisuning conditions.

The set of experiments designed to determine the effectiveness of the flexible $B_{4}^{10} C$ poison wires is given in table B-2. The measurements that were obtained are given in table $B-3$ and cross referenced by "case number" with the original proposed measurements. Table B-3 lists the changes made to the core for each measurement and the reactivity effect produced by that change as well as the cumulative reactivity effect produced during each successive measurement. In order to more clearly visualize the configuration in the core during the measurements 
(W) Astronuclear

WANL-TNR-206

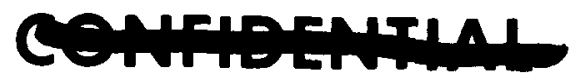

TABLE B-1

\section{DESCRIPTION OF EXPERIMENTAL MATERIALS}

1. Flexible $8_{4}^{10} \mathrm{C}$ Poison Wires

a. Poison wire cross section and moterials:

Given below is a cross section of the flexible poison wire identifying the materials of construction and the various cross-sectional dimensions.

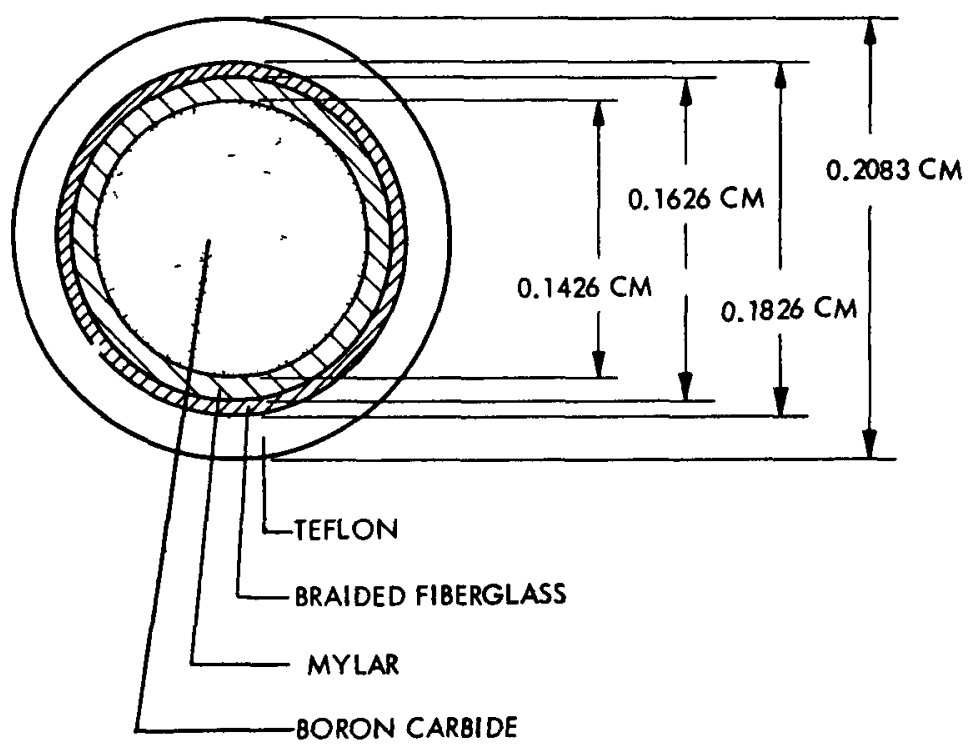

$610730-4$ A

b. Other physical and chemical properties of the flexible poison wires:

1) Average $\mathrm{B}_{4}^{10} \mathrm{C}$ density $1.87 \mathrm{gms} / \mathrm{cc}$

2) Boron content $77 \%$

3) $B^{10}$ enrichment $87 \%$

4) $B^{10}$ form - Sintered rod

Average O.D. of $\mathrm{B}_{4} \mathrm{C}$ rod prior to sintering $-0.1427 \mathrm{~cm}$

5) Overall average length of wire $135.84 \mathrm{~cm}$

6) Average weight of assembled wire $9.32 \mathrm{gms}$ (based on the measured weight of 20 wires)

7) Average weight of $\mathrm{B}_{4}^{10} \mathrm{C}$ in wire $4.06 \mathrm{gms}$

2. Polyethylene Rods

Given below are the mojor physical properties of the polyethylene rods:
Average density of rods
$0.96 \mathrm{gms} / \mathrm{cc}$
$O D$ of rods
$0.218 \mathrm{~cm}$
Length of rods
$132.1 \mathrm{~cm}$
Chemical composition
$\mathrm{CH}_{2}$ 
TABLE B-2

$\mathrm{B}_{4}^{10} \mathrm{C}$ POISON WIRE WORTH

MEASUREMENTS ON PAX-C

\begin{tabular}{|c|c|c|c|c|c|c|}
\hline \multirow{2}{*}{$\begin{array}{l}\text { Case } \\
\text { Number }\end{array}$} & \multicolumn{2}{|c|}{$\mathrm{B}^{10} \mathrm{C}$ Wires/Element } & \multicolumn{2}{|c|}{$\mathrm{CH}_{2}$ Rods/Element } & \multicolumn{2}{|c|}{ Totals } \\
\hline & 000 & A Row & 000 & A Row & $\mathrm{B}_{4}^{10} \mathrm{C}$ & $\mathrm{CH}_{2}$ \\
\hline 1 & 1 & 0 & 18 & 0 & 6 & 108 \\
\hline 2 & $1-1 / 3$ & 0 & $17-2 / 3$ & 0 & 8 & 106 \\
\hline 3 & $1-1 / 2$ & 0 & $17-1 / 2$ & 0 & 9 & 105 \\
\hline 6 & $1-1 / 2$ & $1-1 / 2$ & $17-1 / 2$ & $17-1 / 2$ & 63 & 735 \\
\hline 7 & 0 & $1-1 / 2$ & $17-1 / 2$ & $17-1 / 2$ & 54 & 735 \\
\hline 8 & 0 & $1-1 / 2$ & 0 & $17-1 / 2$ & 54 & 630 \\
\hline 9 & $1-1 / 3$ & $1-1 / 3$ & $17-2 / 3$ & $17-2 / 3$ & 56 & 742 \\
\hline 10 & 0 & $1-1 / 3$ & $17-2 / 3$ & $17-2 / 3$ & 48 & 742 \\
\hline 11 & 0 & $1-1 / 3$ & 0 & $17-2 / 3$ & 48 & 636 \\
\hline
\end{tabular}


TABLE B-3

$\mathrm{B}_{4}^{10} \mathrm{C}$ MEASUREMENTS IN PAX-C

\begin{tabular}{|c|c|c|c|c|c|c|c|c|c|c|c|c|}
\hline \multirow{3}{*}{$\begin{array}{l}{ }_{4}^{10} \mathrm{C} \text { and } \mathrm{CH}_{2} \\
\text { Changes to } \mathrm{Core}\end{array}$} & \multirow{3}{*}{$\begin{array}{l}\text { Cose } \\
\text { No. }\end{array}$} & \multirow{2}{*}{\multicolumn{2}{|c|}{$\begin{array}{c}{ }_{4}^{10} \mathrm{C} \text { Wires } \\
\text { Per } \\
\text { Element } \\
\end{array}$}} & \multirow{2}{*}{\multicolumn{2}{|c|}{$\begin{array}{c}\mathrm{CH}_{2} \text { Rods } \\
\text { Per } \\
\text { Element }\end{array}$}} & \multirow{2}{*}{\multicolumn{2}{|c|}{$\begin{array}{c}\text { Total } \\
\text { Core } \\
\text { Inventory } \\
\end{array}$}} & \multicolumn{2}{|c|}{$\begin{array}{c}\text { Core Reactivity } \\
\text { Changes - } x \\
\end{array}$} & \multicolumn{2}{|c|}{$\begin{array}{c}\text { Unit Worths } \\
\end{array}$} & \multirow{3}{*}{$\begin{array}{l}\text { Degree of } \\
\text { Flooding } \\
\text { Percent } \\
\end{array}$} \\
\hline & & & & & & & & This & & & & \\
\hline & & 000 & A-Row & $\infty 00$ & A-Row & ${ }_{4}^{10} \mathrm{C}$ & $\mathrm{CH}_{2}$ & Step & Toral & ${ }_{4}^{110} \mathrm{C}$ & $\mathrm{CH}_{2}$ & \\
\hline Bosepoint & Bose & 0 & $\mathbf{0}$ & 0 & 0 & 0 & 0 & 0 & 0 & -- & -- & $\cdots$ \\
\hline Add $6 \mathrm{~B}_{4}^{10} \mathrm{C}$ to 000 & & 1 & 0 & 0 & 0 & 6 & 0 & $-35.6 \pm 1.1$ & $-35.6 \pm 1.1$ & $-5.9 \pm 0.2$ & --- & 0 \\
\hline $\begin{array}{l}\text { Remove } 3 \mathrm{~B}_{4}^{10} \mathrm{C} \\
\text { from } 000\end{array}$ & & $1 / 2$ & 0 & 0 & 0 & 3 & 0 & $17.3 \pm 0.3$ & $-18.3 \pm 1.2$ & $-5.8 \pm 0.1$ & --- & 0 \\
\hline $\begin{array}{l}\text { Add } 3 \mathrm{~B}_{4}^{10} \mathrm{C} \text { and } \\
\mathrm{CH}_{2} \text { to } 000\end{array}$ & & 1 & 0 & 9 & 0 & 6 & 54 & $13.3 \pm 0.3$ & $-5.0 \pm 0.8$ & --- & $m$ & 44.6 \\
\hline Add $27 \mathrm{CH}_{2}$ to 000 & & 1 & 0 & $13-1 / 2$ & 0 & 6 & 81 & $+18.5 \pm 0.4$ & $+13.5 \pm 0.9$ & --- & $0.68+0.02$ & 67.0 \\
\hline Add $27 \mathrm{CH}_{2}$ to 000 & 1 & 1 & 0 & 18 & 0 & 6 & 108 & $+19.7 \pm 0.4$ & $33.2 \pm 1.4$ & --- & $0.73 \pm 0.01$ & 89.7 \\
\hline $\begin{array}{l}\text { Romove } 2 \mathrm{~B}_{4}^{10} \mathrm{C} \\
\text { from } 000\end{array}$ & & $2 / 3$ & 0 & 18 & 0 & 4 & 108 & $21.9 \pm 0.4$ & $55.1 \pm 2.0$ & $-11.0 \pm 0.2$ & $\cdots$ & 89.7 \\
\hline $\begin{array}{l}\text { Add } 5 \mathrm{~B}_{4}^{10} \mathrm{C} \text { io } 000 \\
\text { Remove } 3 \mathrm{CH}_{2} \text { from } \\
000\end{array}$ & 3 & $1-1 / 2$ & 0 & $17-1 / 2$ & 0 & 9 & 105 & $-55.0 \pm 1.6$ & $0.1+0.8$ & -- & --- & 89.7 \\
\hline $\begin{array}{l}\text { Remove } 1{ }_{4}^{10} \mathrm{C} \text { from } \\
000 \\
\text { Add } 1 \mathrm{CH}_{2} \text { to } 000\end{array}$ & 2 & $1-1 / 3$ & 0 & $17-2 / 3$ & 0 & 8 & 106 & $10.8 \pm 0.2$ & $10.9 \pm 1.1$ & -- & --- & 89.7 \\
\hline $\begin{array}{l}\text { Remove } 2 \mathrm{~B}_{4}^{10} \mathrm{C} \text { from } \\
000 \\
\text { Add } 2 \mathrm{CH}_{2} \text { to } 000\end{array}$ & 1 & 1 & 0 & 18 & 0 & 6 & 108 & $23.0 \pm 0.5$ & $33.9+1.5$ & --- & -- & 89.7 \\
\hline $\begin{array}{l}\text { Add } 18 \mathrm{~B}_{4}^{10} \mathrm{C} \text { and } \\
210 \mathrm{CH}_{2} \text { to } \mathrm{A} \text { row } \\
\text { Add } 3 \mathrm{~B}_{4}^{10} \mathrm{C} \text { to } 000\end{array}$ & & $1-1 / 2$ & $1 / 2$ & $17-1 / 2$ & $5-5 / 6$ & 27 & 315 & $-38.1 \pm 1.1$ & $-4.2 \pm 0.9$ & -- & --- & --- \\
\hline $\begin{array}{l}\text { Romove } 3 \mathrm{CH}_{2} \text { from } \\
000\end{array}$ & & & & & & & & & & & & \\
\hline $\begin{array}{l}\text { Add } 368_{10}^{10} \mathrm{C} \text { and } \\
420 \mathrm{CH}_{2} \text { to } A \text { row }\end{array}$ & 6 & $1-1 / 2$ & $1-1 / 2$ & $17-1 / 2$ & $17-1 / 2$ & 63 & 735 & $-104.2 \pm 3.0$ & $-108.4 \pm 3.9$ & $\cdots$ & --- & 89.7 \\
\hline $\begin{array}{l}\text { Remove } 2 \mathrm{~B}_{4}^{10} \mathrm{C} \text { from } \\
\text { A row }\end{array}$ & & $1-1 / 2$ & $1-4 / 9$ & $17-1 / 2$ & $17-1 / 2$ & 61 & 735 & $18.5+0.4$ & $-89.9 \pm 3.3$ & $-9.2+0.2$ & $\cdots$ & 89.7 \\
\hline $\begin{array}{l}\text { Remove } 3{ }^{10}{ }_{4}^{10} \mathrm{C} \text { from } \\
\text { A row }\end{array}$ & & $1-1 / 2$ & $1-1 / 3$ & $17-1 / 2$ & $17-1 / 2$ & 58 & 735 & $28.9 \pm 0.6$ & $-61.0 \pm 2.6$ & $-9.6 \pm 0.2$ & $\cdots$ & 89.7 \\
\hline $\begin{array}{l}\text { Remove } 1 \mathrm{~B}_{4}^{10} \mathrm{C} \text { from } \\
000 \\
\text { Romove } 1 \mathrm{~B}{ }_{4}^{10} \mathrm{C} \text { from } \\
\text { A row } \\
\text { Add I } \mathrm{CH}_{2} \text { 10 } 000 \\
\text { Add } 7 \mathrm{CH}_{2} \text { 10 A Row }\end{array}$ & 9 & $1-1 / 3$ & $1-1 / 3$ & $17-2 / 3$ & $17-2 / 3$ & 56 & 742 & $24.5 \pm 0.5$ & $-36.5 \pm 2.0$ & --- & --- & 89.7 \\
\hline $\begin{array}{l}\text { Remove } 3 \mathrm{~B}_{4}^{10} \mathrm{C} \text { from } \\
A \text { row }\end{array}$ & & $1-1 / 3$ & $1-1 / 4$ & $17-2 / 3$ & $17-2 / 3$ & 53 & 742 & $32.1 \pm 0.6$ & $-4.4 \pm 1.1$ & $-10.7 \pm 0.2$ & --- & 89.7 \\
\hline $\begin{array}{l}\text { Remove } 3 \mathrm{~B}_{4}^{10} \mathrm{C} \text { from } \\
\mathrm{A} \text { row }\end{array}$ & & $1-1 / 3$ & $1-1 / 6$ & $17-2 / 3$ & $17-2 / 3$ & 50 & 742 & $33.4 \pm 0.7$ & $29.0 \pm 1.8$ & $-11.1 \pm 0.2$ & --- & 89.7 \\
\hline $\begin{array}{l}\text { Remove } 2 \mathrm{~B}_{4}^{10} \mathrm{C} \text { from } \\
000\end{array}$ & & 1 & $1-1 / 6$ & $17-2 / 3$ & $17-2 / 3$ & 48 & 742 & $25.2+0.5$ & $54.2 \pm 2.3$ & $-12.6 \pm 0.3$ & --- & 89.7 \\
\hline Add $6 \mathrm{CH}_{2}$ to $A$ row & & 1 & $1-1 / 6$ & $17-2 / 3$ & $17-5 / 6$ & 48 & 748 & $3.7 \pm 0.1$ & $57.9 \pm 2.4$ & --- & $0.62 \pm 0.01$ & 89.7 \\
\hline
\end{tabular}


TABLE B-3 (Continued)

\begin{tabular}{|c|c|c|c|c|c|c|c|c|c|c|c|c|}
\hline \multirow{2}{*}{$\begin{array}{l}{ }_{8}^{10}{ }_{4} \mathrm{C} \text { and } \mathrm{CH}_{2} \\
\text { Changes to Core }\end{array}$} & \multirow[b]{2}{*}{$\begin{array}{l}\text { Cose } \\
\text { No. }\end{array}$} & \multicolumn{2}{|c|}{$\begin{array}{c}{ }^{10} \mathrm{C} \text { Wires } \\
\text { Por } \\
\text { Element }\end{array}$} & \multicolumn{2}{|c|}{$\begin{array}{l}\mathrm{CH}_{2} \text { Rods } \\
\text { Por } \\
\text { Eloment }\end{array}$} & \multicolumn{2}{|c|}{$\begin{array}{c}\text { Total } \\
\text { Core } \\
\text { Inventory } \\
\end{array}$} & \multicolumn{2}{|c|}{$\begin{array}{c}\text { Core Reoctivity } \\
\text { Changes - }< \\
\end{array}$} & \multicolumn{2}{|c|}{ Unit Worthe } & \multirow{2}{*}{$\begin{array}{l}\text { Degroe of } \\
\text { Flooding } \\
\text { Percont }\end{array}$} \\
\hline & & 000 & A-Row & $\frac{E}{000}$ & A Row & & $\frac{\text { tory }}{\mathrm{CH}_{2}}$ & $\begin{array}{l}\text { This } \\
\text { Step }\end{array}$ & Total & ${ }_{B}^{10} \mathrm{C}$ & $\mathrm{CH}_{2}$ & \\
\hline $\begin{array}{l}\text { Add } 6 \mathrm{~B}_{4}^{10} \mathrm{C} \text { to } \mathrm{A} \text { row } \\
\text { Remove } 6 \mathrm{CH} \text { from } \\
\text { A row }{ }_{10}^{10} \mathrm{C} \text { to } 000 \\
\text { Add } 24_{4} \mathrm{C} \text {. }\end{array}$ & & $1-1 / 3$ & $1-1 / 3$ & $17-2 / 3$ & $17-2 / 3$ & 56 & 742 & $-94.5 \pm 2.8$ & $-36.6 \pm 2.1$ & --- & --- & 89.7 \\
\hline $\begin{array}{l}\text { Remove } 284_{4}^{10} \mathrm{C} \\
\text { from } 000\end{array}$ & & 1 & $1-1 / 3$ & $17-2 / 3$ & $17-2 / 3$ & 54 & 742 & $23.4 \pm 0.5$ & $-13.2 \pm 1.4$ & $-11.7 \pm 0.2$ & --- & 89.7 \\
\hline $\begin{array}{l}\text { Remove } 2{ }_{B}^{10} C \mathrm{C} \\
\text { from } 000\end{array}$ & & $2 / 3$ & $1-1 / 3$ & $17-2 / 3$ & $17-2 / 3$ & 52 & 742 & $25.3 \pm 0.5$ & $12.1 \pm 1.4$ & $-12.7 \pm 0.2$ & --- & 89.7 \\
\hline $\begin{array}{l}\text { Remove } 2 \mathrm{~B}_{4}^{10} \mathrm{C} \\
\text { from } 000\end{array}$ & 10 & 0 & $1-1 / 3$ & $17-2 / 3$ & $17-2 / 3$ & 48 & 742 & $27.8 \pm 0.6$ & $66.7 \pm 2.7$ & $-13.9+0.3$ & $\cdots$ & 89.7 \\
\hline $\begin{array}{l}\text { Remove } 106 \mathrm{CH}_{2} \\
\text { from } 000\end{array}$ & 11 & 0 & $1-1 / 3$ & 0 & $17-2 / 3$ & 48 & 636 & $-72.0 \pm 2.2$ & $-5.3 \pm 1.3$ & & $0.68+0.02$ & -- \\
\hline $\begin{array}{l}\text { Add } 106 \mathrm{CH}_{2} \text { to } 000 \\
\text { Romove } 6 \mathrm{CH}_{2} \text { from } \\
\text { A row } \\
\text { Add } 6 \mathrm{~B}_{4}^{10} \mathrm{C} \text { to A row }\end{array}$ & 7 & 0 & $1-1 / 2$ & $17-2 / 3$ & $17-1 / 2$ & 54 & 736 & $2.2 \pm 0.1$ & $3.1 \pm 1.2$ & $\cdots$ & --- & $\cdots$ \\
\hline $\begin{array}{l}\text { Remove } 106 \mathrm{CH}_{2} \\
\text { from } 000\end{array}$ & 8 & 0 & $1-1 / 2$ & 0 & $17-1 / 2$ & 54 & 630 & $-66.4 \pm 2.0$ & $-69.5 \pm 2.9$ & -- & $0.62+0.02$ & -- \\
\hline $\begin{array}{l}\text { Remove } 12 \mathrm{~B}^{10} \mathrm{C} \text { and } \\
222 \mathrm{CH}_{2} \text { from } \mathrm{A} \text { row }\end{array}$ & & 0 & $1-1 / 6$ & 0 & $11-1 / 3$ & 42 & 408 & $3.0 \pm 0.1$ & $-66.5 \pm 2.8$ & --- & --- & -- \\
\hline $\begin{array}{l}\text { Remove } 24 \mathrm{~B}_{4}^{10} \mathrm{C} \text { and } \\
408 \mathrm{CH}_{2} \text { from } \mathrm{A} \text { row }\end{array}$ & & 0 & $1 / 2$ & 0 & 0 & 18 & 0 & $-30.0 \pm 0.6$ & $-96.5 \pm 3.4$ & $\cdots$ & --- & 0 \\
\hline $\begin{array}{l}\text { Remove } 5 B{ }_{4}^{10} \mathrm{C} \text { from } \\
\text { A row }\end{array}$ & & 0 & $13 / 36$ & 0 & 0 & 13 & 0 & $26.6+0.5$ & $-69.9 \pm 2.8$ & $-5.3 \pm 0.1$ & -- & 0 \\
\hline $\begin{array}{l}\text { Remove } 5 \mathrm{~B}_{4}^{10} \mathrm{C} \text { from } \\
\text { A row }\end{array}$ & & 0 & $2 / 9$ & 0 & 0 & 8 & 0 & $27.2+0.5$ & $-42.7 \pm 2.2$ & $-5.4+0.1$ & --- & 0 \\
\hline $\begin{array}{l}\text { Romove } 584^{10} \mathrm{C} \text { from } \\
\text { A row }\end{array}$ & & 0 & $1 / 12$ & 0 & 0 & 3 & 0 & $28.9+0.6$ & $-13.8 \pm 1.5$ & $-5.7 \pm 0.1$ & -- & 0 \\
\hline $\begin{array}{l}\text { Remove } 3 B_{4}^{10} \mathrm{C} \text { from } \\
\text { A row }\end{array}$ & & 0 & 0 & 0 & 0 & 0 & 0 & $17.9 \pm 0.4$ & $5.9 \pm 1.2$ & $-5.9+0.1$ & -- & 0 \\
\hline
\end{tabular}


of major interest, a number of figures which are cross-referenced by case number to table B-2 and which show the poison and polyethylene positions for typical cases are included in figures B-2 through B-7. Also given in table B-3 are the percentages of effective flooding that existed in the central core section for the measurements of major interest. These percentages are based on the fraction of polyethylene that was in the test section for each measurement. The data from which these flooding percentages were obtained are given in table B-4 Depending on the flooding and poison array used, the flooding percentage varied from 89.5 to 90 percent which gives an average flooding condition of 89.7 percent. This average flooding percentage has been used in all cases since the accuracy of the actual percent flooding is probably \pm 1.0 percent. From the measurements that were obtained with the central 000 cluster and the A-row clusters at the maximum flooding condition (89.7 percent flooded), the effect of various arrays of flexible $\mathrm{B}_{4}^{10} \mathrm{C}$ poisons wires was determined and is shown in figure $\mathrm{B}-1$.

In addition to the data obtained under fully flooded conditions, several other graphical presentations of the data obtained in the experiment are shown in figures $B-8,9$ and 10 . Figure B-8 indicates the reactivity effect produced in the central cluster as the degree of flooding is varied with one $\mathrm{B}_{4}^{10} \mathrm{C}$ wire per element in the 000 cluster. Also shown are the reactivity effects that could be expected to exist with various other poison arrays as the degree of flooding is varied. These latter cases assure that the shape of the curves obtained with the other poison arrays are the same as that obtained with one poison wire per element.

Figure $B-9$ indicates the reactivity effects produced when the number of poison wires in the 000 central cluster is varied under full flooding conditions in the 000 and A-row. Also shown is the data in figure B-8 with full flooding in the 000 cluster and no flooding in the A-row. In addition to the complete set of data obtained for a given poison inventory in the A-row ( $1-1 / 3$ wires per element), a number of points are plotted showing the effect on reactivity with zero wires in 000 and differing amounts of poison in the A-row.

Figure B-10 shows some of the poison wire worths as a function of the number of wires in the core for both flooded and dry conditions. From this data it can be seen that the dry and flooded worths of the poison wires vary to a great extent, depending on the number of wires

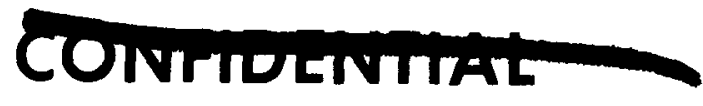


(W) Astronuclear

WANL-TNR-206

\section{POISON WIRES}

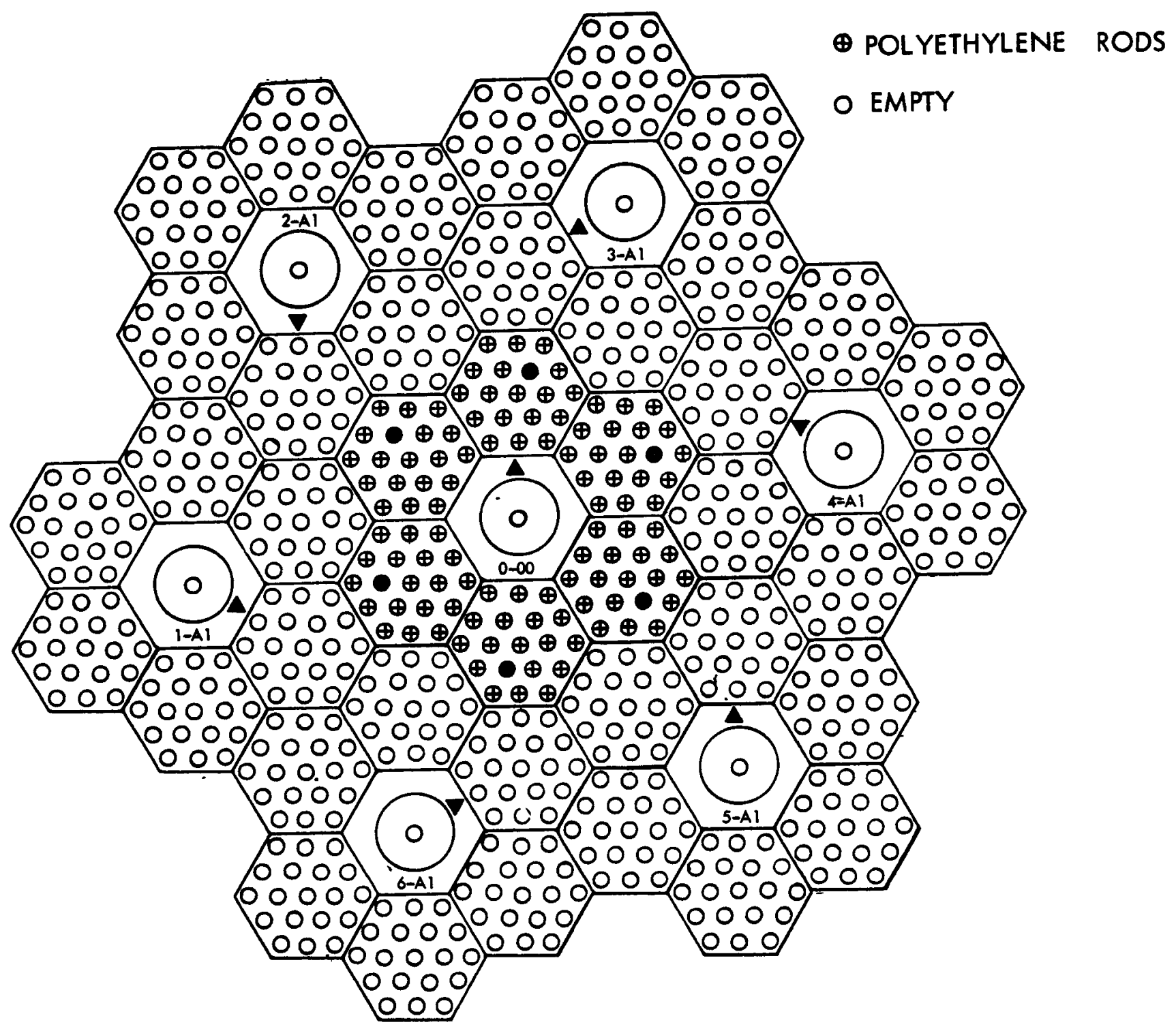

$610730-6-1$

Figure B-2. PAX Test Flexible Poison Wires - Case 1 
(W) Astronuclear

WANL-TNR-206

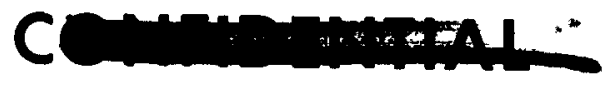

POISON WIRES

$\bigoplus$ POLYETHYLENE RODS

O EMPTY

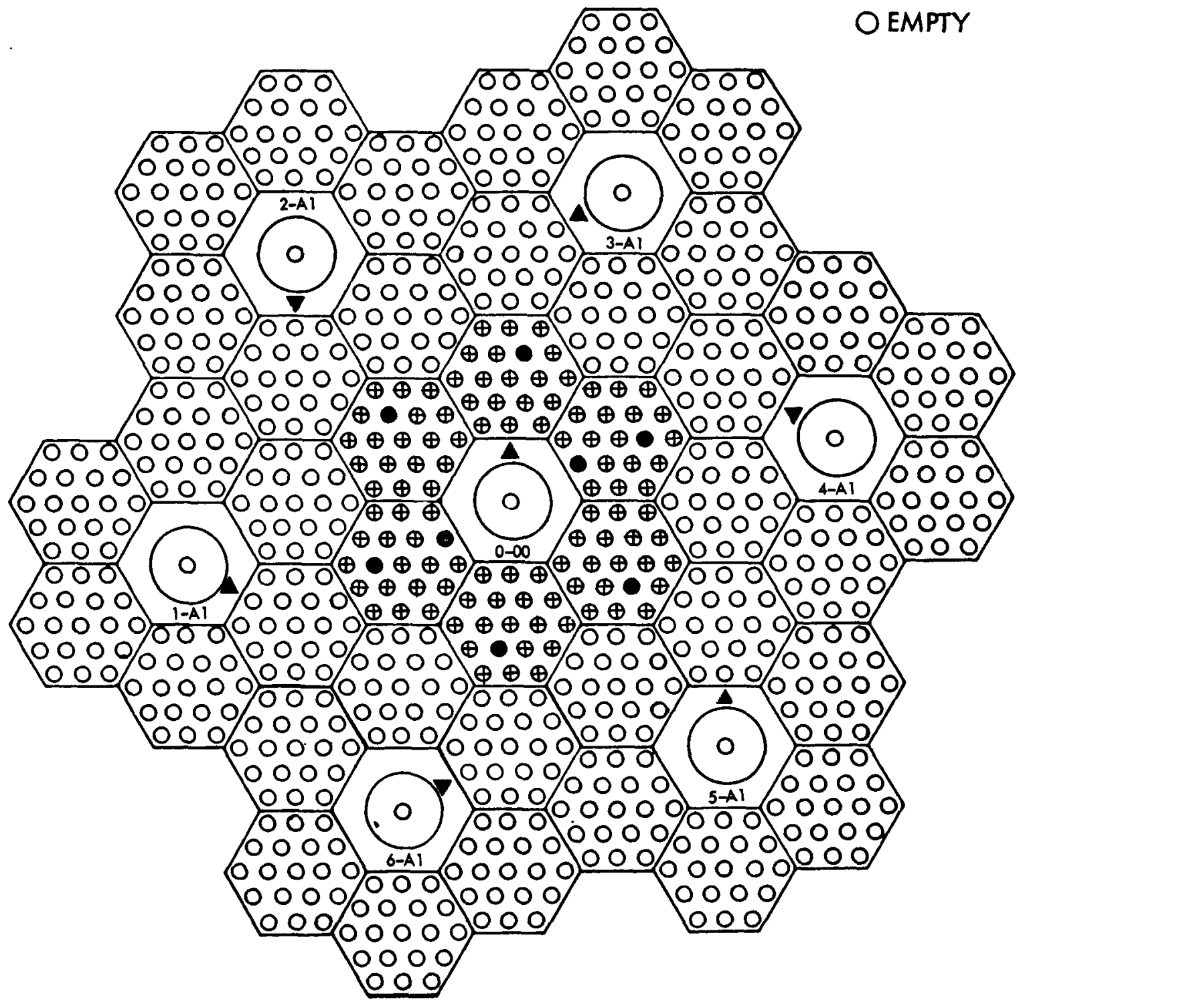

$610730-16 B$

Figure B-3. PAX Test Flexible Poison Wires - Case 2 


\section{POISON WIRES \\ + POLYETHYLENE :RODS \\ O EMPTY}

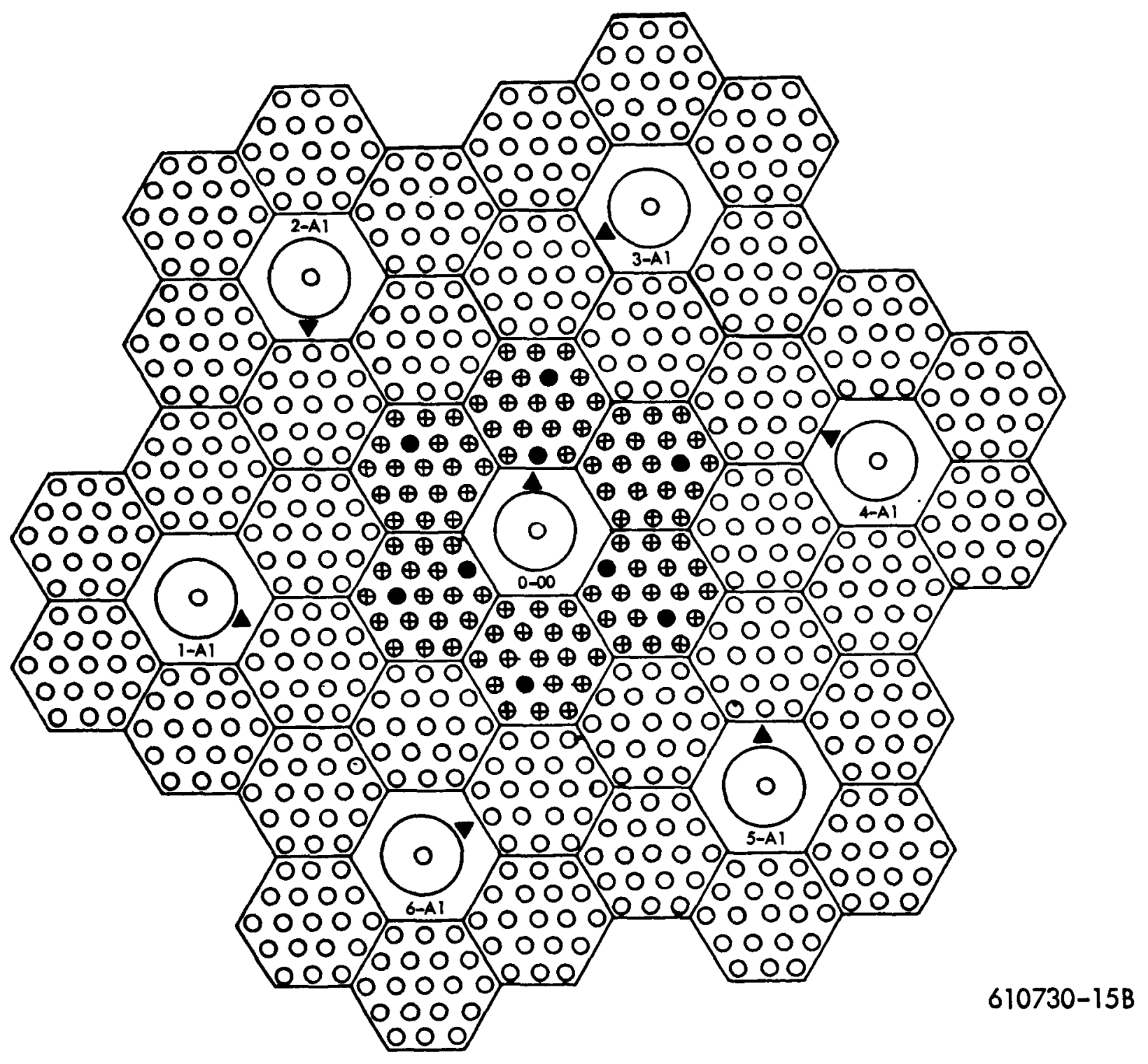

Figure B-4. PAX Test Flexible Poison Wires - Case 3

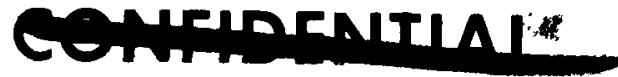


(W) Astronuclear

WANL-TNR-206

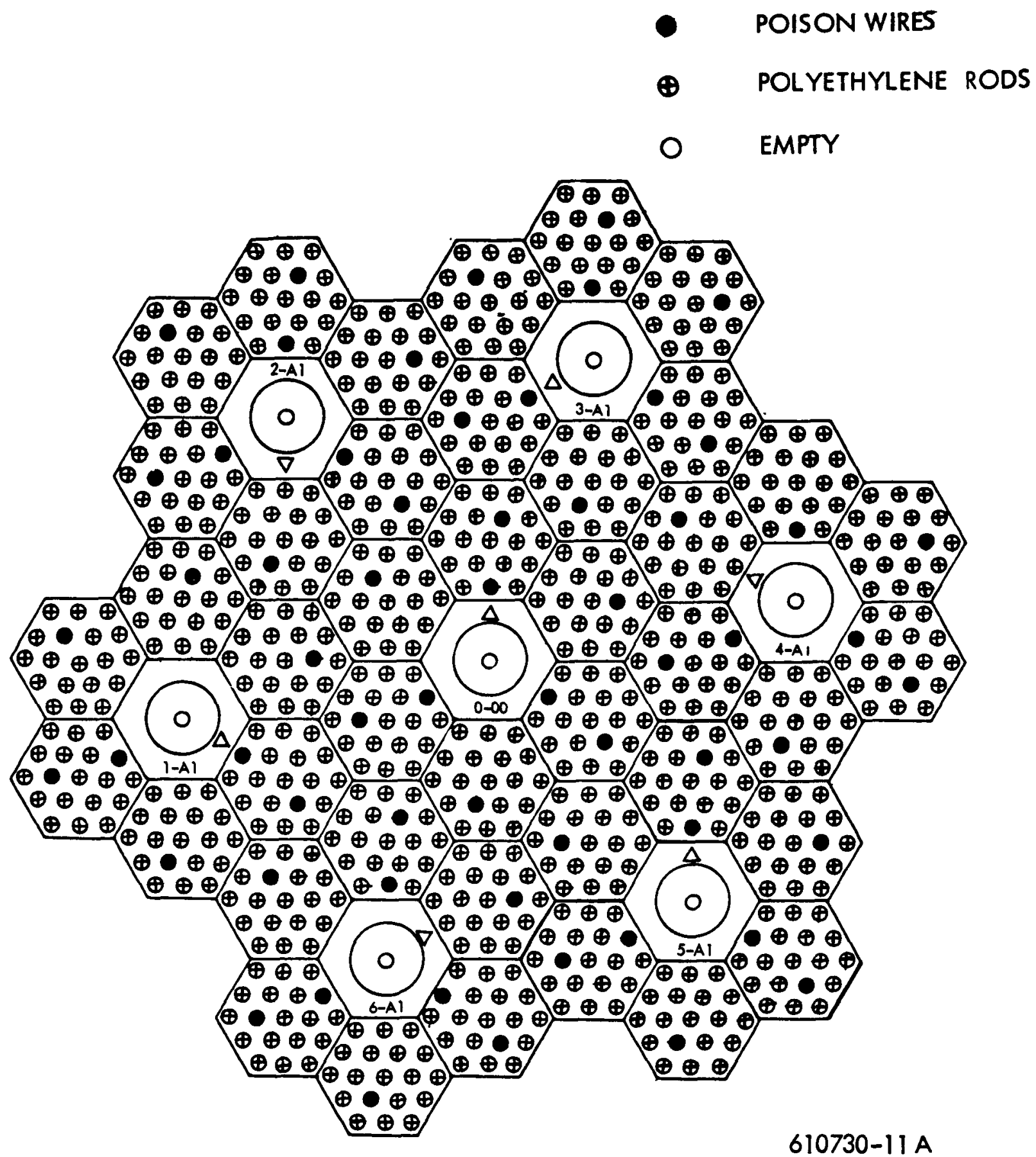

Figure B-5. PAX Test Flexible Poison Wires - Case 6

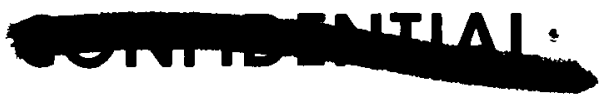




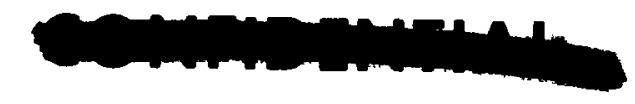

(w) Astronuclear

WANL-TNR-206

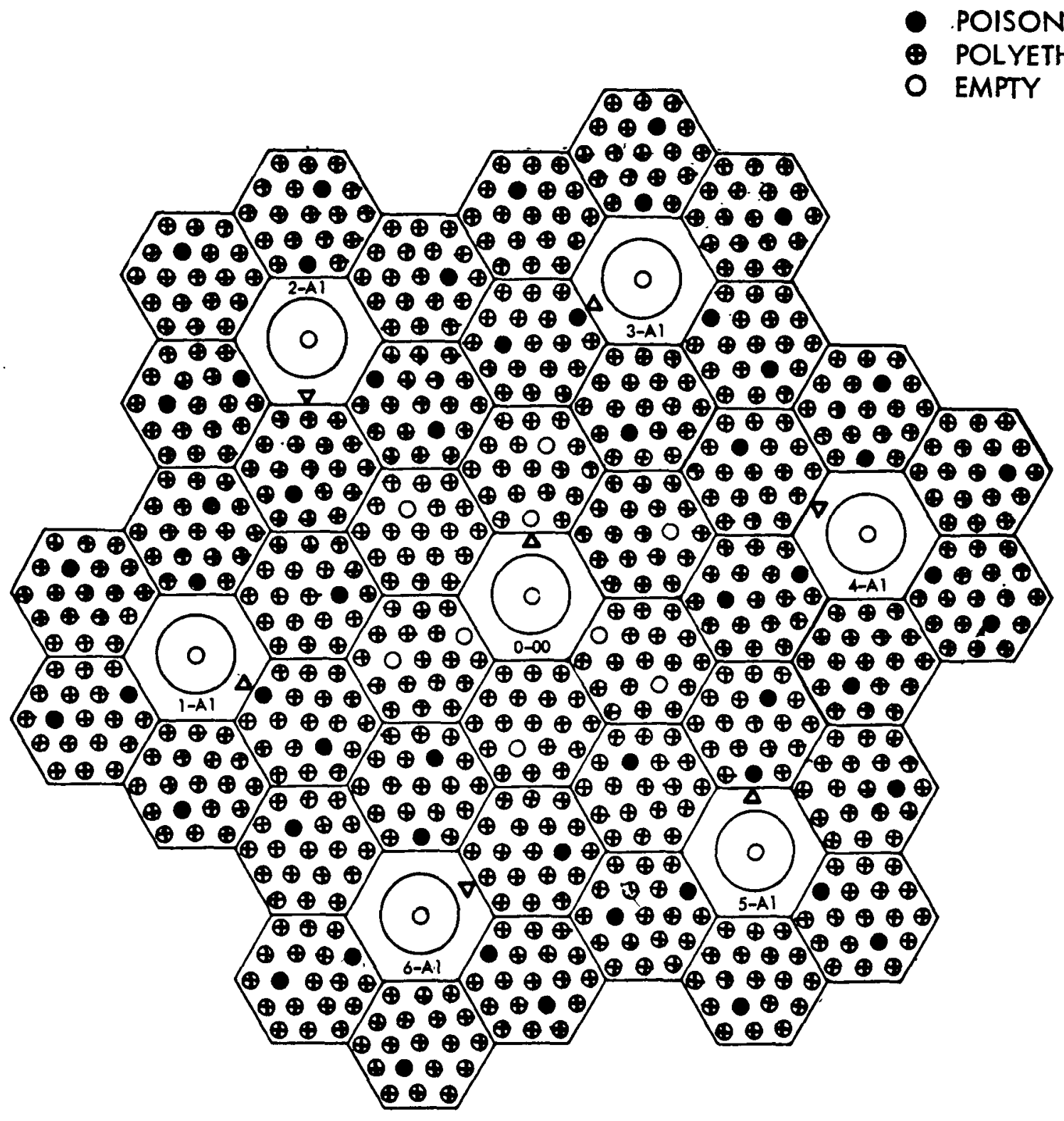

POISON WIRES

$\oplus$ POLYETHYLENE RODS

O EMPTY

Figure B-6. PAX Test Flexible Poison Wires - Case 7

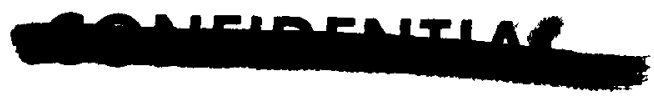



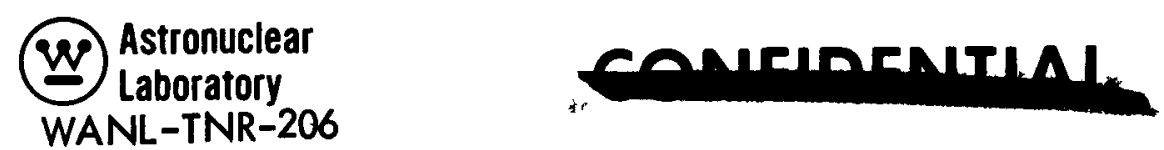

POISON WIRE

$\oplus$ POLYETHYLENE RODS

O EMPTY

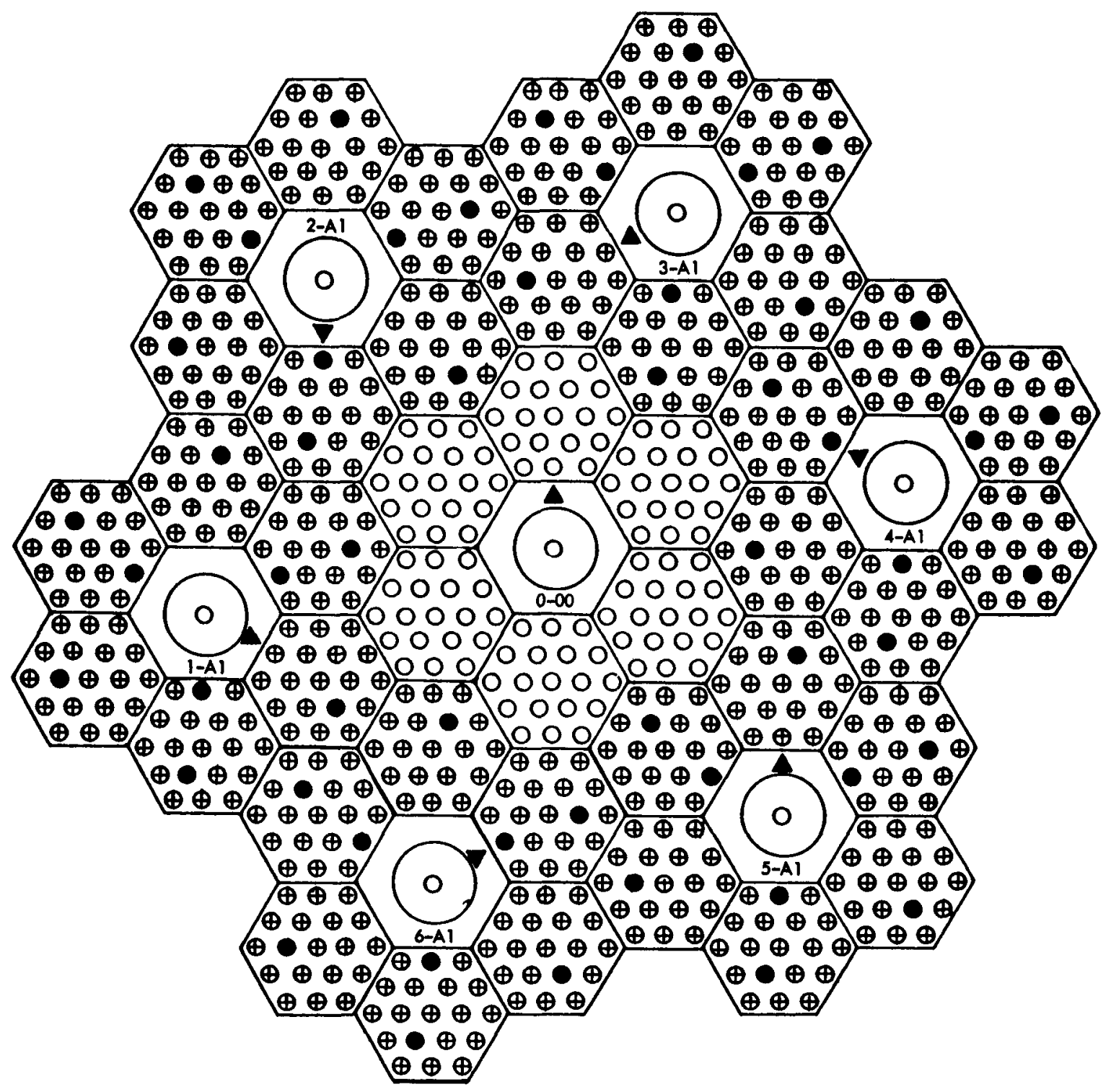

$610730-10 B$

Figure B-7. PAX Test Flexible Poison Wires - Case 8

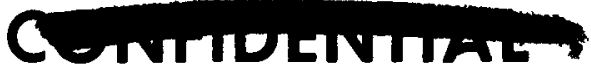




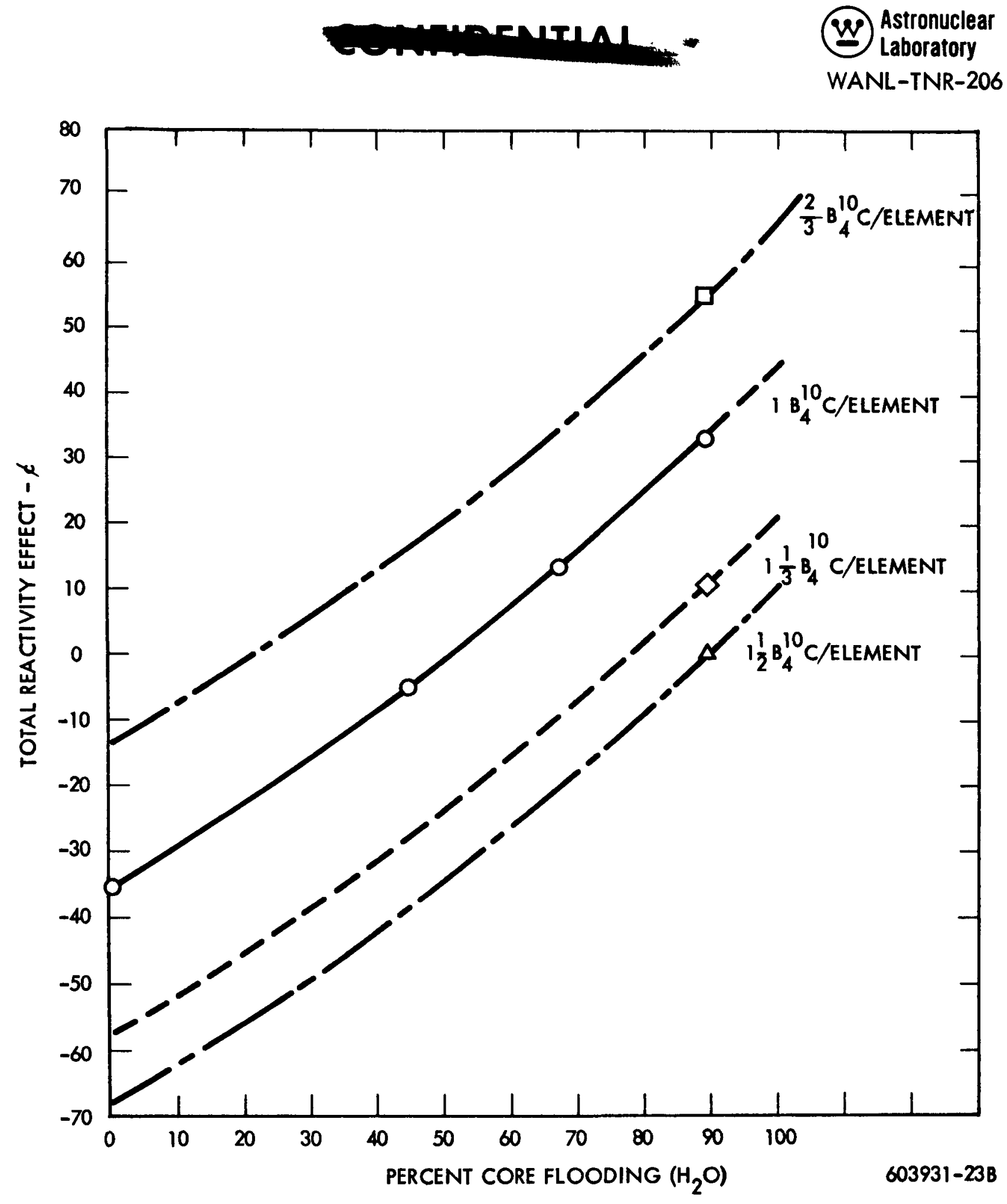

Figure B-8. Poison Wire Effectiveness as a Function of the Degree of Flooding

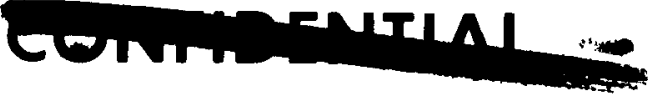


(W) Astronuclear

WANL-TNR-206

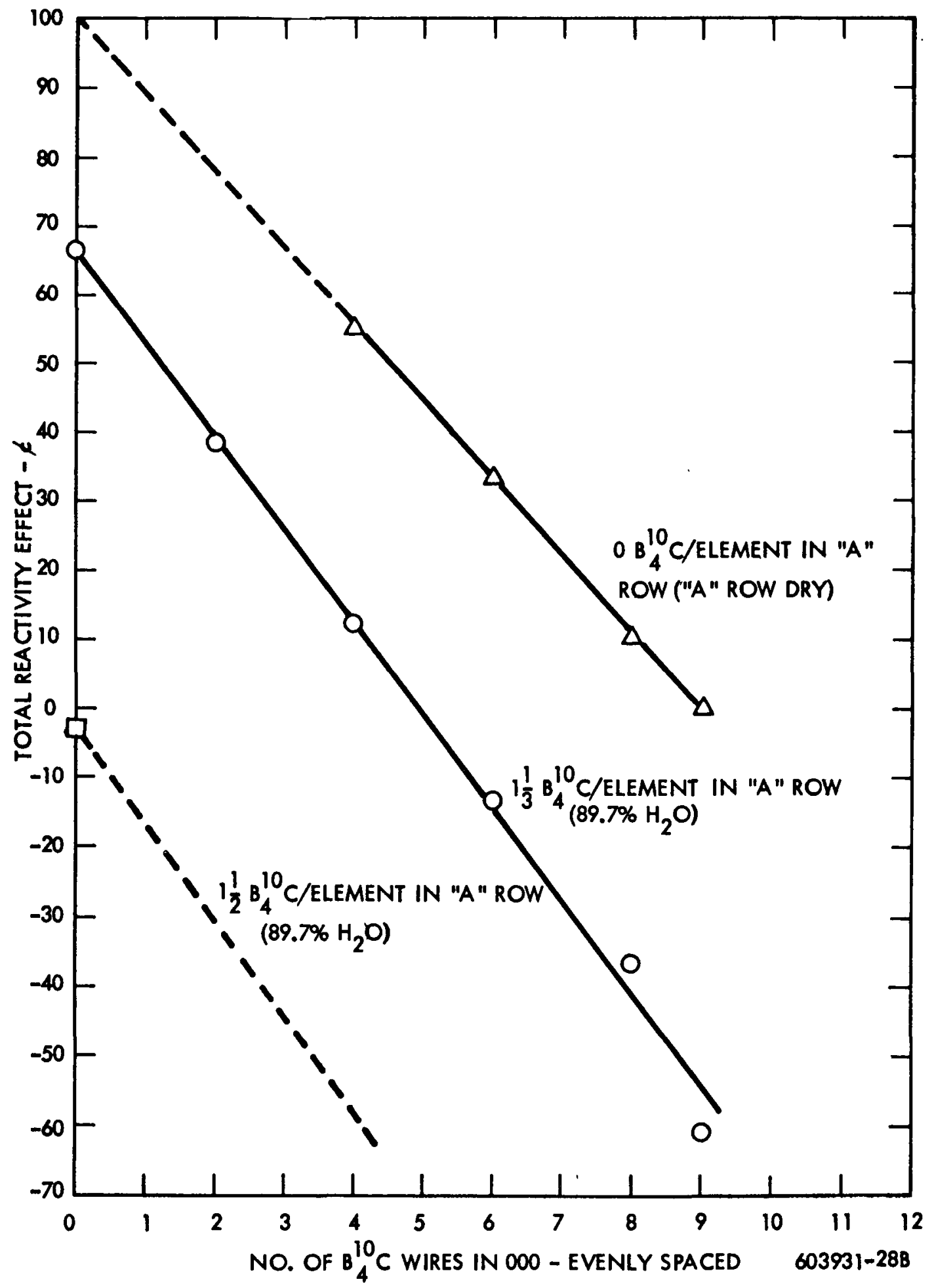

Figure B-9. Core Reactivity Under Various Poisoning and Flooding Conditions 


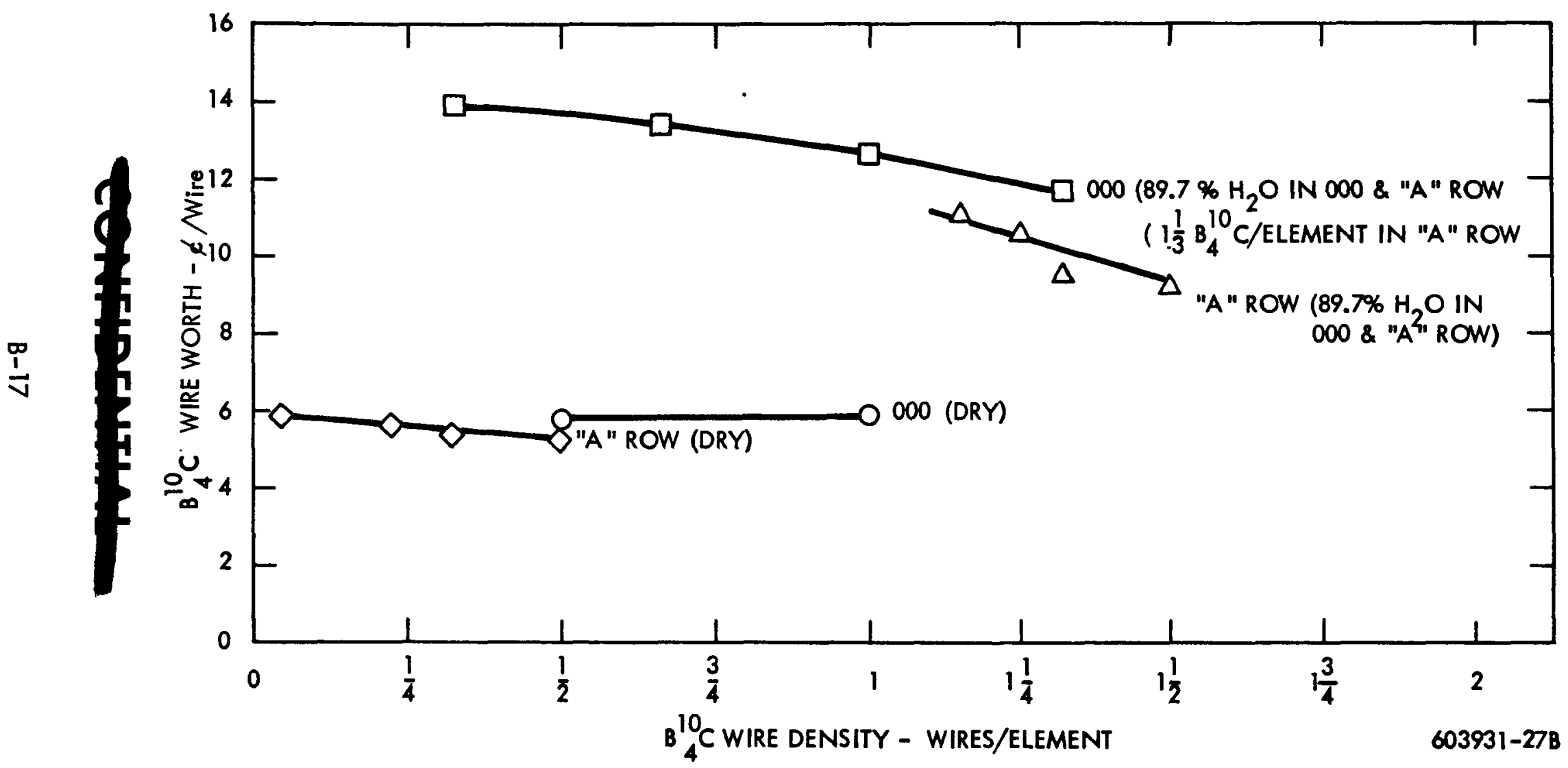

Figure B-10. Poison Wire Worth as a Function of Density - PAX-C Core

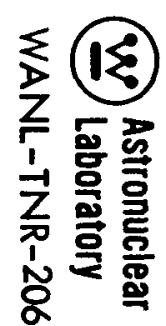


TABLE B-4

\section{PAX-C CENTRAL REGION DEGREE OF FLOODING DATA}

The flooding percentages given below are based on the basic modular unit of one cluster in the PAX $-\mathrm{C}$ core.

Volume of cluster (contained)

Volume of cluster void

Volume of $\mathrm{B}_{4}^{10} \mathrm{C}$ wires per cluster

$$
1 \text { wire per element }
$$

Net volume of cluster void

1 wire per element

Volume of polyethylene rods per cluster

1) 18 rods per element (108)

2) $13-1 / 3$ rods per element (81)

3) 9 rods per element (54)

Percent void occupied by polyethylene

1) 18 rods per element (108)

$70.0 \%$

2) $13-1 / 3$ rods per element ( 81 )

3) 9 rods per element (54)

Percent flooding by $\mathrm{H}_{2} \mathrm{O}$

1) 18 rods per element (108)

2) $13-1 / 3$ rods per element (81)

3) 9 rods per element (54)
$52.5 \%$

$35.0 \%$
$90.0 \%$

$67.0 \%$

$44.6 \%$
$2.929 \times 10^{3} \mathrm{~cm}^{3}$

$0.788 \times 10^{3} \mathrm{~cm}^{3}$

$0.027 \times 10^{3} \mathrm{~cm}^{3}$

$0.761 \times 10^{3}$
$0.533 \times 10^{3}$

$0.400 \times 10^{3}$

$0.266 \times 10^{3}$

(The $\mathrm{H}$ content in $\mathrm{H}_{2} \mathrm{O}$ is $9 / 7$ times the $\mathrm{H}$ content in polyethylene.)

Average flooding percentage for the $18,17-2 / 3$, and $17-1 / 2$ polyethylene rods per element case 
in the core. This is due to a neutron energy spectrum change and possibly a mutual shadowing effect between wires.

During the measurements, a very noticeable effect arose in the reduction in the incremental drum worths of the PAX-C drums. This effect was taken into account in calculating the reactivity effect produced by a given core change. These effects, which were caused by the addition of the polyethylene rods and the flexible poison wires in the 000 and A-row clusters, have been plotted in figure B-11 along with the previously measured incremental drum worths obtained during the initial reactivity shimming of the PAX-C core described in Section III. As can be noted from the curve, the reduction of the incremental drum worths is about 4 to 8 percent, depending on the degree of flooding and the poison inventory. Of particular interest are the incremental worths obtained with only the flexible poison wires in the core. From these data points, it can be seen that the incremental worths are lower by about 4 percent than those obtained with the standard poison wires in the core. This indicates that the redistribution of flux in the reactor with the flexible wires is different than with the standard wires present.

\section{E. EXPERIMENTAL UNCERTAINTIES}

The major uncertainties encountered during the measurements fall into three categories:

1) Those associated with the reproducibility of critical configurations and variations in the measurement of successive periods during any one measurement,

2) Those associated with the uncertainty in the incremental drum worths, $\frac{\Delta \rho}{\Delta \theta}$, and

3) Those associated with the uncertainty involved in converting a measured period to a reactivity using the "inhour" relationship $\delta \rho$.

Of the three uncertainties listed above, the first was determined for each measurement by checking the variation in the reactor period and applying a fixed uncertainty due to core variations and drum angle variations. In most cases, it was found that the magnitude of this error was about 2 percent in reactivity. The second type error involving the unknown in the incremental drum worths was an assigned error of about 3 percent. The error associated with the conversion of a period to a reactivity, using the "inhour" relationship, was taken as being 2.5 percent of the reactivity shift from the base reactivity. The following method was 

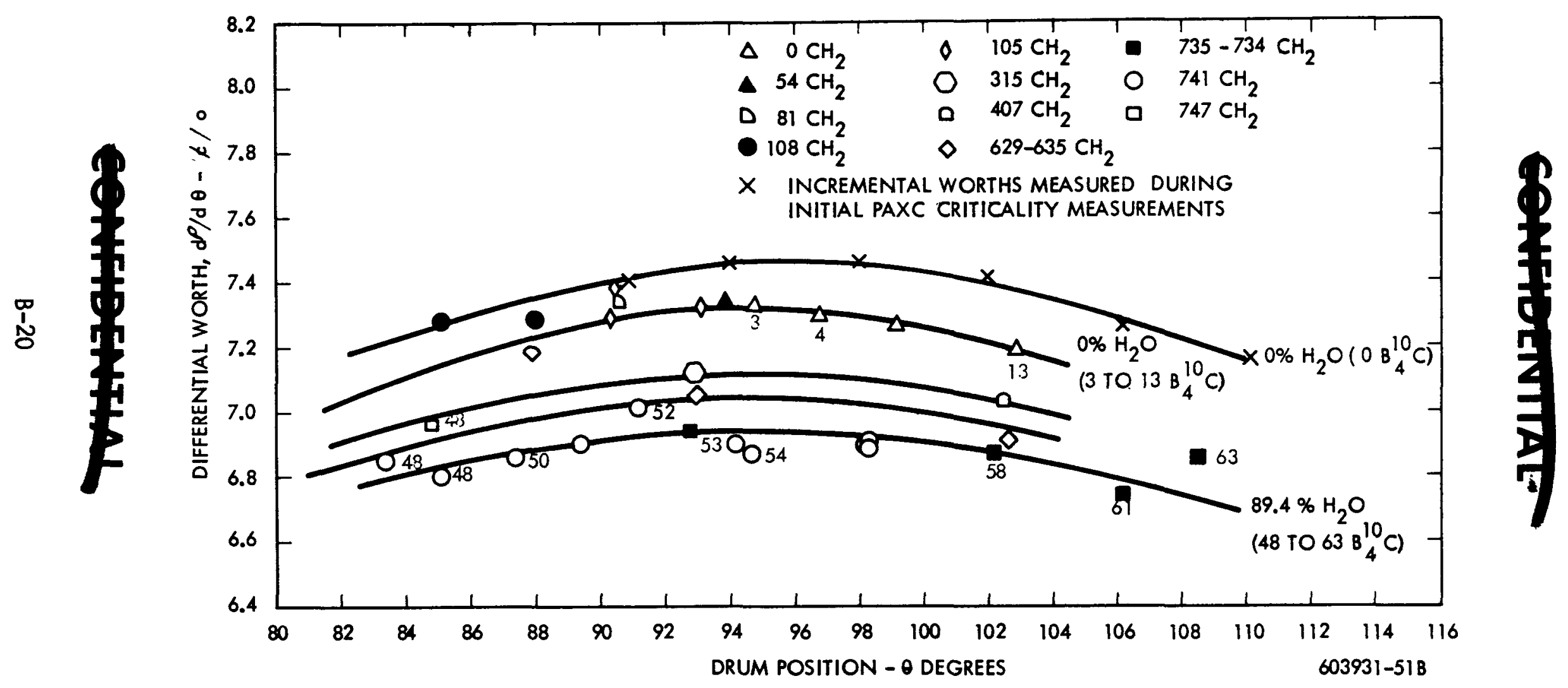

Figure B-11. PAX-C Drum Worths as a Function of the Degree of Flooding 
employed in applying the various uncertainties to the measurements:

If the reactivity values obtained for each of the measurements are $\rho_{1^{\prime}} \rho_{2^{\prime}} \rho_{3^{\prime}} \ldots \ldots$, $\rho_{n}$, then the uncertainty involved in each individual measurement is $\Delta \rho_{1}, \Delta \rho_{2^{\prime}}, \Delta \rho_{3^{\prime}}, \ldots$. , $\Delta \rho_{n^{\prime}}$ and each $\Delta \rho_{i}$ is based on either the uncertainty in the period measuring system or the uncertainty in the incremental drum worths depending on which of these two systems was employed in the particular measurement. The total reactivity change and its associated uncertainty for any number of successive measurements from 1 to $n$ is obtained as follows:

$$
\rho_{T}=\sum_{i=1}^{n} \rho_{i} \pm\left(\sqrt{\sum_{i=1}^{n}\left(\Delta \rho_{i}\right)^{2}}+\delta \rho\right)
$$

The $\delta \rho$, which is based on the "inhour" uncertainty, is applied to the total change, $\rho_{T}$, i.e., $\delta \rho=0.025 \times \rho^{\rho}$. 


\section{APPENDIX C}

\section{REFERENCES}

1 WANL-TME-603, Selection of Material, Number and Distribution of Poison Wires for Anti-Criticality Poison Wire System, November 1963 (CRD)

2

WANL-TNR-155, Status Report on the Anti-Criticality Poison Wire System, March 1964 (CRD)

3

WANL-TME-1172, Status Report on the Flexible Poison Wire Development, May 1965

4

G. V. Samsonov, Handbooks of High-Temperature Materials, Volume 2-Properties Index, Plenum Press, New York, 1964

5

LA-3227-MS, Effects of Adding Hydrogenous Materials to KIWI Reactors, March 1964 (CRD)

6

WANL-TME-713, NRX-A Core Compaction Program, March 1964 (CRD)

7 Private Communication, L. D. P. King, LASL, to J. M. Bridges, WANL, October 1964

8 WANL-TNR-148, Safety Analysis Report - NRX Testing, April 1964

9 WANL-TME-546, Feasibility of a Full Core Nuclear Poison System for use During RIFT Launch Operations, September 1963

10 WANL-TME-840, Reactor Analysis Handbook, February 1965, (CRD)

11 WANL-TME-1091, Improved Nuclear Design Method for NERVA Calculations NSDM-II, March 1965 (CRD)

12 IDO-16898, TOPIC - A Fortran Program for Calculating Transport of Particles in Cylinders, April 1964

13 WANL-TME-603, Selection of Material, Number and Distribution of Poison Wires for the Anti-Criticality Poison System, November 1963

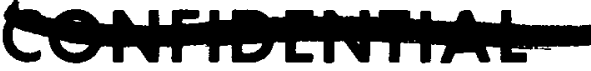

